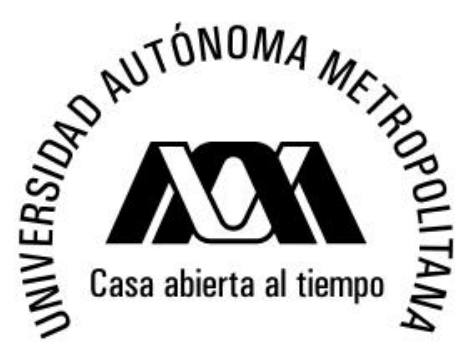

TESIS

QUE PARA OBTENER EL GRADO DE MAESTRA EN ESTUDIOS ORGANIZACIONALES

PRESENTA:

AÍDA LEIDI RIVERA SOLÍS

\title{
TITULADA:
}

LOS PROCESOS DE IMITACIÓN COMO TRADUCCIÓN:

EL SURGIMIENTO DE UN CAMPO ORGANIZACIONAL.

BAZARES DE ARTE Y DISEÑO INDEPENDIENTE EN LA CIUDAD DE MÉXICO 2003-2013.

DIRECTORA DE TESIS:

LECTORES:

CIUDAD DE MÉXICO
DRA. IRENE SÁNCHEZ GUEVARA

DRA. GIOVANNA M. MAZZOTTI PABELLO

DR. PEDRO CONSTANTINO SOLÍS PÉREZ
Estudios 
Con este trabajo finalizo una importante etapa de mi vida profesional. A través de los años, muchas personas han sido parte fundamental de ésta, así que -con el propósito de no omitir a ninguna, de corazón

y al más sincero estilo Cerati- sólo puedo decir:

\section{¡GRACIAS TOTALES!}




\section{ÍNDICE}

PÁG.

INTRODUCCIÓN

4

\section{CAPÍTULO 1. MARCO TEÓRICO}

1.1 El sector cultural y creativo en el ámbito Iberoamericano desde una perspectiva organizacional...

1.2 Reflexiones sobre el concepto de organización en el marco de los Estudios Organizacionales.

1.3 Mecanismos de cambio institucional isomorfo en el proceso de estructuración de un campo organizacional.................. 20

1.4 El Nuevo Institucionalismo Sociológico.

Posibilidades y limitaciones

1.5 Fenómenos globales y su impacto en las transformaciones organizacionales.

1.6 La corriente Institucionalista Escandinava

1.6.1 La pertinencia del proceso de traducción en la identificación del surgimiento de un campo organizacional a través de los campos de imitación.

\section{CAPÍTULO 2. MARCO CONTEXTUAL. PLANTEAMIENTO DEL PROBLEMA Y METODOLOGÍA DE LA INVESTIGACIÓN}

2.1 Contextualizando la relevancia y complejidad de la actividad cultural......

2.2 La participación de la sociedad civil en el ámbito cultural.......................... 36

2.3 Cultura, economía y desarrollo: nociones polémicas................................... 38

2.4 La Economía Creativa y su impacto en las transformaciones del sector cultural.

2.5 Planteamiento del problema.

2.6 Pregunta de investigación........................................................................... 51

2.7 Relevancia para el estudio de las organizaciones........................................... 53

2.8 Delimitación de la investigación.................................................................. 54

2.9 Metodología.......................................................................................... 55 


\section{CAPÍTULO 3. UN CONTEXTO INSTITUCIONAL PARA EL EMPRENDIMIENTO EN EL SECTOR CULTURAL Y CREATIVO DE LA CIUDAD DE MÉXICO}

3.1 Programas académicos en México e lberoamérica creados específicamente para la formación profesional en emprendimiento cultural y creativo.

3.1.1 Antecedentes.

3.1.2 Profesionalizando a los actores de la Economía Creativa

3.2 Eventos y Actividades realizados desde el ámbito académico, social

y gubernamental para impulsar la difusión de emprendimientos culturales

y creativos.

3.3 Políticas y programas gubernamentales, sociales y académicos

a nivel federal y local para el impulso a la creación de emprendimientos culturales y creativos

3.4 Traducción e Isomorfismo en la conformación de un contexto institucional para el emprendimiento en el sector cultural y creativo de la Ciudad de México

\section{CAPÍTULO 4. BAZARES DE ARTE Y DISEÑO INDEPENDIENTE EN LA CIUDAD DE MÉXICO: EL SURGIMIENTO DE UN CAMPO ORGANIZACIONAL.}

4.1 La Ciudad de México: dinamismo y centralización cultural............................. 114

4.2 Algunas premisas sobre los emprendedores culturales y creativos.............. 117

4.3 Aproximaciones a la configuración organizacional de los Bazares de Arte

y Diseño Independiente de la Ciudad de México.

4.3.1 Notas sobre el estudio de la estructura........................................... 119

4.3.1.2Dimensiones contextuales............................................................ 122

4.3.1.3 Dimensiones de la estructura organizacional............................................ 135

4.4 Elementos clave en la configuración organizacional de los Bazares de Arte y Diseño Independiente de la Ciudad de México.

4.5 Los campos de imitación como traducción: el surgimiento de un campo organizacional de Bazares de Arte y Diseño Independiente en la Ciudad de México. 


\section{INTRODUCCIÓN}

Desde hace varias décadas, el reconocimiento del rol protagónico de las ciudades a nivel mundial en prácticamente todos los ámbitos de la vida es innegable. "Todo sucede en la ciudad y, por lo tanto, la cultura es de la ciudad o no es. Y procesos como el de la globalización dejaron ese fenómeno aún más claro: si lo global existe, lo local no es menos cierto. Y lo local es la ciudad. Así, la primera y esencial política cultural es aquella que se hace para la ciudad, por la ciudad y en la ciudad" (Coelho, 2009: 72-73).

En este sentido, ante la pregunta de ¿Por qué las ciudades impulsan proyectos de Economía Creativa?, en el Informe de la $\operatorname{UNCTAD}^{1}$ (2010) se resalta la importancia del diseño de acciones para su fomento por parte de los gobiernos, debido a que es vista como una plataforma fundamental para el desarrollo no sólo de la economía sino de la ciudad misma.

Así, en años recientes y, en el marco de un periodo prolongado de crisis económicas, políticas y sociales a nivel mundial ${ }^{2}$, se percibe un predominio del discurso que resalta las aportaciones económicas de la cultura.

\footnotetext{
${ }^{1}$ Conferencia de las Naciones Unidas sobre Comercio y Desarrollo (por sus siglas en inglés).

2 En México "la tasa de desocupación ascendió a 4.93\% durante mayo de 2013 en donde 29\% de los desocupados no contaba con estudios completos de secundaria, en tanto que los de mayor nivel de instrucción representaron 70.8\%" (Verdusco, 2013 junio 24).
} 
En el caso de nuestro país, mucho se ha mencionado que la producción de bienes y mensajes culturales abarca un 7.3\% del PIB (Piedras, 2009). Particularmente, se afirma que "en el Distrito Federal donde hay mayor concentración de infraestructura, poder económico y demanda, las actividades culturales y creativas aportan el 9\% del PIB, 5.43 en el sector formal y 3.49 en la economía sombra (informal, piratería y flujo de contenidos a través de redes digitales)" (Malvido, 2013 agosto 8).

Si bien estos argumentos y cifras resultan necesarios para dimensionar la importancia de la actividad cultural (por muchos años considerada como no prioritaria en el marco de las acciones y políticas públicas nacionales), también es cierto que se corre el riesgo de limitar únicamente su función e importancia a estos elementos, en detrimento de sus aportaciones simbólicas, estéticas y sociales, por lo que es necesario estar atentos al manejo de la información en este sentido.

No obstante, y regresando a la reflexión sobre la relevancia del rol de las ciudades contemporáneas, es necesario mencionar que los últimos años la Ciudad de México ha participado de manera activa en el impulso e implementación a nivel local de la agenda de temas relacionados con cultura, desarrollo y creatividad.

Así, en 2010 se le nombró Capital Iberoamericana de la Cultura, en 2011 adoptó formalmente la Agenda 21 de la Cultura (que reconoce a la cultura como cuarto pilar del desarrollo sostenible y es uno de los primeros documentos reconocidos a nivel mundial en política cultural desde y para la ciudad) y en 2012 obtuvo la co-presidencia de la Comisión de Cultura de la Organización Mundial de Ciudades y Gobiernos Locales Unidos (CGLU), nombramiento, que de acuerdo con la página web de la Secretaría de Cultura, "reconoce el papel de liderazgo internacional de la Ciudad de México en temas culturales". 
Como consecuencia de dichos acuerdos, en la Ciudad de México y no sólo desde la Secretaría de Cultura sino desde otras instancias tanto del gobierno federal como local, los últimos años se han implementado políticas y programas públicos que fomentan la realización de proyectos en torno a la figura de los denominados emprendimientos culturales y creativos, que han ido acompañados de una amplia producción y difusión de publicaciones (impresas y virtuales) referentes al tema, se han llevado a cabo numerosos eventos y actividades que han facilitado tanto el intercambio entre profesionales de diversos países así como la presentación de "mejores prácticas", al tiempo que también se percibe el incremento de nuevos programas de formación a nivel profesional para la gestión de emprendimientos culturales y creativos.

Aunado a todo esto, se ha presentado una reducción gradual pero constante de los recursos públicos para el financiamiento de actividades y programas culturales, situación que permite entender que actualmente nos encontramos en un momento crucial en donde confluyen diversos factores sociales, económicos y políticos -tanto en el ámbito global como local- que han determinado la transformación de numerosas formas organizacionales al tiempo que, al parecer, están influyendo en el hecho de que éstas también tienden a ser cada vez más similares con el propósito de integrarse a esta dinámica y, por lo tanto, lograr sobrevivir en un entorno sumamente adverso.

De esta manera, como puede observarse, los cambios en la manera de operar y concebir el sector cultural son numerosos. La introducción, desde la Economía Creativa, de nuevas disciplinas que antes no estaban relacionadas directamente con el sector (como el diseño y la gastronomía por mencionar un par de casos), implica nuevos retos, entre los que destaca, la inclusión de nuevos actores con otras lógicas de acción y necesidades que requieren un entorno acorde para su desarrollo. 
$Y$ es en este contexto que se identifica la emergencia en la Ciudad de México de organizaciones nuevas que se caracterizan porque comparten objetivos, maneras de operar y dinámicas de interacción a partir de las cuales se influencian mutuamente de forma constante; elementos que han facilitado el surgimiento de un campo organizacional. De tal manera que la pregunta que guió el desarrollo de la presente investigación se centró en identificar ¿A qué factores se puede atribuir el surgimiento y crecimiento exponencial que han tenido los Bazares de Arte y Diseño Independiente en el sector cultural y creativo de la Ciudad de México entre 2003-2013 ${ }^{3}$ Dado lo anterior, los objetivos quedaron establecidos de la siguiente manera:

\section{Objetivo General:}

Analizar cómo los emprendimientos culturales y creativos en la Ciudad de México, en particular, los Bazares de Arte y Diseño Independiente, han formado un campo organizacional a través del estudio de los modos de imitación.

Objetivos particulares:

- Describir de qué manera se ha desarrollado y difundido globalmente la Economía Creativa y qué transformaciones ha suscitado en el sector cultural de la Ciudad de México.

- Establecer cómo se ha llevado a cabo el proceso de institucionalización del fenómeno emprendedor en el sector cultural y creativo de la Ciudad de México.

- Determinar qué motiva a los actores organizacionales a formar parte de un campo y cómo se lleva a cabo ese proceso.

- Identificar los elementos que caracterizan el campo organizacional de los Bazares de Arte y Diseño Independiente en la Ciudad de México.

\footnotetext{
${ }^{3}$ El periodo de tiempo elegido se justifica, en primera instancia, porque era muy importante rescatar la perspectiva histórica del fenómeno. Por otro lado, porque fue en 2003 cuando surgió el primer Bazar de Arte y Diseño Independiente y 2013 es el año que registró el mayor número de nuevos bazares en la Ciudad.
} 
Para tal efecto, la investigación se estructuró en cuatro capítulos. En el primero se desarrolla el Marco Teórico, el cual inicia con una revisión de los trabajos de investigación en el tema que se han realizado con anterioridad en el ámbito Iberoamericano. Continúa con una serie de reflexiones a partir de la mirada de diversos autores sobre el concepto de organización desde la plataforma de los Estudios Organizacionales, la cual dio lugar a la inclusión, desde el Nuevo Institucionalismo Sociológico (NIS), del estudio de los Mecanismos de Cambio Institucional Isomórficos presentes en el Proceso de Estructuración de un Campo Organizacional ${ }^{4}$ a partir de lo propuesto principalmente por Powell y DiMaggio (1999), lo cual proporcionó al estudio una perspectiva histórica.

Posteriormente, con base en el análisis de las posibilidades y limitaciones del NIS se decidió incluir otra teoría que permitiera destacar el rol activo de los actores en dicho proceso. En este sentido, la noción de Traducción, utilizada y promovida ampliamente por autores como Czarniawska y Sevón $(1996,2005)$, pertenecientes a la Corriente Institucionalista Escandinava, resultó de gran utilidad y fue complementada con el trabajo de Hedmo, Kerstin y Wedlin (2005) quienes proponen un modelo de análisis a través de los denominados Campos de Imitación como Traducción, perspectiva que permitió identificar cómo surge un campo organizacional en primera instancia.

\footnotetext{
${ }^{4}$ Debido a que "los procesos de estructuración son histórica y lógicamente anteriores a los procesos de isomorfismo institucional... Para entender la institucionalización de las formas organizacionales, debemos entender primero la institucionalización y estructuración de los campos organizacionales" (DiMaggio, 1999: 334) se decidió limitar la investigación al estudio de este proceso, para que posteriormente en otros trabajos sea posible, si se desea, proceder al análisis de las formas y prácticas organizacionales.
} 
En el segundo capítulo se desarrolla el Marco Contextual que sitúa la relevancia y complejidad de la actividad cultural a través de la participación de la sociedad civil organizada. Continúa con una exposición de los elementos que vinculan los temas de cultura, economía y desarrollo, que han dado lugar al impulso de la noción de Economía Creativa a nivel mundial, la cual ha transformado de manera importante la dinámica del sector cultural, al tiempo que enmarca el estudio realizado. Finalmente, con base en esta información, se desarrolla el planteamiento del problema, la pregunta y delimitación de la investigación, la relevancia que tiene ésta para el estudio de las organizaciones así como la metodología.

El tercer capítulo se titula Un contexto institucional para el emprendimiento en el sector cultural y creativo de la Ciudad de México, en el cual se realizó un mapeo de los programas académicos que han sido creados en México e Iberoamérica para la formación profesional en emprendimiento cultural y creativo. Continúa con la identificación y análisis, tanto de los eventos y actividades como de las políticas y programas realizados desde el ámbito académico, social y gubernamental para impulsar la difusión y creación de emprendimientos culturales y creativos. Finalmente, los hallazgos de esta sección se interpretan a partir de la fusión de ambas perspectivas teóricas: el isomorfismo institucional y la traducción.

En el cuarto capítulo se desarrolla el análisis detallado del proceso de surgimiento del Campo Organizacional de los Bazares de Arte y Diseño Independiente a través del estudio de los modos de imitación ${ }^{5}$.

\footnotetext{
${ }^{5}$ Cabe mencionar que los tres modos de imitación integran un campo de imitación, que, a su vez, da lugar a la integración de un campo organizacional.
} 
Dicho capítulo inicia con una contextualización de la Ciudad de México en lo que se refiere a la actividad cultural y creativa que en ella se gesta y que determina las características del entorno en el cual emerge el campo. Después se procede con la descripción de las particularidades que definen a los emprendedores culturales y creativos. Los siguientes apartados desarrollan, a partir del material empírico recabado, los elementos que posibilitan identificar la configuración organizacional de los Bazares de Arte y Diseño Independiente así como el sustento que permite afirmar que ha surgido el campo organizacional a través de la imitación y participación de los diversos actores involucrados.

Finalmente, se presentan las conclusiones y consideraciones finales en donde se reflexiona -con una mirada prospectiva- en torno a algunos aspectos que han derivado como consecuencia del impulso emprendedor en el sector cultural y creativo. 


\section{CAPÍTULO I. MARCO TEÓRICO}

\subsection{El sector cultural y creativo en el ámbito Iberoamericano desde una perspectiva organizacional.}

No obstante las numerosas aproximaciones teóricas aplicadas al ámbito cultural y creativo a nivel mundial, la bibliografía en el tema desde una mirada organizacional aún es escasa, sin embargo, los primeros años del Siglo XXI han abierto el camino a la realización de investigaciones en el espacio Iberoamericano que parten de la premisa de que es necesario un acercamiento al sector cultural y creativo a través del conocimiento y comprensión tanto de sus organizaciones como de las diversas formas de trabajo colectivo que existen; elementos que lo caracterizan como uno de los sectores más dinámicos e innovadores en la actualidad.

Si bien la mayoría de dichas investigaciones no se pueden enmarcar específicamente en la disciplina de los Estudios Organizacionales, se han considerado como parte de los antecedentes del tema debido a que proporcionan un acercamiento al estudio y descripción de nuevas formas de organización, modelos de gestión novedosos o que involucran diferentes perspectivas, así como estilos de liderazgo y coordinación colectiva distintos a los tradicionales ${ }^{6}$.

\footnotetext{
${ }^{6}$ Resulta pertinente mencionar que en junio de 2013 se llevó a cabo el "XII Congreso Internacional sobre Administración del Arte y la Cultura" en Bogotá, Colombia, en cuyo marco se presentaron ponencias de proyectos de investigación vinculados con el tema de este trabajo. No obstante, no fueron incluidos debido a que no se pudo tener acceso a ellos, pero deja claro el interés creciente por abordar el tema del emprendimiento y diversas formas de organización en el ámbito cultural y creativo.
} 
A continuación se realiza una breve descripción por país de las investigaciones a las que se pudo tener acceso, ya sea a través de medios digitales o de manera impresa, con el propósito de tener un marco de referencia de lo que se ha trabajado con anterioridad en el tema. Si el lector desea profundizar en algún documento en particular, en la bibliografía serán incluidos los datos completos.

\section{España}

España es sin duda uno de los países que está a la vanguardia en el tema y del cual se recibe la mayor parte de las influencias en aspectos de formación a nivel profesional por su larga y consolidada tradición en el establecimiento de programas universitarios para el sector.

Tal es el caso de Lluís Bonet, Xavier Castañer y Josep Font, reconocidos especialistas a nivel internacional que en 2001 editan Gestión de proyectos culturales. Análisis de casos, un libro que, de acuerdo con sus autores, surge de la necesidad de contar con referentes cercanos a la realidad iberoamericana, ya que hasta esos años, los casos de análisis que se utilizaban en los programas formativos se referían a experiencias norteamericanas, cuya realidad distaba mucho de lo que se vivía en otros países y justo la premisa del libro es que el contexto institucional (marco jurídico, estructura de valores, mercado y tradición cultural) condicionan la forma de gestión y posicionamiento de un proyecto cultural. Una característica distintiva de este material es que analiza organizaciones diversas pero todas altamente relacionadas con su entorno, lo cual proporciona una mirada interesante de la dinámica organizativa de dichos proyectos.

Asimismo, José Ruiz Navarro, Director de la Cátedra de Emprendedores de la Universidad de Cádiz y del "Global Entrepreneurship Monitor" (GEM) Andalucía, en 2009 presenta el libro Creación de empresas en el ámbito cultural, un estudio tanto 
cuantitativo como cualitativo que describe los factores que han propiciado el surgimiento de empresas culturales en España en el marco de interpretación de la Teoría Institucional y la Teoría de la Dependencia de Recursos.

El denominado tercer sector hace su aparición vinculado al tema de la cultura y la creatividad. En su artículo "La empresa social en la lucha contra la exclusión: tres casos innovadores en el campo de la cultura", publicado en 2011, Rocío Nogales Muriel afirma que cada vez más las empresas sociales están recibiendo atención como modelo organizativo capaz de promover un nuevo modelo de desarrollo sostenible, fundamentalmente a través de sus contribuciones en la prestación de servicios a grupos vulnerables. Aporta el término de ESCAs (Empresas Sociales, Culturales y Artísticas) las cuales, en su opinión, ofrecen un raro ejemplo de contexto organizacional que abarca las cuatro dimensiones del desarrollo sostenible impulsado por la Agenda 21 de la Cultura (económica, social, medio ambiente y cultural), que define a partir del estudio de tres empresas sociales en el sector cultura de tres países europeos (Italia, España y Dinamarca) haciendo énfasis en los vínculos existentes entre la cultura y el arte con los emprendimientos sociales y sus procesos de innovación.

En el marco de la Unión Europea, en 2012 se editaron dos tomos titulados La cultura como factor de innovación económica y social y Culture \&Innovation (s) Europe seen from the South, resultado del trabajo realizado desde el año 2009 en el denominado Proyecto Sostenuto (conformado por encuentros de profesionales, seminarios, entrevistas) con académicos e integrantes de organizaciones con el objetivo de identificar un modelo que aportara evidencias de que la cultura juega un papel significativo en los procesos de innovación económica y social, aterrizando la información recabada en las maneras cómo se dan estos procesos en organizaciones culturales específicas. 
La organización cultural Trànsit Projectes siempre se ha distinguido por ser innovadora. En 2012 presentó Música para Camaleones. El Black Álbum de la sostenibilidad cultural un catálogo digital que desde su diseño y presentación transmite la influencia de lo digital y la tecnología en el ámbito cultural. Integra una serie de prácticas de gestión y producción cultural identificadas en España que se caracterizan por ser alternativas a los modelos tradicionales así como por la implementación de estrategias de colaboración, cooperación y coproducción que contribuyen a dar cuenta de la presencia de nuevos paradigmas y nuevas configuraciones organizacionales en el sector.

\section{Uruguay}

Elaborado en 2002, Buscando caminos: Gestión, financiamiento y problemática de las Organizaciones Culturales del Interior del Uruguay. Investigación realizada en Salto, Colonia y Maldonado de Sandra Rapetti, en mi opinión es un estudio pionero desde la perspectiva organizacional del sector cultural en el espacio Latinoamericano que aporta elementos importantes para la identificación de algunas de las características básicas referentes a la gestión, el manejo de recursos humanos, financiamiento, los vínculos con la comunidad y otros actores, los servicios así como la problemática general a la que se enfrentan, en este caso, las organizaciones del sector en Uruguay pero que, sin duda, comparte retos con organizaciones culturales y creativas del resto de Latinoamérica.

\section{Costa Rica}

El tercer sector en la cultura: redes, asociaciones, organizaciones realizado por Sylvie Durán Salvatierra en 2009, aporta un análisis detallado del denominado Tercer Sector en sentido amplio, y a partir de ahí, en su vínculo directo con el ámbito cultural a través del mapeo de experiencias y relaciones entre el Estado, el mercado y la sociedad civil como elementos definitorios del sector. Con una postura crítica, describe el complejo panorama del tercer sector en cultura y aboga por el reconocimiento de otras formas de 
organización y asociatividad informales (tales como redes sociales, de amigos, familiares, comunitarias, etc.) que muchas veces quedan fuera de los estudios y políticas públicas porque no se ajustan a las lógicas del mercado.

\section{Colombia}

Otro de los países que en los últimos años se ha convertido en un referente fundamental en el tema del emprendimiento cultural y creativo a nivel Latinoamérica es Colombia, quien con políticas y programas específicamente diseñados para el sector ha conseguido dinamizar y aprovechar en términos sociales el impulso creativo a nivel mundial.

En este sentido, un documento básico es el Manual para la implementación de procesos de emprendimiento y creación de industrias culturales, coordinado por María Elisa Holguín en 2010. Dicho manual, editado por el Ministerio de Cultura, se ajusta a las acciones implementadas por la política de emprendimiento de aquel país ofreciendo un marco metodológico para que los creadores del sector estén en posibilidades de iniciar procesos de emprendimiento. Se ofrecen elementos jurídicos, conceptuales (basados en los principios de la economía creativa) y otras herramientas administrativas y de gestión para constituir una empresa cultural y creativa.

\section{Argentina}

El libro Gestión Cultural para el desarrollo. Nociones políticas y experiencias en América Latina, de Bruno Maccari y Pablo Montiel, publicado en 2012, integra un conjunto de experiencias de organizaciones culturales de diversos países latinoamericanos en donde se pretende demostrar cómo la acción cultural aporta elementos valiosos al desarrollo en sentido amplio, donde el desarrollo institucional y organizacional desempeña un papel importante para el campo cultural en su conjunto. 


\section{México}

En 2011 Néstor García Canclini y Maritza Urteaga coordinan la investigación interdisciplinaria titulada Cultura y desarrollo: una visión distinta desde los jóvenes, financiada por la Fundación Carolina y realizada en el marco de trabajo de la Universidad Autónoma Metropolitana. Entre las múltiples aportaciones de dicha investigación, se destaca -para los fines de este estudio- lo referente a las novedosas formas de organización y trabajo colectivo de los denominados jóvenes creativos de la Ciudad de México para generarse empleo en un contexto de crisis, tomando como marco de referencia los emprendimientos de los jóvenes en disciplinas como las artes visuales, música, editoriales independientes y diversas prácticas digitales desde una perspectiva crítica a los modelos y términos empleados en otros países.

Desde la plataforma de los Estudios Organizacionales, la Universidad Autónoma Metropolitana con el Posgrado en Estudios Organizacionales ha iniciado el trabajo de reconocimiento e investigación de organizaciones del sector cultural en el país desde diversas perspectivas.

Tal es el caso de la Tesis Doctoral de Irene Sánchez Guevara (2007) sobre la Organización del teatro independiente de México: de la red de cooperación al conflicto que, entre otras cosas, aporta una caracterización desde la perspectiva organizacional del teatro en México muy clara que lo divide en comercial, institucional e independiente con base en sus modelos de producción, objetivos, formas organizacionales, relaciones laborales, fuentes de financiamiento, tipo de público y función social; siendo el independiente el que sirve de referente para el análisis de la compleja dinámica de los grupos que se crean en su interior estableciendo una red de cooperación que de acuerdo con la autora, no está exenta de tensiones, pero que finalmente es el sustento que permite transitar de la idea hasta la escenificación y constituye el pilar de este tipo de organizaciones. 
La tesis de Maestría de Silvia Viridiana Ramírez Atilano titulada Una propuesta para el análisis estructural de una osc: el caso del Centro de Arte y Cultura CV (CACCV), una organización referente del sector en el trabajo cultural con jóvenes desde mediados de la década de los noventa, cuyos elementos estructurales y de vínculo con otros sectores tanto a nivel nacional como internacional le han permitido permanecer en la escena independiente de la Ciudad de México implementando estrategias innovadoras de gestión.

Finalmente, Organizaciones de la sociedad civil en la transformación del espacio público, el caso del corredor cultural de Regina (2011), realizado por Carolina Sue Andrade Díaz, aborda un tema actual y de gran relevancia en las ciudades contemporáneas, el cual vincula con la construcción de redes de organizaciones de la sociedad civil que surgen como consecuencia de un proceso de institucionalización del discurso gubernamental, para lo cual se basa en los principios del Nuevo Institucionalismo Sociológico con el propósito de recuperar una lectura histórica de su evolución.

Como se observa, las posibilidades para aproximarse al estudio de las organizaciones culturales y creativas son considerablemente amplias e interesantes. Hay muchos aspectos aún sin abordar y eso constituye un reto interesante para la investigación en el tema. El contexto actual es sumamente dinámico y crea un entorno propicio para las transformaciones constantes en el sector, lo que desde luego, permea en las dinámicas organizacionales que se asumen para enfrentar la incertidumbre.

A continuación, se presentan las definiciones teóricas que servirán de referente en la interpretación de datos producto de la presente investigación. 


\subsection{Reflexiones sobre el concepto de organización en el marco de los Estudios Organizacionales}

Si bien como estudiosos de las organizaciones, se nos hace evidente desde el inicio de nuestra formación que vivimos en una sociedad organizacional, que gran parte de nuestra vida se desarrolla en y con relación a organizaciones, en realidad no hay un consenso en torno a la definición de lo que es una organización. Ello radica en gran parte en la multidisciplinariedad que caracteriza a los Estudios Organizacionales, lo cual hace necesario un conjunto de definiciones para trasmitir la esencia de la palabra, de acuerdo al tipo de disciplina y perspectiva teórica desde donde se aborde, no obstante, para los fines de esta investigación, coincidiendo con lo que afirma Parsons: "el desarrollo de organizaciones es el principal mecanismo a través del cual, en una sociedad altamente diferenciada, es posible "que se hagan las cosas", alcanzar metas que están más allá de los límites inmediatos del individuo" (Parsons, 1960: 41 en Scott, 2005: 442).

Así, una de las aportaciones que en lo personal me parece más interesante y útil es la idea de ver a las organizaciones como un sistema abierto. "Las organizaciones son sistemas de actividades interdependientes que vinculan coaliciones de participantes que operan el cambio: los sistemas están integrados en los entornos en los que operan" (Scott, 2003), esto es importante ya que por un lado se caracteriza a las organizaciones como sistemas complejos, cuya particularidad de emergencia se presenta en los cambios en el entorno que ha determinado en gran medida las transformaciones en las formas organizacionales, describiendo así la evolución de sus estrategias. 
Por su parte, Crozier y Friedberg afirman que "no hay organización que pueda existir en lo abstracto; [la organización] es parte de una determinada sociedad que ha alcanzado un cierto grado de desarrollo técnico, económico, y cultural, caracterizado por una determinada estructura social y que lleva consigo valores, a los que están particularmente ligados sus miembros”(Crozier y Friedberg, 1990:110).

Pese a la diversidad de aproximaciones conceptuales, una que en primera instancia ha parecido útil y se retoma en varias investigaciones porque integra diversos elementos considerados en otras teorías y enfoques es la siguiente (lo cual cabe mencionar no quiere decir sea la única, pero hasta el momento parece ser una opción aceptable para iniciarnos en su estudio) "una organización es una colectividad con una frontera relativamente identificable, un orden normativo, niveles de autoridad, sistemas de comunicaciones y sistemas de coordinación de membresías; esta colectividad existe de manera continua en un ambiente y se involucra en actividades que se relacionan por lo general con un conjunto de metas; las actividades tienen resultados para los miembros de la organización, la organización misma y la sociedad" (Hall, 1996: 33).

Sin embargo, conforme se avanza en el estudio de las organizaciones resulta claro que la complejidad y la ambigüedad son algo inherente a éstas. En este sentido, poco a poco se ha ido desmitificando la idea de racionalidad, control y orden; para ir integrando en la realidad organizacional elementos como el caos, el desorden, la falta de claridad de sus objetivos así como la diversidad y subjetividad que existe en su interior, lo cual no tiene que interpretarse como algo negativo, simplemente así es, debido a que las organizaciones no son "entes abstractos" sino que al estar conformadas por individuos, reflejan toda la complejidad y contradicciones de éstos. 
Así vemos que de la mirada tradicional (basada en la eficiencia) que ha dominado la Teoría de la Organización, desde la plataforma de los Estudios Organizacionales poco a poco nos acercamos al conocimiento de nuevos paradigmas que emergen necesariamente en nuevos escenarios, los cuales a su vez, imponen distintos retos en el marco de una sociedad dinámica, diversa y plural, por lo que las organizaciones cada vez más se caracterizan por su flexibilidad y adaptabilidad para lograr sobrevivir en un entorno dinámico y, en muchos casos, totalmente adverso.

\subsection{Mecanismos de cambio institucional isomorfo en el proceso de estructuración de un campo organizacional}

En principio, la teoría institucional contribuye con importantes elementos para el análisis que aquí se propone cuya pregunta de investigación es: ¿A qué factores se puede atribuir el surgimiento y crecimiento exponencial que han tenido los Bazares de Arte y Diseño Independiente en el sector cultural y creativo de la Ciudad de México entre 2003-2013?, ya que "hace énfasis en que las organizaciones son sistemas abiertos, fuertemente influenciados por su medio ambiente, pero que muchas de sus fuerzas más decisivas son resultantes, no de presiones racionales hacia una mayor eficiencia, sino de presiones sociales y culturales que conforman las creencias convencionales (Scott, 1992). Esta perspectiva representa un importante rompimiento con la hegemonía conceptual de los utilitaristas modelos del actor-racional y una estrategia prometedora para explicar y modelar instancias de cambio organizacional que no son dirigidas por procesos donde el interés está en la base de la movilización" (DiMaggio, 1988 en Barba y Solís, 1994: 66).

Por otro lado, dentro del universo del denominado Nuevo Institucionalismo, es el Nuevo Institucionalismo Sociológico (NIS) el que aporta elementos para comprender por qué ante ciertos cambios en el entorno, las organizaciones tienden a parecerse. 
DiMaggio y Powell (1999) en su texto "Retorno a la Jaula de Hierro: el isomorfismo institucional y la racionalidad colectiva en los campos organizacionales" sugieren que son el Estado y las profesiones, los que se han convertido en los grandes racionalizadores de la segunda mitad del siglo XX.

Para tal efecto, proponen el concepto de isomorfismo como el proceso que hace que las organizaciones tiendan a ser iguales a otras en las mismas condiciones ambientales. De acuerdo con Aldrich (1979: 165), "los principales factores que las organizaciones deben tener en cuenta son las otras organizaciones". De esta manera, DiMaggio y Powell (1999: 109) afirman que "las organizaciones compiten no sólo por recursos y clientes, sino también por poder político y legitimidad institucional, por una buena condición social y económica. El concepto de isomorfismo institucional es un instrumento útil para atender la política y la ceremonia que subyacen en gran parte de la vida organizacional moderna".

Identifican tres mecanismos de cambio institucional isomorfo: "el isomorfismo coercitivo, que se debe a influencias políticas y al problema de legitimidad; el isomorfismo mimético, que resulta de respuestas estándares a la incertidumbre, y el isomorfismo normativo, asociado con la profesionalización" (DiMaggio \& Powell, 1999: 109).

Por lo que se refiere al mimético, se plantea que ante la incertidumbre las organizaciones tienden a copiar los modelos de otras organizaciones, a veces incluso de manera inconsciente, por moda o por seguir una tendencia que se considera "legítima".

El normativo es interesante al sustentarse en la profesionalización. En este sentido, de acuerdo con los autores, "dos aspectos de la profesionalización son fuentes importantes de isomorfismo. Uno es que la educación formal y la legitimidad tienen una base cognoscitiva producida por especialistas universitarios; el segundo es el crecimiento y complejidad de 
redes profesionales que van más allá de una sola organización y a través de las cuales se difunden rápidamente los nuevos modelos" (DiMaggio \& Powell, 1999: 114).

En esta parte se incluye también el intercambio de información entre los especialistas así como la misma rotación que se da entre éstos en los mismos campos organizacionales, en donde los juegos por la búsqueda del prestigio y el status son altamente recurrentes.

Es interesante que también se toca el asunto de las fuentes de financiamiento y dicen los autores: "la centralización de recursos causa la homogeneización, debido a que existe presión por parte de los proveedores y cuanto mayor es el grado en que las organizaciones en un campo realizan transacciones con agencias del Estado, mayor será el grado de isomorfismo en el campo entero" (DiMaggio \& Powell, 1999: 120). Lo anterior se logra a través de diversos mecanismos y estrategias que inducen transformaciones en las organizaciones que aceptan ajustar sus estructuras y maneras de operar a los mecanismos propuestos por parte de las instancias financiadoras.

Estas tendencias isomórficas propician el surgimiento y estructuración de lo que denominan un campo organizacional que "son aquellas organizaciones que, en conjunto, constituyen un área reconocida de la vida institucional: los proveedores principales, los consumidores de recursos y productos, las agencias reguladoras y otras organizaciones que dan servicios o productos similares. La virtud de esta unidad de análisis es que nos hace prestar atención no sólo a las empresas competidoras, sino también a la totalidad de los actores importantes. Así, la idea del campo abarca la importancia tanto de la conexión como de la equivalencia estructural" (DiMaggio y Powell, 1999: 106). 
Señalan que el proceso de definición institucional o "estructuración" consiste en cuatro etapas:

1) Un aumento en el grado de interacción entre las organizaciones en el campo

2) El surgimiento de estructuras interorganizacionales de dominio y de patrones de coalición claramente definidos

3) Un incremento en la carga de información de la que deben ocuparse las organizaciones que participan en un campo

4) El desarrollo de la conciencia entre los participantes de un conjunto de organizaciones de que están en una empresa común (DiMaggio y Powell, 1999: 106).

Si bien la estructuración de un campo puede darse en todos los sectores, afirman que en el sector no lucrativo, donde no existen barreras legales para la colusión, la estructuración puede proceder incluso más rápido, ya que la competencia entre organizaciones no se da tanto en términos económicos o de eficiencia sino en búsqueda de estatus y legitimidad social en donde, "el prestigio y los recursos organizacionales son elementos clave para atraer profesionales. Este proceso favorece la homogeneización a medida que las organizaciones procuran proporcionar los mismos beneficios y servicios que sus competidores" (DiMaggio y Powell, 1999: 116-117). Por lo tanto, en dicho sector incluso se estimula el trabajo coordinado entre las organizaciones que forman parte del campo y eso es visto de manera positiva.

Ante la pregunta de ¿Por qué es importante estudiar los campos organizacionales?, coincidiendo con Naime (2004: 58) "la primera tarea por realizar es tener una visión de conjunto sobre lo que socialmente significan las organizaciones en un contexto determinado, ya que el origen de cada una de ellas, los modelos que adoptan para desarrollar sus políticas, así como sus estructuras y actores son determinantes para conocer el papel social que desarrollan". 
En esta misma línea DiMaggio (1999: 333) afirma que "estas construcciones son fundamentales al intentar explicar los patrones de competencia, influencia, coordinación y las corrientes de innovación interorganizacionales, porque definen las fronteras dentro de las cuales ocurren estos procesos".

Asimismo, DiMaggio y Powell sugieren, entre muchos argumentos, que "el examen de la difusión de estrategias y estructuras organizacionales similares debe ser un medio productivo para evaluar la influencia del interés de las élites" ya que éstas definen de manera constante ideas y modelos de organización que en muchos casos se aceptan sin cuestionar, no obstante que tienen un impacto importante en términos económicos, políticos, sociales y culturales en un país.

\subsection{El Nuevo Institucionalismo Sociológico. Posibilidades y limitaciones}

Ahora bien, luego de exponer los elementos teóricos que constituyen referentes clave para la identificación de las características generales del campo organizacional, en este caso de los emprendimientos en el sector cultural y creativo de la Ciudad de México, resulta pertinente mencionar las posibilidades y limitaciones de esta corriente de pensamiento (el NIS) a partir de los postulados del isomorfismo institucional.

En el primer rubro, de acuerdo con De la Rosa (2002: 37-38), "la conformación de un campo organizacional, en tanto ambiente organizacional, permitiría entender mejor la conformación histórica de la estructura organizacional y, de esta forma, el factor histórico puede ser recuperado. Y, por otra parte, con el NIS la estructura de la organización adquiere un carácter sociocultural. Así, el hecho de que la estructura de la organización esté institucionalmente conformada, implica repensar -entre otros aspectos- los procesos organizacionales". 
Dentro de las limitaciones, Montaño (2006:11), afirma que "está caracterizado por una tendencia a la reducción de la diversidad organizacional, lo cual implicaría una disminución de la variedad institucional, empobreciendo con ello la vida social e imponiendo una sola lógica de acción a las organizaciones, la económica; este es el riesgo de una evolución institucional".

Por su parte, Naime (2004: 48) señala que "si bien es cierto que como exponen Powell y DiMaggio, el avance tecnológico le ha dado uniformidad a la estructura de las organizaciones, también lo es que éstas no estandarizan al elemento humano ni al contexto en el cual se va a desarrollar".

Estos últimos argumentos son los que dan pie a la inclusión de otros paradigmas teóricos que complementen la lectura y comprensión sobre ¿cómo surgen los campos organizacionales y de qué manera se les puede identificar? ya que se ha mencionado es un tema que desde la corriente institucionalista ha recibido poca atención.

El mismo DiMaggio en su texto sobre la "Construcción de un campo organizacional como un proyecto profesional: los museos de arte de los Estados Unidos, 1920-1940" reconoce que la investigación institucional se ha ocupado primordialmente del estudio del isomorfismo institucional, no obstante que "para entender la institucionalización de las formas organizacionales, debemos entender primero la institucionalización y estructuración de los campos organizacionales. Los campos donde los procesos institucionales tienen la mayor influencia sobre el cambio organizacional no son simples construcciones del investigador, sino que son significativos para los participantes e incluyen organizaciones especializadas que limitan, regulan, organizan y representan en el nivel del campo mismo. El descuido de los investigadores respecto de los procesos de estructuración proporciona una visión unilateral del cambio institucional que hace hincapié en la evolución que se da por hecho, no dirigida, no conflictiva, a costa de los procesos intencionales, dirigidos y conflictivos" (DiMaggio, 1999: 334). 
Con base en los argumentos anteriores, antes de incluir otro paradigma que nos permita identificar los elementos determinantes en el proceso de formación de un campo organizacional, resulta de utilidad reflexionar sobre lo que sucede en el entorno mundial en la actualidad y su influencia en las organizaciones.

\subsection{Fenómenos globales y su impacto en las transformaciones organizacionales}

Es un hecho que el fenómeno que ha sido denominado como globalización ${ }^{7}$ ha impactado en prácticamente todos los ámbitos de la vida actual. En el campo de estudio de las organizaciones, es un elemento de transformación fundamental que no ha podido pasarse por alto, debido a que el dinamismo y acelerado crecimiento de las tecnologías de la información facilitan más que nunca los vínculos globales entre individuos a través de diversos mecanismos, lo cual obviamente impacta en la manera cómo se conciben y estructuran las organizaciones contemporáneas y, parece ser, que la tendencia seguirá a la alta en los próximos años. De acuerdo con Scott (2005: 444), "la erudición actual reconoce el grado en que las organizaciones son afectadas por conexiones verticales por ejemplo, lazos de propiedad y control-, así como por vínculos horizontales y por influencias locales y no locales. Las fuentes de innovación e ideas respecto a nuevas maneras de organizar pueden llegar por Internet desde el otro lado del mundo". Entonces, al cambiar el ambiente e integrar referentes globales, las organizaciones tienden a modificar su configuración.

\footnotetext{
7 "Actualmente, el término globalización describe un aumento vertiginoso del comercio inter y transnacional que, combinado con una preferencia por las políticas del mercado libre por encima de las protecciones de las economías locales o nacionales, busca la expansión de una sola economía capitalista con un impacto planetario... En este sentido, la globalización condensa el tiempo y el espacio, achicando el mundo por acelerar el tiempo necesario para que la gente interactúe, sin importar su ubicación geográfica. Entonces, a partir de los años ochenta, la globalización se ha vuelto un término popularizado que se refiere tanto a la alta velocidad de los cambios en la experiencia de lo local, como al aumento de los vínculos mundiales en los campos económicos, políticos y culturales" (Birón, Rebecca en Szurmuk y Mckee, 2009: 120).
} 
En este sentido, siguiendo con Scott, éste sugiere cinco cambios que considera trascendentales: 1) cambios en la naturaleza de los límites organizacionales, 2) cambios en las estrategias organizacionales, 3) cambios en las formas organizacionales, 4) cambios en los componentes organizacionales y, más fundamentalmente, 5) cambios en la manera en que concebimos a las organizaciones.

Sobre este último aspecto, sugiere como necesaria la transición hacia una concepción de la organización como proceso -remitiéndose a Weick (1969) como pionero en dicho enfoque- resaltando que "los acontecimientos cruciales que deben explicarse son procesos, su estructura, modificación y disolución" (Weick, 1969: 16 en Scott, 2005: 454).

Así, la pertinencia de reflexionar en torno al concepto de organización o, en un sentido más amplio, "lo organizacional" radica en que al tener clara esta noción se nos puede facilitar la posibilidad de mirar diversos fenómenos sociales desde esta óptica y, en esta medida, se podría aportar algo a su comprensión de manera más integral.

Por lo tanto, afirma como argumento para defender su propuesta, que "los enfoques relacionales celebran los procesos sobre la estructura. Lo que está siendo procesado varía mucho. En algunas versiones, son símbolos y palabras, en otras son relaciones y contratos, y en otras más, activos. Pero en los enfoques relacionales, si existe estructura, es porque continuamente están siendo creadas y recreadas y, si el mundo tiene significado, es porque los actores están construyendo y reconstruyendo las intenciones en descripciones y, por tanto, sus identidades propias y las de otros (Scott, 2001 en Scott 2005: 455). 
De lo anterior se desprende otro elemento importante para el análisis y es que los individuos que integran las organizaciones no son entes estáticos a la espera de ideas, formas, modelos. Coronilla (2004: 103), señala que "la organización aprende a través de la acción colectiva de individuos que discuten, interpretan eventos, juzgan la utilidad de la información disponible y determinan si es suficiente, excesiva u óptima. El cambio ocurre cuando los actores del sistema asumen nuevas formas de interpretar la realidad organizacional a través de la creación de renovados modelos relacionales y de razonamiento y de la adquisición de renovadas capacidades colectivas de actuación".

\subsection{La corriente institucionalista Escandinava}

De tal suerte que una nueva corriente que puede facilitar el trabajo de reconocimiento del papel de los actores en el proceso de formación de un campo organizacional es el concepto de Traducción, que surge desde la plataforma del Colegio Institucionalista Escandinavo cuya utilización "se basa en el trabajo de Bruno Latour (1986)para referirse a la transferencia y la representación de una forma diferente a través de una cadena de actores, un proceso que involucra a los remitentes y receptores y la transformación de una idea a la práctica"(Morris y Lancaster, 2005: 209). Unas de las figuras más importantes y representativas de esta corriente son Czarniawska y Sevón $(1996,2005)^{8}$, cuyo trabajo constituye un referente fundamental en esta investigación.

En el libro titulado Translating organizational change (Czarniawska y Sevón, 1996), los autores observan que "las ideas de la administración traducidas en objetos (modelos, libros, transparencias) son enviadas a otros lugares distintos de donde surgieron, traducidos en un nuevo tipo de objetos y, algunas veces en acciones, las cuales si son repetidas pueden posiblemente estabilizarse en instituciones, que a su vez, podrían ser

\footnotetext{
${ }^{8}$ Las referencias a estas obras se han hecho con base en una traducción propia de los textos.
} 
descritas y resumidas a través de ideas abstractas y así sucesivamente" (Czarniawska, 1996 en Czarniawska y Sevón, 2005: 8)

Si bien la noción de traducción de inmediato se relaciona con el lenguaje, "traducción es un concepto que inmediatamente evoca asociaciones simbólicas, mientras al mismo tiempo es obstinadamente material: sólo una cosa puede ser movida de un lugar a otro y de un tiempo a otro. Las ideas deben materializarse, al menos en la cabeza de alguien, los símbolos deben ser inscritos... Una práctica o una institución no pueden viajar, debe ser simplificada y abstraída en una idea o por lo menos aproximada a una narrativa que permita una experiencia indirecta y, por lo tanto, convertirse a palabras o imágenes. Ni las palabras ni las imágenes pueden viajar hasta que se han materializado, hasta que están incorporadas, inscritas u objetivadas, como cuerpos o cosas sólo pueden moverse en el tiempo y el espacio" (Czarniawska 2002:7 en Czarniawska y Sevón, 2005: 9).

De manera central, el concepto de traducción aporta algo muy importante que es la consideración de que las organizaciones, más bien sus integrantes, son agentes activos en el proceso de selección de ideas, modelos, nombres, algo que sin duda había faltado en los estudios enfocados únicamente en la difusión de ideas.

\subsubsection{La pertinencia del proceso de traducción en la identificación del surgimiento de un campo organizacional a través de los campos de imitación}

Ahora bien, con base en lo anterior y dando continuidad al tema que se abordó previamente sobre el proceso de estructuración de los campos organizacionales y las limitaciones que la teoría institucionalista presenta para su análisis, desde la perspectiva de la traducción resulta pertinente preguntar antes ¿Cómo llegan a formar parte de un campo las organizaciones? y ¿Cómo surgen los campos? 
Hedmo, Kerstin y Wedlin (2005) proponen un modelo de análisis a través de los denominados Campos de Imitación como Traducción, el cual se toma como referente para la realización de esta investigación.

Las autoras afirman que "un campo se forma a través de múltiples y entrelazados procesos de imitación. Por esta razón, la imitación es un proceso más central en la formación del campo de lo que los estudios anteriores de los campos de organización han asumido, la imitación no sólo se desarrolla en los campos organizacionales, en realidad es central para la formación de tales campos. La imitación es, por lo tanto, el medio fundamental por el cual los campos se desarrollan y son reconocidos como un área en particular de la vida institucional. Para poner de relieve la importancia de la imitación en el surgimiento de campos organizacionales, nos referimos a los campos como campos de imitación" (Hedmo, et al. 2005: 191).

En el caso de esta investigación que se refiere al estudio del surgimiento del campo organizacional de los Bazares de Arte y Diseño Independiente de la Ciudad de México, las preguntas son: ¿Por qué han surgido numerosas propuestas similares en los últimos años? ¿A qué factores se puede atribuir el crecimiento exponencial que han tenido? ¿Por qué y cómo se han desarrollado y difundido estas formas de organización en el sector cultural y creativo de la Ciudad de México? ¿Cuáles han sido los medios por los que se ha dado mayor interacción y el reconocimiento mutuo entre los actores del campo?

Para responder a los cuestionamientos anteriores, se recurre a lo que Hedmo, et al. (2005) han trabajado sobre la imitación:

"la imitación no sólo es un mecanismo que aumenta las presiones isomorfas una vez se forman los campos, también impulsa el proceso de estructuración. La imitación no sólo sigue la formación de los campos, sino que también abre el camino para la formación de los campos y de hecho constituye campos. Para 
entender esta dinámica tenemos que mirar más de cerca los procesos de imitación, en particular, la forma en que éstos se relacionan con los procesos de formación de identidad... La imitación es un mecanismo social básico que ata a la gente (Tarde, 1902/1969). Los actores tienden a imitar a aquellos que quieren parecerse (Sevón, 1996). Ciertos modelos, actores, o prácticas llegan a ser ampliamente conocidos, por lo tanto, estas formas, deseos e ideales proporcionan el impulso necesario para su posterior imitación. Por lo tanto, la identidad percibida forma imitación: uno imita aquellos con los se relaciona y a aquellos con los que uno se identifica. El proceso de imitación implica tanto la auto-identificación como el reconocimiento de lo que a uno le gustaría ser (Sevón, 1996). Lo opuesto también es verdadero, sin embargo, en esa imitación se forma identidad. La imitación construye nuevas relaciones, referencias e identificaciones y abre nuevas posibilidades para la comparación y para crear nuevas identidades" (Hedmo, et al. 2005: 194).

Por otra parte, apuntan que la imitación es un proceso activo ya que los actores seleccionan, traducen y editan las ideas en el proceso de imitación lo que da lugar a versiones locales de las formas globales, así que "tanto los que buscan ser imitados como los que imitan traducen ideas y prácticas para satisfacer sus propios deseos y de las circunstancias específicas en las que operan" (Hedmo, et al. 2005: 195). 
El modelo que proponen se sustenta en tres modos de imitación, los cuales se describen a continuación:

\section{TABLA 1. MODOS DE IMITACIÓN}

\begin{tabular}{|c|c|}
\hline MODO DE IMITACIÓN & CARACTERÍSTICAS \\
\hline Transmisión & $\begin{array}{l}\text { - Se basa en un modelo específico o un conjunto central de ideas } \\
\text { elegidas por los actores en diversos ámbitos. } \\
\text { - La imitación conduce a la homogeneización de las prácticas. } \\
\text { - Surge un modelo central único que se convierte en un prototipo } \\
\text { para ser imitado. } \\
\text { - La imitación es dirigida por la participación activa, iniciativa y } \\
\text { motivos de aquellos que hacen la imitación. } \\
\text { - Tanto los imitados como los imitandos son formadores activos } \\
\text { del proceso. }\end{array}$ \\
\hline Cadena de imitación & $\begin{array}{l}\text { - Una idea es imitada y después esta imitación es a su vez imitada } \\
\text { - } \quad \text { así sucesivamente. } \\
\text { la imitación }\end{array}$ \\
\hline Mediada & $\begin{array}{l}\text { - Personas y organizaciones actúan como portadores y/o } \\
\text { mediadores en la imitación. } \\
\text { - La identidad del portador a menudo se reduce a una entidad que } \\
\text { sólo informa sobre lo que está ocurriendo en varios lugares, } \\
\text { pero no es en sí mismo una entidad de activación ni un actor con } \\
\text { influencia (investigadores, medios de comunicación, comités de } \\
\text { expertos y organizaciones internacionales). } \\
\text { - Estos editores no sólo reportan y/o transmiten ideas y } \\
\text { experiencias, también las formulan y reformulan en el proceso. } \\
\text { - Enseñan -más o menos directamente- a otras organizaciones } \\
\text { cómo actuar a fin de ser reconocidas y legitimadas. }\end{array}$ \\
\hline
\end{tabular}

Fuente: Elaboración propia con base en Hedmo, et al. (2005: 196)

Se indica que estos tres modos de imitación deben verse como tipos ideales y pueden estar presentes de manera simultánea e interconectada en un campo. 
Finalmente, es importante tener claro que un sólo paradigma organizacional en muchas ocasiones no es suficiente para interpretar la compleja realidad y entonces surge la necesidad de integrar varios y ponerlos a dialogar, como se propone en este trabajo.

\section{FIGURA 1. MODELO UTILIZADO EN LA INVESTIGACIÓN}

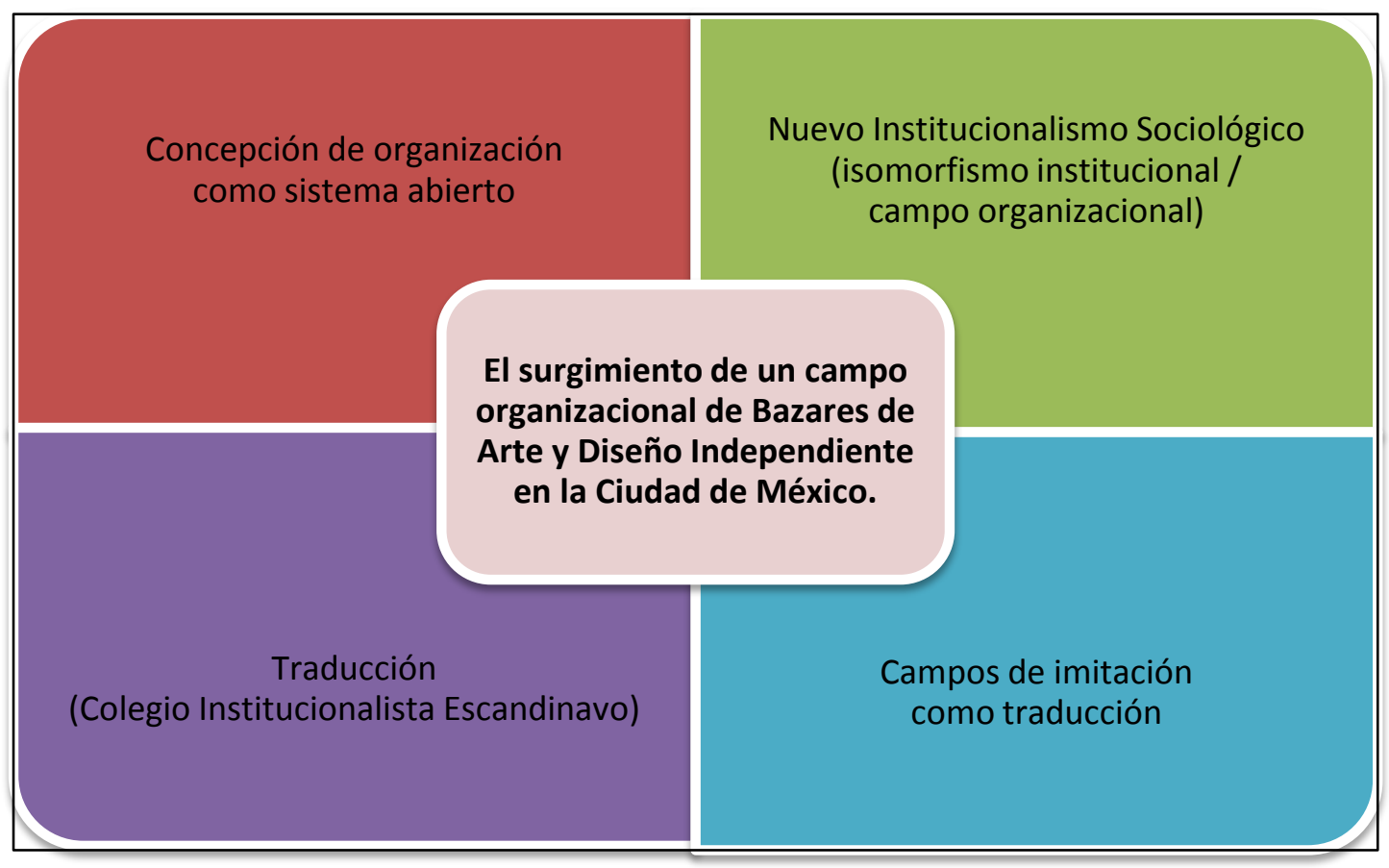

Fuente: Elaboración propia 


\section{CAPÍTULO 2. MARCO CONTEXTUAL. PLANTEAMIENTO DEL PROBLEMA Y METODOLOGÍA DE LA INVESTIGACIÓN}

\subsection{Contextualizando la relevancia y complejidad dela actividad cultural}

A diferencia de otros sectores, el cultural se dice es uno de los que se encuentra más íntimamente vinculado con el desarrollo humano y social en sentido amplio pues se sustenta en gran medida en un universo de prácticas y elementos simbólicos. En este sentido, es muy importante superar la visión de que cultura es sinónimo de Bellas Artes. Más bien la cultura engloba, como señaló la UNESCO (Organización de las Naciones Unidas para la Educación, la Ciencia y la Cultura por sus siglas en inglés) desde 1982, "las artes y las letras, los modos de vida, los derechos fundamentales del ser humano, los sistemas de valores, las tradiciones y las creencias".

Néstor García Canclini amplía la concepción anterior y afirma que "la cultura abarca el conjunto de procesos sociales de producción, circulación y consumo de la significación en la vida social". Situados en el contexto actual, sugiere "asumir la propuesta de Arjun Appadurai de utilizar el término cada vez menos como substantivo (cultura) y más como adjetivo (cultural), para enfatizar en los procesos más que en los objetos y abarcar esas zonas locales y globales en que tienen lugar dinámicas de interculturalidad" (García Canclini 2004:34 en Lobato y Quintero, 2008).

Según las definiciones de los especialistas, podemos reunir bajo la denominación común de sector cultural a "distintos ámbitos de la actividad humana donde se crea, se produce y se reproduce, se distribuye y se consume una amplia gama de bienes y servicios, cuya característica común es la de poseer un alto contenido simbólico. Es decir, un tipo particular de productos que por un lado cumplen con el fin para el que fueron hechos, y 
cuya existencia -o inexistencia- tiene una influencia importante sobre los valores que rigen en las sociedades donde se originan o se consumen".

Por otra parte, coincidiendo con lo que establece Durán (2009:11), "hoy día la cultura se debate alrededor de la diversidad cultural entendida como un amplio conjunto de recursos, de reivindicaciones y de formas de ser en el mundo. En ese vasto campo de la diversidad cultural -en proceso de disección y precisión- también debería incluirse la variedad de formas organizativas que toma el sector cultura o, incluso de forma más general, la sociedad para hacer lo que definimos como trabajo cultural".

Es por todo esto que su estudio resulta necesario y tiene implicaciones no sólo para los actores involucrados directamente (creadores, promotores, gestores, estudiosos del tema, público) sino para la sociedad en general.

Y en esta necesidad de establecer diálogo con diversas instancias -que cabe mencionar la mayoría de las veces todavía están poco sensibilizadas al respecto- resulta importante dimensionarla en su relación con otros ámbitos de la vida social y económica así como con su inevitable vínculo con otras realidades culturales, es decir, ubicar su actuar en múltiples niveles, lo cual implica que el sector cultural en sí mismo sumamente complejo y, por lo tanto, podemos suponer que lo son sus organizaciones. 


\subsection{La participación de la sociedad civil en el ámbito cultural}

Ante las dificultades que enfrenta el Estado para atender las demandas de una sociedad diversa y dinámica, en nuestro país y en el resto del mundo, se aprecia el surgimiento de diversas formas de participación que desde el ámbito social toman como suya la responsabilidad de llevar a cabo e impulsar proyectos culturales ${ }^{9}$ diversos que cumplen una función muy importante que tiene que ver con el rescate y conservación de las tradiciones e identidad de un país o una comunidad, así como con elementos de desarrollo económico y social fundamentales.

En México, de acuerdo con la Ley Federal de Fomento a las Actividades Realizadas por Organizaciones de la Sociedad Civil (2010) en su Artículo 3 señala que "se entiende por organizaciones civiles aquellas agrupaciones u organizaciones mexicanas que, estando legalmente constituidas (asociación civil, IAP ${ }^{10}$, sociedad civil, sociedad cooperativa, sociedad de solidaridad social, fundación o institución de beneficencia privada) no persigan fines de lucro ni de proselitismo partidista, político-electoral o religioso".

\footnotetext{
${ }^{9}$ Para entender a qué nos referimos cuando se habla de proyectos culturales, se recurre a lo establecido en el Marco de Estadísticas Culturales de la UNESCO (2009) en donde se afirma que los bienes culturales proyectan ideas, símbolos y modos de vida, algunos de los cuales pueden estar sujetos a derechos de autor. Por su parte, los servicios culturales no representan bienes culturales materiales en sí mismos, aunque facilitan su producción y distribución. Por ejemplo, entre los servicios culturales se incluyen las actividades de distribución de productos audiovisuales, la promoción de eventos culturales y artes escénicas, así como los servicios de información cultural y la preservación de libros, grabaciones y artefactos (en bibliotecas, centros de documentación y museos). Esta caracterización permite ubicar el ámbito de acción en el que incursionan las organizaciones culturales a partir de la realización de proyectos diversos.

${ }^{10}$ Institución de Asistencia Privada.
} 
El mismo documento en su Artículo 5 reconoce dieciséis ámbitos de acción para las actividades de las Organizaciones de la Sociedad Civil (OSC), entre las que se encuentran las registradas en el rubro de "promoción y fomento educativo, cultural, artístico, científico y tecnológico", las cuales constituyen uno de los principales referentes a partir de los cuales surge la necesidad de realizar esta investigación.

Así, con base en información proporcionada por el Instituto Nacional de Desarrollo Social (2012), en México existen 18, 313 organizaciones inscritas en el Registro Federal de las Organizaciones de la Sociedad Civil. De éstas, 7,064 se ubican en el rubro de actividad "Promoción y fomento educativo, cultural, artístico, científico y tecnológico" siendo el Distrito Federal la entidad con mayor número de organizaciones registradas en esta actividad, $1,775^{11}$.

Ahora bien, el identificar en términos numéricos la participación de la sociedad civil organizada en el sector cultural no quiere decir que no se reconozca el trabajo y las aportaciones -ya sea desde lo individual o desde colectivos y formas de organización que no están formalizadas- que se han hecho a la legitimación e impulso de la actividad cultural en nuestro país. Además, coincidiendo con Alfons Martinell (2002) "las organizaciones culturales, de la misma manera que otras estructuras, han de adaptarse a un entorno cada vez más global en la denominada sociedad de la información y los procesos de globalización cada vez más caracterizados por conexiones transversales y horizontales, donde las vías de cooperación cultural se han democratizado con la presencia de la sociedad civil".

\footnotetext{
${ }^{11}$ No obstante, cabe mencionar que la dependencia informa que las organizaciones registran generalmente más de un rubro de actividad de manera simultánea, por lo que su identificación es complicada, sin embargo, los datos permiten visualizar el interés de los ciudadanos por participar de manera organizada en el trabajo cultural, sin embargo es necesario mencionar que, al menos en nuestro país, no han sido estudiadas lo suficiente.
} 
Lamentablemente, si de las organizaciones registradas existen pocos datos sobre sus características, modos de gestión e incluso de la incidencia que pudiesen llegar a tener en sus comunidades inmediatas, el acceder a información confiable y representativa del trabajo de las iniciativas que se realizan desde otras plataformas, resulta sumamente complicado. Al mismo tiempo, para los fines de esta investigación resultaba necesario vincular el trabajo de las organizaciones del sector cultural con el ámbito de acción de la sociedad civil organizada, debido a que es la figura legal a la que más recurren los proyectos culturales en nuestro país ${ }^{12}$.

Para finalizar este apartado, es importante hacer notar que durante muchos años, el trabajo cultural que se realizaba desde las organizaciones de la sociedad civil en México estuvo caracterizado, en su mayoría, por su participación en programas de estímulo, becas y financiamiento gubernamental. Sin embargo, a partir de la década de los noventa se percibe un cambio sustancial en la manera en que los gobiernos y los diversos sectores (sobre todo el económico, se aproximan al tema cultural), situación que se aborda en el siguiente apartado.

\subsection{Cultura, economía y desarrollo: nociones polémicas}

David Throsby (2008) en su libro ya clásico sobre Economía y Cultura, hace una revisión detallada y crítica de la evolución histórica de los orígenes del vínculo entre ambos términos a nivel mundial así como su proceso legitimación ${ }^{13}$.

\footnotetext{
${ }^{12}$ De acuerdo con datos proporcionados en 2012 por el programa Imaginación en Movimiento. Creación de Empresas Culturales de la Secretaría de Cultura de la Ciudad de México, de las 55 empresas culturales creadas entre 2007 y 2008, 20 fueron registradas como (A.C.), 34 como (S.C.) y 1 como (S.R.L).

${ }^{13} \mathrm{Si}$ se desea profundizar en el tema, se sugiere revisar el libro, cuyos datos completos se anexan en la bibliografía.
} 
Destaca, entre otras cosas, algunos eventos que han sido determinantes en el impulso del tema en las políticas públicas de los países alrededor del mundo, como el establecimiento en 1995 de la Comisión Mundial de Cultura y Desarrollo (WCCD), por sus siglas en inglés, de la UNESCO, instancia que desde entonces ha insistido en que los conceptos de cultura y desarrollo están fuertemente relacionados en cualquier sociedad.

A partir de ese momento, otras instituciones como el Banco Mundial, se han adherido a dicha iniciativa. De esa concepción han derivado numerosos enfoques, documentos y políticas públicas tendientes a estimular tal relación, en donde las agencias de financiamiento internacionales han jugado un papel fundamental en el establecimiento de requisitos muy específicos a los que las organizaciones deben ajustarse si desean acceder a dichos fondos para llevar a cabo sus proyectos.

Este fenómeno ha impactado a su vez en la manera cómo las organizaciones operan e incluso en la forma en que se visualizan a sí mismas. Así, para David Throsby (2008: 108) "la aceptación por parte del Banco Mundial y otros organismos de que la cultura tiene un papel explícito en el desarrollo, es una prueba de que se está produciendo el cambio de paradigma".

En el caso específico de lo que ha sucedido en México en los temas relacionados de cultura, desarrollo y economía, de acuerdo con George Yúdice:

"como indica Cervantes Barba, este subsector cultural, consolidado en los años ochenta de manera dependiente de la Secretaría de Educación Pública, también recibió la impronta modernizadora y reformadora de las políticas de desarrollo y descentralización de la UNESCO. Y, desde luego, hay que tener en cuenta la acción reestructurante del nuevo modelo económico que México fue obligado a adoptar frente a la crisis económica desatada por la deuda externa de 1982. Con el gobierno de Salinas, se sentaron las bases para entrar en el TLCAN [Tratado de 
Libre Comercio de América del Norte], el contexto que llevaría a México de una economía protegida por el Estado a la desregulación, la privatización, la apertura a la sociedad civil y al libre mercado y otras armonizaciones con las políticas económicas estadounidenses... el TLCAN es fundamental para entender el enorme viraje en el concepto de cultura. Obligó a los artistas, investigadores e intelectuales interesados en la cultura a tener en cuenta que el objetivo del desarrollo tenía un doble o triple sentido -matriz de identidad, factor de cohesión social, activo económico- al poner la cultura en su centro, como recomendaban tanto UNESCO como Banco Mundial" (Yúdice, George en Szurmuk y Mckee, 2009: 217-218).

Si bien se reconoce el impacto que han tenido estos conceptos en el ámbito de la cultura a nivel mundial, es importante no perder de vista, como señala Coelho (2009: 122) que "la expresión desarrollo cultural es sumamente polémica debido a que la práctica cultural propiamente dicha es de difícil manejo, así como la formación de recursos humanos que la alimentan. La idea de desarrollo implica de alguna manera la existencia de un $<<$ crecimiento cultural $>>$, tal como se habla de un crecimiento económico, aunque esta noción es muy rebatida; las transformaciones culturales no se inscriben propiamente en una escala de evolución o de progreso... El $<<$ desarrollo cultural $>$ pierde sentido si se le relaciona con un aumento cuantitativo de la producción y del consumo cultural que puede ser medido en números sin que sea posible evaluar con tranquilidad en qué contribuye esto a la dinámica cultural en general".

Así, con polémicas o no, con argumentos a favor o en contra de estos conceptos, la breve revisión que se ha dado sobre el origen de la conjunción de estos tres elementos (cultura, desarrollo y economía) era necesaria pues nos permite transitar con mayores elementos para comprender otra idea que en los últimos años ha destacado por su rápida difusión y adopción a nivel mundial como es la Economía Creativa, la cual además 
es notable porque, como se demostrará más adelante, ha impactado de manera significativa en la conceptualización actual del sector cultural y sus maneras de organizarse.

\subsection{La economía creativa y las transformaciones del sector cultural}

Como se ha mencionado anteriormente, México está inserto desde hace ya varios años en una dinámica globalizadora. Así, "lo que hoy se llama globalización se traduce, además de la apertura de mercados y mayor circulación de bienes, servicios y capital, en la transferencia de modelos de organización que implican actitudes de comportamiento, modelos de pensamiento y visiones del mundo que afectan la percepción que las organizaciones locales tienen de sí mismas" (Naime, 2004: 47).

En este sentido y con el propósito de tener un marco de referencia más acotado que nos permita aproximarnos al estudio de los cambios que ha enfrentado el sector cultural en los últimos años producto de la fusión de los temas de economía, cultura y desarrollo, es que se recurre al concepto de Economía Creativa.

Si bien no existe una definición universal, una que sirve como referente a numerosas investigaciones y programas es la de la $\operatorname{UNCTAD}^{14}$ (2008) que señala que "el concepto de Economía Creativa implica un desplazamiento fuera de los modelos convencionales y hacia un modelo multidisciplinario que abarca la interfaz entre economía, cultura y tecnología".

De acuerdo con Ana Carla Fonseca, coordinadora del libro Economía Creativa como estrategia de desarrollo: una visión de los países en desarrollo, "el concepto de economía creativa tiene su origen en el término industrias creativas, que a su vez, se inspira en el proyecto Creative Nation, de Australia, de 1994. Posteriormente en 1997, desde una política impulsada en el Reino Unido, se da continuidad a su impulso como un sector

\footnotetext{
${ }^{14}$ Conferencia de las Naciones Unidas sobre Comercio y Desarrollo (UNCTAD) por sus siglas en inglés.
} 
importante para la creación de riqueza y empleo basado en la generación y explotación de la propiedad intelectual. Este concepto se ha replicado en diversos países y en torno a él han surgido algunas iniciativas respecto a una preocupación por la inclusión socioeconómica de áreas o clases marginadas, dado que el énfasis en los resultados del concepto recayó sobre las estadísticas agregadas de impacto económico, sobre todo su contribución al PIB y a la tasa de crecimiento de la economía" (Fonseca, 2008: 17-18).

Siguiendo esta línea, continúa Fonseca (2008: 25-27), se dice que "es posible resaltar al menos cuatro enfoques del concepto de economía creativa: industrias creativas, economía creativa, ciudades y espacios creativos y economía creativa como estrategia de desarrollo".

Es importante mencionar que existen distintas metodologías para entender y enmarcar las actividades que forman parte de la economía creativa de acuerdo a las características del país de que se trate ${ }^{15}$.

Dado que el objetivo de esta investigación no es realizar una revisión exhaustiva de los documentos y programas elaborados en torno al concepto, el siguiente esquema se realizó con la intención de ofrecer una idea sintética de la evolución histórica que ha tenido el término a fin de entender sus características generales y, de esta manera, se facilite el enmarcar una parte del entorno que ha determinado algunos cambios en la concepción del sector cultural nacional en general, y de la Ciudad de México, en particular.

\footnotetext{
${ }^{15}$ Para profundizar sobre el tema, algunos documentos de referencia básicos son los Reportes de la UNCTAD The Creative Economy Report 2008: The Challenge of Assessing the Creative Economy. Toward. Informed Policy making y The Creative Economy Report 2010: The Creative Economy: A Feasible Development Option, la Convención sobre la protección y promoción de la diversidad de las expresiones culturales de la UNESCO (2005), Políticas para la creatividad. Guía para el desarrollo de las industrias culturales y creativas, UNESCO (2010).
} 


\section{TABLA 2. EVOLUCIÓN HISTÓRICA DEL CONCEPTO DE ECONOMÍA CREATIVA}

\begin{tabular}{|c|c|}
\hline AÑO & SUCESO \\
\hline 1947 & $\begin{array}{l}\text { Theodor Adorno y Max Horkheiner comenzaron a utilizar el término industria cultural para } \\
\text { referirse a la subordinación de la cultura a los intereses del capital vinculado con las técnicas } \\
\text { de producción industrial en la creación y difusión masiva de obras culturales. }\end{array}$ \\
\hline 1966 & $\begin{array}{l}\text { Con la publicación de la monografía de Baumol y Bowen, Performing Arts } \\
\text { The Economic Dilemma, se da el nacimiento de la economía del arte como disciplina } \\
\text { independiente dentro de la ciencia económica moderna. No obstante, hasta ese momento se } \\
\text { maneja una concepción restrictiva de cultura, sólo se considera a las bellas artes. }\end{array}$ \\
\hline $\begin{array}{l}\text { Finales de la } \\
\text { década de los } \\
\text { setenta }\end{array}$ & $\begin{array}{l}\text { El concepto de industria cultural acuñado por Adorno y Horkheiner es retomado y se vincula } \\
\text { con la formulación de políticas públicas }\end{array}$ \\
\hline 1982 & $\begin{array}{l}\text { La UNESCO publica The Culture Industries. A challenge for the future of culture que, si bien } \\
\text { tiene referencias directas al trabajo de Adorno y Horkheiner, incluye diversidad de } \\
\text { perspectivas, tanto a favor como en contra del concepto. }\end{array}$ \\
\hline $\begin{array}{l}\text { Décadas de } 1980 \text { y } \\
1990\end{array}$ & $\begin{array}{l}\text { El rol de las industrias culturales como factor de desarrollo cultural gana posiciones y se } \\
\text { introduce en las agendas políticas. }\end{array}$ \\
\hline 1994 & $\begin{array}{l}\text { El gobierno australiano publica un documento titulado Creative Nation: } \\
\text { Commonwealth Cultural Policy, en el que por primera vez aparece la idea del sector creativo } \\
\text { en donde se intenta englobar todas aquellas micro empresas, trabajadores autónomos y } \\
\text { agentes independientes que trabajan en los márgenes de las industrias culturales y que, } \\
\text { aunque no tenían un tamaño considerable, eran de extrema importancia a la hora de } \\
\text { computar el valor total que la cultura aporta a las ciudades. }\end{array}$ \\
\hline 1997 & $\begin{array}{l}\text { El gobierno del Reino Unido adopta las ideas plasmadas en Creative Nation: Commonwealth } \\
\text { Cultural Policy. Así, nace el concepto de las industrias creativas entendidas como aquellas } \\
\text { que tienen su origen en la creatividad individual, la destreza y el talento y que tienen } \\
\text { potencial de producir riqueza y empleo a través de la generación y explotación de la } \\
\text { propiedad intelectual. Este concepto rebasa las industrias culturales y va más allá de las artes. }\end{array}$ \\
\hline 1998 & $\begin{array}{l}\text { El gobierno británico realiza el primer mapa de industrias creativas donde se identificaron } \\
\text { trece sectores pertenecientes a la actividad cultural: artesanías, arquitectura, artes } \\
\text { escénicas, artes y antigüedades, cine, diseño, editorial, moda, música, publicidad, software, } \\
\text { software interactivo de entretenimiento (video juegos), televisión y radio. Dichos sectores } \\
\text { abarcan tanto las industrias culturales tradicionales como aquellas basadas en términos más } \\
\text { amplios en la creatividad. }\end{array}$ \\
\hline 2001 & $\begin{array}{l}\text { El término economía creativa fue utilizado por primera vez por John Howkins en su libro } \\
\text { Creative economy: how people make money from ideas que, de una forma muy amplia, } \\
\text { incluye en este concepto todas las actividades relacionadas con la propiedad intelectual, la } \\
\text { propiedad industrial, las marcas y el diseño. Esta definición tan extensa incluye las } \\
\text { denominadas industrias culturales y creativas, así como las patentes. }\end{array}$ \\
\hline 2008 & $\begin{array}{l}\text { UNCTAD publica un primer informe sobre economía creativa titulado The Creative Economy } \\
\text { Report 2008: The Challenge of Assessing the Creative Economy. Toward. Informed Policy } \\
\text { making, en donde además del valor económico se promueve la inclusión social, la diversidad } \\
\text { cultural y el desarrollo humano. }\end{array}$ \\
\hline 2010 & $\begin{array}{l}\text { UNCTAD publica un Segundo informe titulado The Creative Economy Report 2010: The } \\
\text { Creative Economy: A Feasible Development Option. En éste se analizan diversos conceptos } \\
\text { entre los que se encuentran creatividad, innovación, bienes y servicios culturales, así como } \\
\text { industrias culturales y creativas. }\end{array}$ \\
\hline
\end{tabular}




\begin{tabular}{|c|c|}
\hline 2010 & $\begin{array}{l}\text { UNCTAD propone la siguiente definición de las industrias creativas: } \\
\text { - son los ciclos de creación, producción y distribución de bienes y servicios que utilicen la } \\
\text { creatividad y el capital intelectual como insumos primarios; } \\
\text { a constituyen un conjunto de actividades basadas en el conocimiento, pero que no se limita a } \\
\text { las artes, potencialmente pueden generar ingresos del comercio y de los derechos de } \\
\text { propiedad intelectual } \\
\text { a comprenden los productos tangibles e intangibles, servicios con contenido creativo, } \\
\text { intelectual o artístico, tienen valor económico y objetivos de mercado; } \\
\text { a se encuentran en la encrucijada de los servicios artesanales, y sectores industriales; } \\
\text { constituye un nuevo sector dinámico del comercio mundial. }\end{array}$ \\
\hline 2010 & $\begin{array}{l}\text { Definición de la UNCTAD de la economía creativa } \\
\text {-La "economía creativa" es un concepto que evoluciona sobre la base de activos creativos que } \\
\text { potencialmente pueden generar crecimiento económico y desarrollo. } \\
\text {-Puede fomentar la generación de ingresos, la creación de empleo y las exportaciones, así } \\
\text { como la promoción de la inclusión social, la diversidad cultural y el desarrollo humano. } \\
\text { a Abarca aspectos económicos, culturales y sociales que interactúan con la tecnología, la } \\
\text { propiedad intelectual y objetivos turísticos. } \\
\text { - Se trata de un conjunto de actividades económicas basadas en el conocimiento con una } \\
\text { dimensión de desarrollo y vínculos intersectoriales en los niveles macro y micro en la } \\
\text { economía en general. } \\
\text { - Se trata de una opción de desarrollo viable que pide respuestas innovadoras y } \\
\text { multidisciplinarias sobre políticas y de acción interministerial. } \\
\text { En el corazón de la economía creativa están las industrias creativas. }\end{array}$ \\
\hline
\end{tabular}

Fuente: Elaboración propia con base en información de UNCTAD (2010), Pallarés (2012) y Casani et al., (2012).

En lo que se refiere a la idea de Ciudades Creativas, término introducido por Richard Florida en la década de los noventa, la cual también es una noción que ha suscitado controversia en diversos sectores, al menos en la parte discursiva oficial -que finalmente es la que se difunde más ampliamente y que adoptan los organismos e instituciones en los diferentes países- propone, entre otras cosas, que "las ciudades tienen un recurso fundamental -su gente-. La inteligencia humana, los deseos, motivaciones, la imaginación y la creatividad están reemplazando a la ubicación, los recursos naturales y el acceso al mercado, así como los recursos urbanos. La creatividad de aquellos que viven en ciudades determinará el éxito futuro" (UNCTAD, 2010: 13). 
Ahora bien, para los fines de esta investigación, del complejo y polémico universo que implica el concepto de Economía Creativa y las múltiples aproximaciones que se pueden hacer al fenómeno, es que amplía el ámbito de actuación del sector cultural, que ahora se tiende a denominar Sector Cultural y Creativo por las disciplinas que fueron integradas resultado de la evolución y fusión de los conceptos de Industria Cultural e Industria Creativa.

A continuación se presenta un esquema que permite visualizar claramente las actividades que forman parte de este nuevo paradigma. 


\section{FIGURA 2. CLASIFICACIÓN DE LAS INDUTRIAS CREATIVAS}

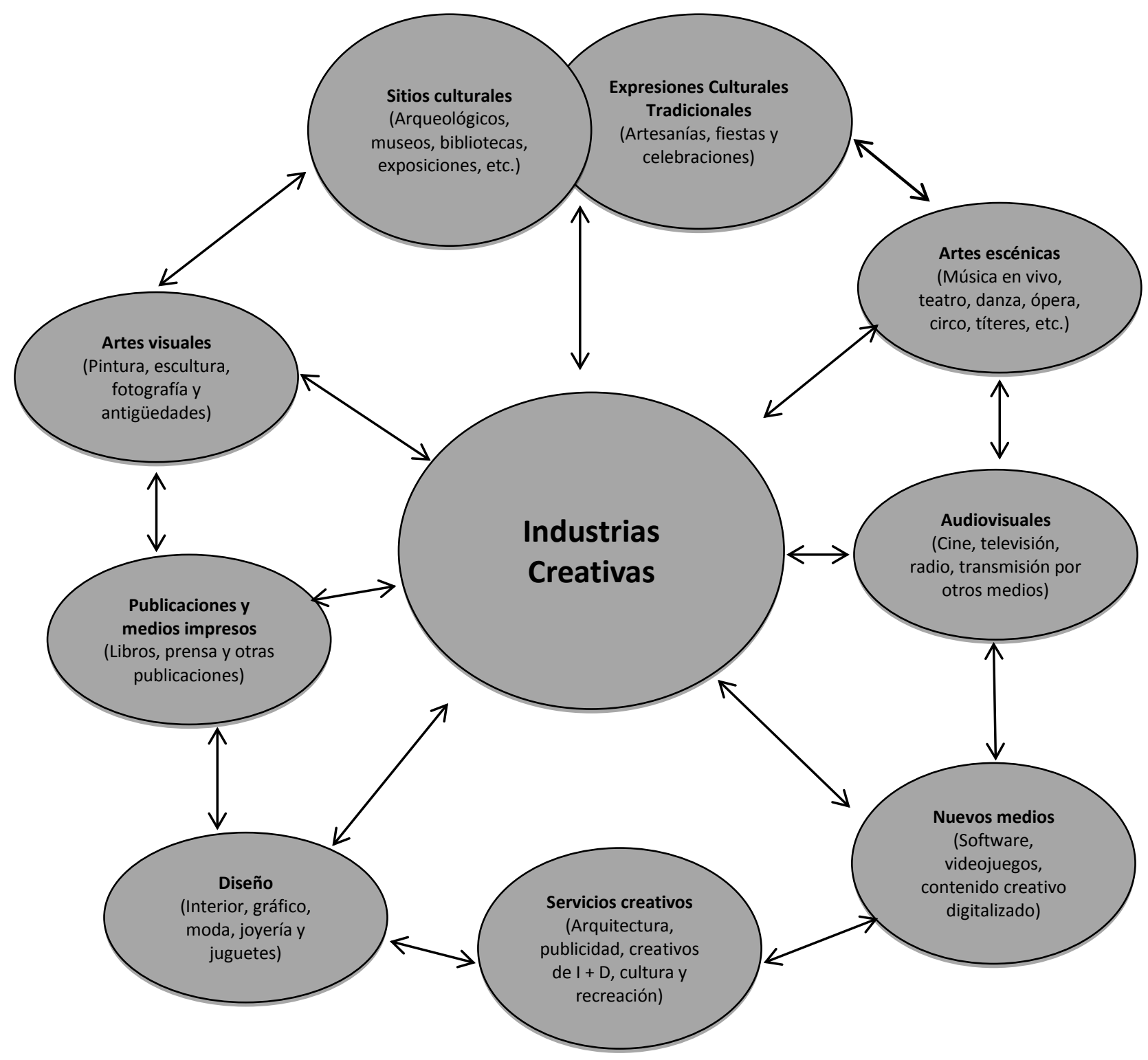

Fuente: UNCTAD (2010).

Entre las áreas que se fueron integrando destacan las que se refieren a los servicios creativos, los denominados nuevos medios y el diseño en todas sus ramas. 
En esta línea, se afirma que "la principal característica de la Economía Creativa es el hecho de que existe un predominio de un pequeño número de empresas muy grandes que trabajan internacionalmente, contrarrestado por un gran número de micro empresas locales, muchas de las cuales son simplemente personas individuales" (UNCTAD, 2010: 74), situación que implica nuevos retos y la implementación de nuevas estrategias en el sector.

$Y$ es en este contexto de integración de nuevos sectores, nuevas actividades y nuevos actores en el ámbito cultural y, ahora también, creativo, que emerge con gran fuerza el concepto de emprendedor, el cual se define como "una persona con capacidad de innovar; entendida ésta como la capacidad de generar bienes y servicios de una forma creativa, metódica, ética, responsable y efectiva" (Holguín, 2010: 28).

Ahora, desde el ámbito de lo cultural, se comienza a trabajar en la diferenciación de otro tipo de emprendedores (distintos a los tradicionales que se relacionaban más con innovaciones tecnológicas y las empresas lucrativas) que se caracterizan porque su propósito central no es económico, sino "mostrar su trabajo, hace reconocer su cultura, conservar su patrimonio cultural, ser reconocido por su talento, cuestionar la sociedad a partir del arte o generar productos innovadores y útiles para la sociedad desde la estética" (Holguín, 2010: 39).

Casi de manera simultánea empieza a circular también la noción de emprendimientos culturales, los cuales son designados como "procesos de crecimiento y sostenibilidad económica, que a la vez protejan la propiedad intelectual de los artistas y generen impacto social, mejorando la calidad de vida de los ciudadanos, mediante el fortalecimiento de la identidad cultural y el desarrollo del potencial creativo, la educación, la cultura y la integración social" (Holguín, 2010: 10). 
Como puede observarse, las transformaciones en la manera de operar y concebir al sector cultural son numerosas. La introducción de nuevas disciplinas que antes no estaban relacionadas con el sector cultural, implica nuevos retos, entre los que destaca, la inclusión de nuevos actores con otras lógicas de acción y necesidades que requieren un entorno acorde para su desarrollo, aspecto que, como hemos visto, se ha venido impulsando desde programas y acuerdos internacionales que se trasladan a los ámbitos locales para su implementación. Tal ha sido el caso de la Economía Creativa en nuestro país.

\subsection{Planteamiento de investigación y metodología}

Con base en lo desarrollado anteriormente y desde una concepción de las organizaciones como sistemas abiertos en constante interacción con su entorno, las transformaciones que ha enfrentado el sector cultural en los últimos años producto de la globalización, el impulso desde el ámbito internacional de nuevos paradigmas (como la Economía Creativa) que amplían la manera de operar y visualizar la función de deben cumplir las organizaciones e individuos que llevan a cabo el trabajo cultural, aunado a las crisis económicas que estallaron a nivel mundial a finales de la década de los noventa (que en el caso de nuestro país no han desaparecido desde la década de los ochenta), las cuales, a su vez, se han reflejado en la reducción de los recursos públicos para el financiamiento de actividades y programas, tenemos elementos que nos permiten visualizar que actualmente nos encontramos en un momento crucial en donde confluyen diversos factores sociales, económicos y políticos -tanto en el ámbito global como localque están influyendo en el hecho de que las organizaciones tiendan a ser cada vez más similares en el sector con el propósito de integrarse a esta dinámica y, por lo tanto, lograr sobrevivir en un entorno adverso. 
Tal es el caso de la Ciudad de México, que los últimos años ha participado de manera activa en el impulso e implementación a nivel local de la agenda de temas relacionados con cultura, desarrollo y creatividad.

Así, en 2010 se le nombró Capital Iberoamericana de la Cultura, en 2011 adoptó formalmente la Agenda 21 de la Cultura (que reconoce a la cultura como cuarto pilar del desarrollo sostenible) y en 2012 obtuvo la co-presidencia de la Comisión de Cultura de la Organización Mundial de Ciudades y Gobiernos Locales Unidos (CGLU), nombramiento, que de acuerdo con la página web de la Secretaría de Cultura, "reconoce el papel de liderazgo internacional de la Ciudad de México en temas culturales".

En el marco de dichos acuerdos, en la Ciudad de México y no sólo desde la Secretaría de Cultura sino desde otras instancias tanto del gobierno federal como local, se ha llevado a cabo el establecimiento de políticas y programas públicos que fomentan la realización de proyectos en torno a la figura de los denominados emprendimientos culturales y creativos, existe una amplia difusión de publicaciones (impresas y virtuales) referentes al tema, se han llevado a cabo numerosos eventos y actividades que facilitan el intercambio entre profesionales de diversos países así como la presentación de "mejores prácticas" al tiempo que también se percibe el incremento de programas de formación a nivel profesional así como cursos, talleres y diplomados en gestión de emprendimientos culturales y creativos, las cuales en su conjunto constituyen acciones que se pueden interpretar como detonantes para que las organizaciones en el sector tiendan a ser cada vez más similares.

Fue entonces que se retomó el esquema derivado de la clasificación de las industrias creativas para identificar las disciplinas en las que se podían percibir mayores similitudes. 
En el caso de nuestro país, y más específicamente para la Ciudad de México, ${ }^{16}$ se ha propuesto el siguiente esquema:

\section{FIGURA 2.1 MAPA DE LAS INDUSTRIAS CULTURALES Y CREATIVAS EN LA CIUDAD DE MÉXICO.}

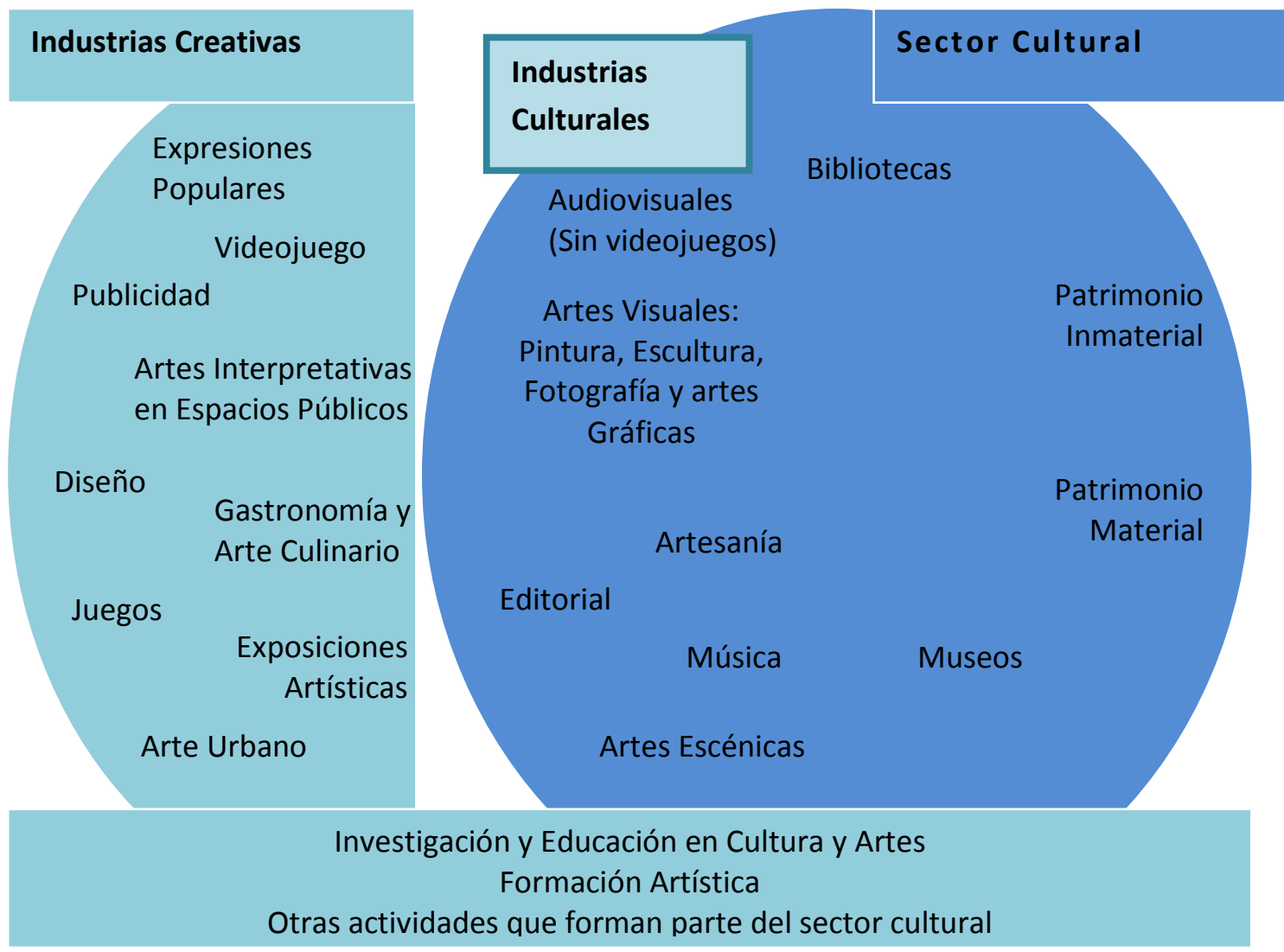

Fuente: Ernesto Piedras (2009), tomado de Piedras (2010).

\footnotetext{
${ }^{16}$ La Ciudad de México ha sido un agente sumamente activo en el impulso del tema en los últimos años a través de diversos programas y publicaciones. Entre los documentos podemos destacar los siguientes: la serie Cultura y Desarrollo Humano. Aportes para la discusión publicada por el Programa de las Naciones Unidas para el Desarrollo, PNUD México, que incluye los títulos Economía y Cultura en la Ciudad de México de Ernesto Piedras (2010), Desarrollo y cultura en la Ciudad de México de Eduardo Nivón Bolán(2010) y De las Políticas a los Ciudadanos. Una reflexión crítica sobre los supuestos y definiciones que asumen las políticas culturales para conceptualizar sus acciones de desarrollo cultural de Rosalía Winocur que forman parte del proyecto Fortalecimiento y construcción de políticas culturales equitativas y diversas en el Distrito Federal. Asimismo, el Libro Verde para la institucionalización del Sistema de Fomento y Desarrollo Cultural de la Ciudad de México (2010) coordinado por Eduardo Nivón Bolán, Rafael Mesa Iturbide, Carmen Pérez Camacho y Andrés López Ojeda; Economía Cultural para emprendedores. Perspectivas (2010), coordinado por Eduardo Cruz Vázquez del Grupo de Reflexión Sobre Economía y Cultura de la UAM Xochimilco.
} 


\subsection{Pregunta de investigación}

Con base en el esquema previo, se identificó que las áreas de diseño (en todas sus modalidades), gastronomía, artesanía y artes visuales de manera particular representaban un ámbito de acción dinámico cuyas características específicas en términos de los productos y servicios que brindan les habían permitido trabajar de manera conjunta ${ }^{17}$ para impulsar sus proyectos a través de la organización de Bazares de Arte y Diseño Independiente, que además compartían características similares, los cuales nos permiten, de manera inicial, visualizar una de las formas organizacionales emergentes que han derivado como consecuencia del traslado de la Economía Creativa a la Ciudad de México.

Así, de la primera interrogante que se percibía mucho más general, la pregunta que finalmente guió el resto de la investigación fue:

¿A qué factores se puede atribuir el surgimiento y crecimiento exponencial que han tenido los Bazares de Arte y Diseño Independiente en el sector cultural y creativo de la Ciudad de México entre 2003-2013?

De tal manera, el Nuevo Institucionalismo Sociológico, a partir de los mecanismos de cambio institucional isomorfo, permitía establecer relaciones causales para explicar la tendencia de las organizaciones a parecerse en un mismo contexto y así estructurar un campo organizacional.

\footnotetext{
${ }^{17}$ Estos profesionales vinculados con la creatividad (emprendedores creativos) tienen un conocimiento especializado en su disciplina y, al mismo tiempo, están más familiarizados con aspectos de comercialización para su trabajo -a diferencia de otros ámbitos de la cultura, en donde genera más tensión considerar el aspecto económico como parte del ciclo de su producción-.
} 
Si bien -como se revisó a detalle en el marco teórico- la perspectiva es útil, resulta limitante, tanto del reconocimiento de la diversidad organizacional como del rol activo de los individuos en la selección de las ideas que les interesa imitar o seguir. Así, se hizo necesaria la integración de otro paradigma teórico que permitiera además una comprensión del proceso en primer término, es decir:

¿Cómo es que surgen en un inicio los campos organizacionales? y

¿De qué manera se les puede reconocer?

En este punto, el concepto de Traducción resulta pertinente para identificar el proceso y los medios a través de los cuales las ideas globales "viajan" y, posteriormente, son reinterpretadas o traducidas en los espacios locales, en donde específicamente la Teoría de los Campos de Imitación como Traducción se ajusta perfectamente a los objetivos de esta investigación, los cuales quedaron reflejados de la siguiente manera:

\section{Objetivo General:}

Analizar cómo los emprendimientos culturales y creativos en la Ciudad de México, en particular, los Bazares de Arte y Diseño Independiente, han formado un campo organizacional a través del estudio de los Modos de Imitación como Traducción.

\section{Objetivos particulares:}

- Describir de qué manera se ha desarrollado y difundido globalmente la Economía Creativa y qué transformaciones ha generado en el sector cultural de la Ciudad de México.

- Establecer cómo se ha llevado a cabo el proceso de institucionalización del fenómeno emprendedor en el sector cultural y creativo de la Ciudad de México.

- Determinar qué motiva a los actores organizacionales a formar parte de un campo y cómo se lleva a cabo ese proceso. 
- Identificar los elementos que caracterizan el campo organizacional de los Bazares de Arte y Diseño Independiente en la Ciudad de México.

\subsection{Relevancia para el estudio de las organizaciones}

En años recientes, la dinámica organizacional del sector cultural nacional y, en particular, de la Ciudad de México, ha sufrido transformaciones importantes derivadas de la ampliación de actividades que forman parte del sector, con la inclusión de las denominadas industrias creativas.

En este contexto, el surgimiento de numerosos Bazares de Arte y Diseño Independiente ${ }^{18}$ constituye un ejemplo interesante como forma de organización que posibilita una aproximación al estudio del ámbito cultural desde otra perspectiva, ya que si bien el tema cultura ha sido estudiado desde diversas disciplinas (políticas públicas, economía, los estudios culturales, el consumo cultural, la formación de públicos, entre otros) poco se sabe de sus organizaciones.

De tal manera, este estudio pretende aportar elementos que permitan tener una lectura lo más integral posible sobre la manera cómo se han venido dando estas transformaciones, desde el análisis de los referentes globales que la han determinado, hasta la forma cómo ha sido trasladada al ámbito local, a partir del estudio de las organizaciones que han emergido como consecuencia de ello.

\footnotetext{
${ }^{18}$ Cabe mencionar que también se han identificado Bazares de Arte y Diseño Independiente en diversos estados de la República Mexicana (Oaxaca, Tijuana, Guadalajara, Guanajuato, Querétaro, Puebla, Michoacán) sin embrago, no se incluyen porque están fuera de la delimitación espacial de esta investigación.
} 
Así, se pretende contribuir a que nuevos temas y nuevos tipos de organizaciones sean incluidos en el campo de análisis de los Estudios Organizacionales y, lo mismo en temas culturales, que éstos sean abordados desde otros paradigmas teóricos que enriquezcan su comprensión, funcionamiento y reconocimiento.

\subsection{Delimitación de la investigación}

Una vez delimitado que la investigación se enfocaría en estudiar los factores a que se puede atribuir el surgimiento y crecimiento que han tenido los Bazares de Arte y Diseño Independiente en el sector cultural y creativo de la Ciudad de México entre 2003-2013, con el propósito de identificar cómo dichos emprendimientos culturales y creativos han conformado un campo organizacional a través del estudio de los modos de imitación como traducción, se procedió a delimitar el espacio temporal para la realización del estudio.

La selección de este periodo se justifica porque fue en el año 2003 cuando surgió el primer Bazar de Arte y Diseño Independiente en la Ciudad de México y el año 2013 porque además de ser el tiempo actual, constituye un periodo de tiempo representativo que permite visualizar la evolución del fenómeno, al tiempo que es el año en que se ha registrado la mayor cantidad de nuevos Bazares en la ciudad.

Si bien entre 2011 y 2013 se realizó de manera periódica la visita y el seguimiento de la actividad de casi todos los Bazares de Arte y Diseño Independiente que se ubican en la Ciudad de México, ${ }^{19}$ con el propósito de identificar los elementos que permitirían definirlos como un campo organizacional de acuerdo con DiMaggio y Powell (1999), por sus características y el rol que desempeñan al interior del campo, cabe mencionar que al menos 5 de ellos son utilizados como referente de manera reiterada a lo largo de la investigación.

\footnotetext{
${ }^{19}$ Hasta el momento de cerrar la investigación se contabilizaron 28.
} 


\subsection{Metodología}

La presente investigación se desarrolló a través de la aplicación de una metodología cualitativa, la cual "se refiere en su más amplio sentido a la investigación que produce datos descriptivos: las palabras de las personas, habladas o escritas y la conducta observable" (Taylor y Bogdan, 1987 en Rodríguez, 2010: 39).

Entre los argumentos señalados por (Rodríguez, 2010: 39) y que fueron determinantes en su elección, ya que coinciden en general con el estudio de las organizaciones así como con los objetivos propuestos en esta investigación ubicamos los siguientes:

1. En este paradigma los individuos son conceptuados como agentes activos en la construcción y determinación de las realidades que encuentran

2. Percibe la vida social como la creatividad compartida de los individuos

3. El mundo social no es fijo ni estático, sino cambiante y dinámico

4. No existen series de reacciones tajantes a las situaciones, sino que por el contrario y a través de un proceso negociado e interpretativo, emerge una trama aceptada de interacción

5. Está relacionado con las preguntas qué, cómo, cuándo y dónde se da un fenómeno, su esencia, su ambiente

Por lo tanto, "los fundamentos de la indagación cualitativa son la fenomenología y la teoría interpretativa. La naturaleza de la realidad es dinámica, múltiple, holística, construida y divergente. Su finalidad es comprender e interpretar la calidad, los significados de las personas, percepciones, intenciones y acciones. Sus criterios de calidad son la credibilidad, confirmación, transferibilidad. Los instrumentos y estrategias de investigación son la observación, la entrevista en profundidad, acopio documental, artefactos culturales y otras técnicas. El análisis de datos es a través de la inducción analítica y la triangulación" (Rodríguez, 2010: 41). 
El proceso de recolección de datos se dividió en tres etapas.

Primera etapa:

- Revisión documental y bibliográfica para identificar los antecedentes del tema a investigar (considerando un periodo del año 2000 al 2013)

- Revisión bibliográfica para la construcción del marco teórico (el cual se fue replanteando y ajustando conforme se avanzó en el desarrollo de la investigación).

Segunda etapa:

- Revisión y análisis de documentos del Gobierno Federal y Local a los cuales se tuvo acceso a través de Solicitudes Oficiales de Información de las Instancias involucradas con el objetivo de conocer los resultados de los programas (incubadoras, convocatorias) impulsados por dichas instancias en el tema.

- Monitoreo de medios y búsqueda específica en páginas de internet de instancias gubernamentales, organizaciones y universidades con el objetivo de identificar la difusión y/o reseñas de actividades relacionadas con el tema (congresos, seminarios, encuentros, programas de formación profesional) en un periodo de que comprende de 2003-2013.

- Simultáneamente, el monitoreo de medios -tanto impresos como virtuales- se llevó a cabo para identificar la presencia y grado de visibilización del tema de investigación en el ámbito local, así como para tener acceso a los argumentos planteados por los funcionarios o especialistas respecto al impulso de una actividad o programa en particular.

- Realización de entrevistas semiestructuradas a actores clave (coordinadores académicos, integrantes de organizaciones y proyectos, artistas, creadores). 
Tercera etapa ${ }^{20}$ :

- Seguimiento de redes sociales ${ }^{21}$ (Facebook y Twitter) para identificar los Bazares de Arte y Diseño Independiente de la Ciudad de México y su dinámica de operación.

- Revisión y análisis de publicaciones virtuales de los Bazares de Arte y Diseño Independiente de la Ciudad de México (flyers, convocatorias, reseñas, fotografías, etc.) con el objetivo de elaborar una caracterización de éstos.

- Visitas periódicas ${ }^{22}$ a los distintos Bazares de Arte y Diseño Independiente durante el periodo de 2011-2013 para observar su funcionamiento, afluencia, la interacción entre los emprendedores, entre éstos y los coordinadores, los comentarios del público asistente, entre otros aspectos.

- Realización de entrevistas semiestructuradas a emprendedores culturales y creativos que participan en los bazares, a coordinadores de bazares y público asistente para identificar los orígenes de estas iniciativas en el sector y las maneras cómo se han propagado a través del campo organizacional.

\footnotetext{
${ }^{20}$ Cabe mencionar que se llevó a cabo de manera simultánea con la segunda etapa.

${ }^{21}$ Uno de los hallazgos de esta investigación respecto a las estrategias y formas de operar de las organizaciones que integran el campo de los Bazares de Arte y Diseño Independiente es que la mayor parte de sus actividades (difusión, gestión, coordinación y comunicación) las llevan a cabo a través de estos medios.

${ }^{22}$ Producto de las constantes visitas como cliente de los bazares, en algunos casos, se pudieron establecer conversaciones espontáneas e informales con emprendedores sobre su experiencia y motivaciones para participar en este tipo de actividades.
} 
A partir de la interpretación de todos los elementos anteriores, se construyeron narrativas con los testimonios encontrados, los cuales además permitieron trazar la circulación de la idea de Economía Creativa desde mediados de la década de los noventa y su respectiva traducción en la Ciudad de México.

Finalmente, en lo que se refiere al proceso de análisis e interpretación de los datos recabados, éstos fueron integrados en tablas y figuras a lo largo de la investigación, con el propósito de que permitiesen al lector visualizar la evolución histórica del fenómeno así como los motivos de los diversos actores y sectores involucrados, a fin de identificar los Modos de Imitación que han sido determinantes en el surgimiento del campo organizacional de los Bazares de Arte y Diseño Independiente en la Ciudad de México. 


\section{CAPÍTULO 3. \\ UN CONTEXTO INSTITUCIONAL PARA EL EMPRENDIMIENTO EN EL SECTOR \\ CULTURAL Y CREATIVO DE LA CIUDAD DE MÉXICO}

\subsection{Programas académicos en México e Iberoamérica creados específicamente para la formación profesional en Emprendimiento Cultural y Creativo}

\subsubsection{Antecedentes}

Antes de dar cuenta del surgimiento de los programas de formación profesional en el contexto de la Economía Creativa, resulta necesario identificar las funciones -e incluso la manera de nombrar y, por lo tanto, visualizar- a los individuos que llevan a cabo las tareas de promoción, difusión y gestión de la actividad cultural.

Lo anterior es pertinente porque rescata la perspectiva histórica de cómo han evolucionado y se han institucionalizado los perfiles profesionales en el sector cultural, al tiempo que da cuenta de la manera en que los gobiernos, las instituciones e incluso los receptores perciben la acción cultural.

Así, en el Diccionario crítico de política cultural. Cultura e imaginario (Coelho, 2009), se realiza una sintética y clara descripción de la evolución de los términos empleados hasta llegar a la noción de gestor cultural, la cual se resume en el siguiente cuadro: 


\section{TABLA 3. EVOLUCIÓN HISTÓRICA DEL TÉRMINO GESTIÓN CULTURAL}
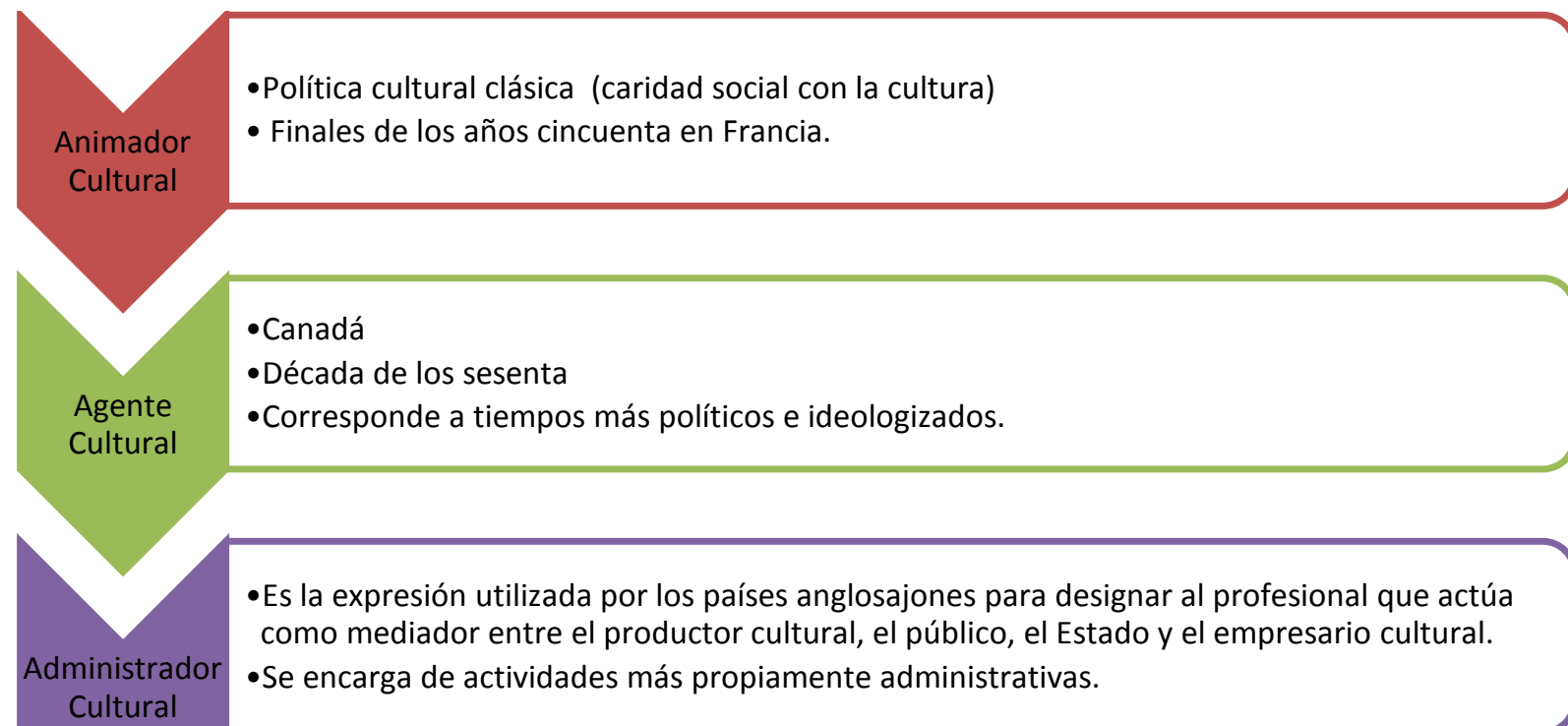

- Es la expresión utilizada por los países anglosajones para designar al profesional que actúa como mediador entre el productor cultural, el público, el Estado y el empresario cultural.

- Se encarga de actividades más propiamente administrativas.

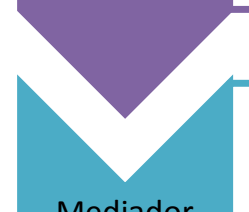

Mediador

Cultural

-Término inspirado en los estudios de los medios de comunicación

-Década de los setenta

- Es un profesional con formación cada vez más especializada, obtenida en países europeos.

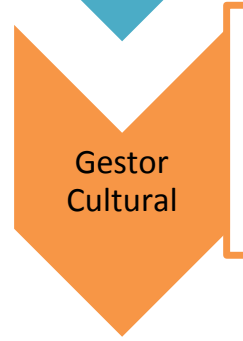

- Mediados de la década de los ochenta y noventa (globalización)

- Se relaciona con el papel de las finanzas en el mundo.

-Ascenso del ejecutivo, del administrador.

- Se recurre a la cultura como motivo para la expansión económica y la promoción de la paz.

-Profesional formado en las universidades

Fuente: Elaboración propia con base en Coelho (2009: 9-11). 
De esta manera, con los cambios introducidos en el ámbito cultural producto de la globalización, desde mediados de la década de los noventa con el reconocimiento por parte de los gobiernos del claro vínculo entre cultura y desarrollo, se observa que los programas de formación a nivel universitario y posgrado para el sector se han ido ajustando a dichos requerimientos. En la Conferencia Internacional en Políticas Culturales para el Desarrollo (Estocolmo 1998 en UNESCO, 2005: 9-11), surgió el planteamiento de "la necesidad de profundizar la profesionalización del sector cultural, de mejorar los resultados en la oferta de servicios culturales, y de lograr una mayor eficiencia en la administración y el manejo de las instituciones culturales... Así, la gestión cultural es sin duda un campo emergente, con una gran fuerza dinámica, tanto desde la óptica favorecedora de la cohesión y el desarrollo de las sociedades, como desde la perspectiva de la cultura como generadora de riqueza y empleo".

De esta manera, "el gestor cultural se perfila como una persona que conoce su entorno cultural y es capaz de establecer e implantar estrategias para crear o transformar organizaciones culturales y propiciar su buen funcionamiento" (Lobato y Quintero, 2008:3). No obstante, es un término aún en construcción y existen diversas aproximaciones conceptuales a su actuar.

Para Mariscal (2011: 6), "la gestión cultural es un campo multidisciplinar que articula conceptos, metodologías, elementos técnicos y financieros para el análisis e intervención de una organización social dada, a partir del diseño, implementación y evaluación de estrategias desde el ámbito cultural". El autor hace una revisión detallada de los elementos que permitieron que la formación en gestión cultural se fuera profesionalizando a través del análisis de elementos sociales, políticos y económicos que coadyuvaron en dicho proceso ${ }^{23}$.

\footnotetext{
${ }^{23}$ En México, el estudio del proceso de profesionalización de la gestión cultural ha sido abordado en años recientes, entre otros, por José Luis Mariscal y Blanca Brambila, ambos docentes de Gestión Cultural en la Universidad de Guadalajara. Para profundizar en el conocimiento de la historia de dicho proceso, se sugiere revisar Mariscal (2006), (2011) y Brambila (2009).
} 
Como consecuencia de lo anterior, señala que en Gestión Cultural "a nivel nacional existen actualmente 42 ofertas de formación, [72\% corresponde a licenciatura, 19\% maestrías], el Distrito Federal es el Estado con mayor número de ofertas (13 programas) y fue durante 2006 y 2007 que se incrementó exponencialmente la oferta académica, pasando de 12 a 29 programas y de ahí, sucesivamente" (Mariscal, 2011: 20) ${ }^{24}$.

En el ámbito Iberoamericano, México ocupa el tercer lugar (después de España y Argentina) en opciones formativas (Mariscal, 2006). Entre las características que destaca sobre dichos programas, identifica cuatro modelos de conceptualización-formación en gestión cultural:

- La cultura como elemento de refinamiento social

- La cultura como repertorio de manifestaciones socialmente construido y de valor patrimonial

- La cultura como mercancías (en su mayoría mediáticas)

- La cultura como dimensión estratégica para el desarrollo de las naciones.

En el último modelo, "la formación académica está dirigida a formar especialistas en políticas culturales encaminadas a la conformación de acciones que tengan un impacto a la vez social y económico dentro de las comunidades donde se desarrollan, acorde a un modelo de desarrollo económico (su conceptualización de cultura es de corte evolucionista centrándose en las identificaciones culturales y su articulación con políticas económicas desarrollistas)" (Mariscal, 2006: 67).

\footnotetext{
${ }^{24}$ Respecto a estos datos, es importante considerar lo siguiente: "En realidad actualmente sólo existen dos licenciaturas con este nombre concreto ya que otras ofertas educativas tienen títulos como "Desarrollo cultural", "Estudios y Gestión de la Cultura", "Gestión intercultural para el desarrollo", etc. El criterio utilizado para tomarlo en cuenta como una oferta en Gestión Cultural, es que en su plan de egreso contemple su desempeño profesional en el ámbito de la Gestión Cultural y que en su plan curricular contemple de manera explícita al menos un $40 \%$ de materias relacionadas con las competencias básicas en Gestión Cultural, regularmente estas asignaturas se contemplan como una orientación terminal" (Mariscal, 2011: 15)
} 
En este modelo se puede identificar que los temas referentes a la Economía Creativa y los emprendimientos que de ella derivan, se integraron al campo de la gestión cultural. Prueba de ello son los foros, congresos, eventos y publicaciones que en los últimos 10 años han tenido siempre un espacio para presentar proyectos y reflexiones sobre el tema, razón por la cual, la gestión cultural como disciplina profesional constituye un antecedente inseparable del marco de acción de la actividad emprendedora vinculada con la creatividad.

\subsubsection{Profesionalizando a los actores de la Economía Creativa}

Actualmente, al hablar de manera reiterada de Economía Creativa desde instancias tanto internacionales como nacionales, el ámbito de lo cultural se amplía, agregando disciplinas que hasta hace unos años no se consideraban directamente relacionadas el sector, razón por la cual se hacen necesarias nuevas opciones para la profesionalización de ese tipo de proyectos, los cuales tienen características distintas de las meramente culturales (los denominados emprendimientos culturales y creativos).

En consecuencia, alrededor del año 2010 se percibe el surgimiento de nuevos programas académicos que incluyen en sus contenidos los temas clave impulsados desde la Economía Creativa, a fin de integrar sus preceptos en la formación de las y los profesionales de la cultura.

A continuación, se presentan los programas que fueron identificados en el ámbito Iberoamericano que ofertan formación profesional desde la perspectiva específica de los emprendimientos en el sector cultural y creativo. 


\section{México}

\section{Licenciatura en Emprendimiento Social y Cultural ${ }^{25}$}

Entre los programas de formación profesional a nivel nacional que se vinculan directamente con la traducción de la Economía Creativa en el ámbito local, la Licenciatura en Emprendimiento Social y Cultural constituye un referente que es necesario mencionar, debido a que, como se observó anteriormente, entre la amplia oferta de opciones que existen actualmente en el país para la profesionalización del sector, ésta se distingue porque se encuadra perfectamente como un medio de transferencia de una idea global materializado a través del viaje y traslado de los nombres (en este caso de los programas de formación).

El Instituto Tecnológico de Estudios Superiores Monterrey (ITESM) desde su creación se ha caracterizado por ser una institución educativa con una marcada tendencia a la formación de líderes y emprendedores competitivos a nivel global. Si bien durante muchos años su oferta de programas académicos estuvo más bien relacionada con las ingenierías y programas de administración en distintos niveles, en 2007 presenta el plan de estudios de la Licenciatura en Humanidades y Ciencias Sociales, que surge bajo la premisa de "reconciliar los estudios universitarios con la multifacética sociedad de hoy, proporcionando una formación humanística, integral y de carácter interdisciplinario que tenga en cuenta de modo especial la perspectiva contemporánea".

\footnotetext{
${ }^{25}$ Información tomada del sitio web de la universidad. Para mayor información visitar http://www.itesm.mx/wps/wcm/connect/itesm/tecnologico+de+monterrev/carreras+profesionales/areas+de+estudio $\angle$ ciencias+sociales+y+humanidades/Ics
} 
El plan de estudios ${ }^{26}$ en ese entonces se estructuró a partir de las siguientes áreas de concentración o especialización:

-Políticas Públicas del Desarrollo

-Administración de Instituciones Sociales y Culturales

-Gestión del Conocimiento

-Negocios y Relaciones Internacionales.

Con base en lo anterior, "el Licenciado en Humanidades y Ciencias Sociales es un profesionista capacitado en el manejo estratégico de las ideas con una visión global e interdisciplinaria, capacitado para proponer y dirigir proyectos de desarrollo social y cultural que contribuyan al progreso de nuestro país. Tendrá también la capacidad de intervenir directamente en el debate de ideas convirtiéndose en un líder de opinión gracias a su espíritu crítico, analítico y dialéctico que le brindará la capacidad de diálogo y argumentación en las facetas más importantes en el desarrollo de la vida social y económica de su entorno".

Si bien, a partir de dicha descripción se perciben términos y conceptos clave de la visión de dicho programa académico que empatan con los principios rectores del ITESM (estratégico, visión global, interdisciplinaria, dirigir, desarrollo social y cultural, progreso), también se observa el interés de la institución por incluir otros ámbitos para el quehacer de sus egresados (intervención, debate, espíritu crítico, analítico y dialéctico).

\footnotetext{
${ }^{26}$ Para consultar el mapa curricular completo visitar: https://serviciosva.itesm.mx/PlanesEstudio/Consultas/Planes/ConsultaPlanEstudio.aspx?form=PLANESTUDIO\&cont enido=perfilegresado\&modovista=default\&Idioma=ESP\&claveprograma $=$ LHCSO7\&UnaCol=NO\&VerReq=\&VerEqui $=$ \&ldTipoArea=\&IdMateriaPuente=
} 
No obstante el título genérico de Licenciatura en Ciencias Sociales y Humanidades, debido a su perfil, pasó a formar parte del catálogo de programas que se relacionan con el campo de la promoción y la gestión de la cultura, lo que le abrió el camino al ITESM para introducirse de alguna manera al sector cultural nacional. Cuatro años después, en 2011, desaparece esa licenciatura y se transforma en lo que hoy es la Licenciatura en Emprendimiento Cultural y Social $^{27}$, que si bien conserva varias de las asignaturas básicas del plan 2007, el encuadre es marcadamente vinculado a las directrices de la Economía Creativa y el ámbito emprendedor (lógicamente mucho más acorde con el resto de las opciones académicas de la institución).

En una conversación en las instalaciones del ITESM Campus Santa Fe, realizada en mayo de 2013, con la Mtra. Sarabeth Ávila Abud, Directora de la Licenciatura en Emprendimiento Cultural y Social, sobre las características que definen a este programa comenta:

"son pequeñas las generaciones del Tec. Actualmente la carrera tiene 40 alumnos (de ambos planes) y la primer generación de egresados de Emprendimiento Cultural y Social será de 15 alumnos, de los cuales aproximadamente el $80 \%$ son mujeres y el $20 \%$ hombres".

Por otra parte, respecto a las áreas en las cuales han incursionado los alumnos de la licenciatura, menciona:

"hasta el momento, ubico más proyectos en artes visuales, música y video. Los alumnos han participado en eventos nacionales e internacionales de emprendimiento como Global Entrepreneurship en donde han sido reconocidos por su capacidad de trabajo interdisciplinario e innovación. Otra cosa que es importante y que hace que se distingan, es que sus proyectos deben ser autosustentables, ya no se trata de que pidan becas al Fonca, Conaculta, sino que generen sus propios recursos y para eso se les está formando".

${ }^{27}$ El programa es presencial. Se imparte de manera integral en la Ciudad de México (en el Campus Santa Fe y, de manera parcial, en los planteles de Chiapas y Ciudad Obregón). 
Hay varios elementos que resulta permitente mencionar de este programa. En primer lugar, en la presentación, tanto en la página web como en el folleto informativo, lo primero que el lector encuentra es lo siguiente:

$$
\text { ¿Sabias que...?: }
$$

- En los últimos años la economía ha llevado a que las empresas desarrollen conciencia ética, evolucionando del valor financiero al valor social.

- México es la primera Economía Creativa de América Latina.

- En México la economía cultural representa directa e indirectamente a cerca de 3 millones de personas y es medio de sustento para 34 mil artistas, creadores y alrededor de 22 mil promotores y gestores del arte.

- En México existen más de 12,600 organizaciones de la sociedad civil y la mayoría de los corporativos cuentan ya con un área de responsabilidad social.

Fuente: Folleto informativo de la Licenciatura en Emprendimiento Cultural y Social, 2013.

Con referencia en el plan 2007, éste agrega dos ámbitos nuevos al campo laboral de los egresados:

\section{1) Empresas creativas}

2) Think-Tanks

(Ambos, términos aportados por el paradigma de la Economía Creativa)

También, se modifican las áreas de especialización:

-Gestión Cultural e Industrias Culturales

-Emprendimiento y Responsabilidad Social

-Sociedad civil y políticas públicas de desarrollo 
Entre las materias que se incluyeron en el nuevo plan de estudios ${ }^{28}$, para los fines de esta investigación destacan:

-Administración e innovación en modelos de negocios

-Economía de la empresa

-Comportamiento organizacional y desarrollo del talento humano

-Marco legal y fiscal de las instituciones sociales y culturales

-Emprendimiento

-Análisis de las industrias culturales

- Modelos y procesos de planeación.

"Finalmente respondemos a la tendencia mundial que tiene el sector empresarial, la cual además de sus negocios, se preocupa por regresar algo a las comunidades más vulnerables, para lo que crean fundaciones en los sectores cultural, social y económico. Aquí entran nuestros chicos" (Bautista, 2013 septiembre 30).

\footnotetext{
${ }^{28}$ Para ver el mapa curricular completo consultar en http://www.itesm.mx/wps/wcm/connect/itesm/tecnologico+de+monterrev/carreras+profesionales/areas+de+estu dio/ciencias+sociales+y+humanidades/licenciado+en+emprendimiento+cultural+y+social/santa+fe+lcs
} 


\section{Argentina}

Argentina ha sido un país clave en el desarrollo tanto de la profesionalización como de la consolidación del ámbito de la Gestión Cultural en el ámbito latinoamericano. En el caso de su relación con México, el intercambio entre especialistas ha sido sumamente intenso las últimas décadas. Así, la Universidad Nacional de Córdoba, a través de la Facultad de Ciencias Económicas, tiene desde 2002 un Área de Gestión Cultural con una sólida propuesta de formación en cursos de posgrado y extensión con modalidad presencial y a distancia.

Como resultado del impulso dado los últimos años a la Economía Creativa a nivel mundial, en 2012 amplió su oferta de formación con dos programas ${ }^{29}$ :

1) Curso de Posgrado en Gestión de Emprendimientos Creativos (presencial)

2) Curso de Posgrado en Gestión de Ciudades y Emprendimientos creativos (virtual)

\section{Curso de Posgrado en Gestión de Emprendimientos Creativos}

El programa se estructura en torno al análisis de las principales características, políticas, problemáticas y perspectivas de las industrias culturales y creativas en el medio local como internacional, abordando en paralelo, el desarrollo del modelo y plan de negocio del emprendimiento de cada estudiante.

\footnotetext{
${ }^{29}$ Información tomada del sitio web de la universidad. Para mayor información visitar http://www.gestioncultural.eco.unc.edu.ar/presentacion-empr/\#inicio-curso
} 


\section{Objetivos}

- Contribuir en la profesionalización de quienes participan en la gestión, desarrollo y administración de emprendimientos creativos.

- Promover la creación, fortalecimiento y desarrollo de micros, pequeños y medianos emprendimientos vinculados a las industrias culturales y creativas.

- Brindar nociones teóricas y herramientas prácticas, que apunten a profesionalizar el campo de la producción y de la gestión de los distintos sectores creativos.

\section{Módulos temáticos}

- Economía creativa

- Las industrias culturales y creativas: características, dinámicas y perspectivas

- Los principales sectores de las industrias culturales y creativas

- Administración de emprendimientos culturales y creativos

- Modelos de asociativismo

- Economía social y cooperativismo

- Estudio de mercado y posicionamiento de marca

- Planificación estratégica y herramental de control de gestión

- Análisis económico financiero

- Herramental de costos y presupuestos

- Modelos de negocios

- Plan estratégico del negocio

- Seminarios Especiales 
El cuerpo docente está integrado por especialistas argentinos reconocidos a nivel internacional. Destaca la participación de la brasileña Ana Carla Fonseca Reis, compiladora, entre otros, del libro Economía Creativa como Estrategia de Desarrollo (2008), un material de referencia básico y de gran influencia en la traducción del paradigma de la Economía Creativa al ámbito latinoamericano.

\section{Curso de Posgrado en Gestión de Ciudades y Emprendimientos Creativos}

Esta opción invita al análisis crítico y a reflexionar sobre la Economía Creativa como estrategia de desarrollo para ciudades, comunidades y emprendedores de diversas actividades con base en la cultura y en la creatividad ${ }^{30}$.

\section{Objetivos:}

- Promover la planificación de estrategias locales de desarrollo económico, cultural y social con base en la economía cultural y creativa.

- Promover la creación y desarrollo de emprendimientos creativos pertenecientes a las industrias culturales y creativas.

- Contribuir en la profesionalización de quiénes participan en la planificación, gestión y administración de planes y emprendimientos culturales y creativos.

- Ampliar el horizonte de percepción del rol de los emprendedores creativos en el contexto socioeconómico contemporáneo.

\footnotetext{
${ }^{30}$ Para mayor información visitar http://www.gestioncultural.eco.unc.edu.ar/presentacion-gcec/\#inicio-curso
} 


\section{Plan de estudios}

- Industrias creativas y economía creativa como estrategia de desarrollo.

- Cultura, creatividad y urbanismo.

- Gestión del patrimonio en las ciudades creativas.

- Espacios creativos, clusters creativos y ciudades creativas.

- Emprendedurismo creativo y sostenibilidad.

- Cultura y transformación Social.

- Asociativismo y desarrollo.

- Nuevas tecnologías y gestión de emprendimientos creativos.

- Estudio de mercado y posicionamiento de productos y servicios culturales.

- Marketing, identidad estratégica y comunicación.

- Diseño y gestión de un plan de negocios para emprendimientos creativos.

- Gestión de un emprendimiento vuelto a las ciudades creativas.

- Innovación, creatividad y desarrollo de emprendimientos culturales.

- Trabajo Final.

Al ser un programa de formación virtual, tiene al menos dos ventajas: 1) el claustro de profesores tiene la posibilidad de ser más diverso e incluir profesionales de distintos países $^{31} .2$ ) Desde cualquier parte del mundo se puede acceder al programa, lo cual facilita enormemente la diseminación de la información y, por lo tanto, la idea viaja rápidamente e impacta directamente en los ámbitos locales.

\footnotetext{
${ }^{31}$ Cabe mencionar que, en este caso, están presentes algunos de los más activos agentes -tanto del impulso como de la crítica- de los preceptos de la Economía Creativa (muchos de ellos citados en esta investigación). Se puede destacar la presencia de Ana Carla Fonseca (Brasil), George Yúdice (Estados Unidos), Sylvie Durán (Costa Rica) y Jorge Melguizo (Colombia), por mencionar algunos.
} 


\section{Maestría y Especialización en Administración de Organizaciones del Sector Cultural y Creativo ${ }^{32}$}

La Universidad Buenos Aires a través de la Facultad de Ciencias Económicas alberga este programa de posgrado que surge con la idea de abrir un ámbito de producción e investigación en el cual los profesionales del sector cultural y creativo profundicen sus conocimientos académicos sobre temáticas específicas vinculadas a la administración y gerencia de las organizaciones públicas y privadas del sector.

\section{Objetivos}

- Formar especialistas de alto nivel capaces de desempeñarse en organizaciones públicas y privadas en el campo de la gestión y administración de bienes y servicios culturales.

- Formar profesionales capaces de desempeñarse en la alta gerencia en funciones de consultoría, asesoramiento e investigación en materia de diseño, planificación e implementación de políticas y proyectos culturales y creativos.

Plan de estudio - especialización Trimestres 1ㅇ, 2으 y 30

- Administración de organizaciones del sector cultural y creativo.

- Sociología de la cultura e historia de las organizaciones del sector cultural y creativo

- Políticas Culturales.

- Economía de la Cultura.

- Gestión estratégica de la identidad institucional

- Creatividad e innovación aplicadas al sector cultural.

\footnotetext{
${ }^{32}$ Información tomada del sitio web de la universidad. Para mayor información visitar http://web.econ.uba.ar/
} 
- Derecho de la Cultura.

- Marcos jurídicos de las organizaciones culturales.

- Gestión de recursos del sector cultural y creativo.

- Taller de análisis de casos.

- Seminarios.

Orientaciones Trimestre 4으

- Administración de Artes Escénicas (AE)

- Administración del Patrimonio y las Artes Visuales (PAV)

- Administración de Emprendimientos Audiovisuales (EA)

Programa de maestría Trimestres 50 y 6으

- Gestión de los procesos de cambios e innovación.

- Análisis político-económico del sector cultural y creativo.

- Administración avanzada en organizaciones del sector cultural y creativo.

- Metodología de la Investigación.

- Ética y buenas prácticas en la administración de organizaciones del sector cultural y creativo.

El programa es dirigido por Dr. Héctor Schargorodsky, quien cabe mencionar es un reconocido especialista argentino que ha participado de manera muy cercana con la Secretaría de Cultura de la Ciudad de México en la impartición de seminarios de profesionalización de empresas culturales y creativas. Los profesores son en su mayoría de nacionalidad argentina y destaca la participación de Lluís Bonet de España. Su concepción es local pues se refiere específicamente al contexto argentino y desde una perspectiva netamente administrativa que incluye los sectores ampliados desde la Economía Creativa. 


\section{España}

\section{Máster en Gestión de Industrias Culturales y Creativas de la Universidad Nacional de Educación a Distancia (UNED) y la Fundación Alternativas ${ }^{33}$}

Este programa creado en 2013 tiene la característica de ser on line y parte de la premisa del cambio en el sector cultural con la inclusión de las industrias creativas. Ofrece a los alumnos herramientas que le ayudan a conformar competencias centrales y aplicadas a las siguientes capacidades:

- Análisis de la realidad de las Industrias Culturales (IC) e Industrias Creativas (ICR), de sus transformaciones y tendencias, especialmente en las redes digitales (Internet, móviles, redes sociales...).

- Creación y gestión integral de empresas culturales, de diseño y lanzamiento de sus proyectos y productos, con atención especial a las empresas culturales 2.0.

- Conocer y aprovechar todos los programas de apoyo a la cultura y la cultura digital (Estado español, Comunidades Autónomas, Unión Europea, Iberoamérica...).

- Desarrollar una visión completa y profundizada de los principales sectores de la cultura industrializada, de sus estructuras y agentes principales.

- Visión práctica de consultoría y estudios de caso, de análisis de buenas prácticas en la creación cultural y en sus modelos de negocio.

- Ofrecer patrones de modelización y prospección de los cambios suscitados por las redes digitales, y de la gestión de tales desafíos en empresas y servicios culturales.

\footnotetext{
${ }^{33}$ Información tomada del sitio web de la universidad. Para mayor información visitar http://www.mastericc.com/
} 
Los contenidos del Máster están planificados de forma modular y son los siguientes:

1. Las industrias culturales y creativas: motor de una nueva economía del conocimiento.

2. La demanda cultural: entre la sociedad y el mercado.

3. La gestión específica de la empresa cultural: de la creación de empresas y proyectos a la nueva financiación.

4. Marketing, publicidad y promoción cultural.

5. Exportación y cooperación cultural

6. Las artes escénicas

7. Las artes visuales

8. Las industrias de la música

9. Las industrias editoriales

10. Las industrias audiovisuales

11. Las industrias creativas y el entorno digital

Los cinco primeros módulos otorgan el título de especialista universitario. Los 11 módulos otorgan el título de Máster. El profesorado está integrado casi en su totalidad por académicos de diversas áreas de la Universidad Complutense de Madrid.

\section{Máster en Economía Creativa, Gestión Cultural y Desarrollo ${ }^{34}$.}

Anunciado como el primer Máster en Economía Creativa en España, el Departamento de Economía de la Empresa (Administración, Dirección y Organización) de la Universidad Rey Juan Carlos impulsa este posgrado en modalidad presencial.

\footnotetext{
${ }^{34}$ Información tomada de http://www.mastereconomiacreativa.es/
} 
En la presentación del programa se puede leer: conscientes del entorno actual de crisis económica, social y cultural, éste máster tiene una orientación hacia el mundo empresarial y laboral, potenciando el Emprendimiento Cultural y Creativo, al mismo tiempo que se plantea desde una perspectiva de diálogo interdisciplinario de la Gestión Cultural y en el marco de la nueva Economía Creativa como estrategia de Desarrollo Territorial, tanto a nivel internacional como local. Es presencial y se caracteriza por una gran flexibilidad, ya que se puede cursar en bloques independientes, los cuales otorgan reconocimiento académico a nivel de especialización.

De esta manera se ofertan las siguientes modalidades:

1. Especialista en Gestión Cultural y Emprendimiento Creativo

2. Experto en Dirección y Gestión de Industrias Culturales y Creativas en Patrimonio y artes

3. Experto en Dirección y Gestión de Industrias Culturales y Creativas en Edición Audiovisual y Creaciones Funcionales

4. Experto en Ciudades y Territorios Creativos: Gestión Cultural y Desarrollo

\section{Master en Innovación Social e Industrias Culturales y Creativas ${ }^{35}$}

Este programa es resultado de la alianza entre SPRI (Sociedad para la Promoción y Reconversión Industrial) y UPV/EHU (Universidad del País Vasco/Euskal Herriko Unibertsitatea). El programa académico se divide en los siguientes módulos:

\footnotetext{
${ }^{35}$ Información tomada del sitio web de la universidad, para mayor información visitar: http://www.berrimaster.eu/es/aspectos/modulos/
} 
Módulo 1:

- Competencias para la Innovación: Habilidades Personales y Profesionales

- Conciencia de uno mismo

- Autogestión

- Conciencia social

- Gestión de las relaciones

Módulo 2:

- Hibridaciones: Innovación Social e Industrias Culturales y Creativas

- Campos y tipos de innovación

- Innovación e I.C.C.: una visión global

- El entorno actual de la innovación y la Industria Cultural y Creativa(I.C.C.)

Módulo 3:

- Conocer la Innovación Social: Desarrollo y Contexto Económico Social

- La emergencia de la innovación social

- La nueva economía: cuadro interpretativo

- La economía social

- Agencias de innovación social

Módulo 4:

- Comprender la Innovación Social (I.S.): Casos y Oportunidades

- Planes y programas para la financiación de la I.S.

- Estudios de caso

- Organizaciones

Módulo 5:

- Aplicar la Innovación Social: Kit de Herramientas y Gestión de Proyectos

- Lanzamiento, ejecución y cierre de un proyecto

- La aplicación de la innovación social 
Módulo 6:

- Deconstrucción de las I.C.C.

- Definiciones y clasificaciones de las I.C.C.

- La economía de la cultura y la creatividad

- Herramientas prácticas

Módulo 7:

- Políticas públicas en el sector de las I.C.C.

- Casos prácticos en el sector de las I.C.C.

Módulo 8:

- Estudio de Caso

- Talleres de I.C.C.

El área docente está integrada por especialistas de diversas disciplinas que no sólo son académicos sino consultores o miembros activos de alguna ONG cultural o empresa del sector. Entre éstos ubicamos miembros de Kultiba - Fábricas de Creación, Sostenuto, MediaLab Prado, Ashoka, Goteo, por mencionar sólo algunos.

\section{Máster en Gestión de Industrias Creativas y Culturales}

El programa se lleva a cabo en la Universitat Pompeu Fabra de Barcelona y se presenta como una formación extensa y detallada sobre el diseño, coordinación, evaluación, administración y gestión de proyectos en empresas creativas y culturales. Sus objetivos son los siguientes: 
- Preparar a expertos profesionales en la dirección y gestión de todo tipo de empresas y modelos de negocio del ámbito creativo-cultural.

- Adquirir conocimientos precisos sobre creación de empresas culturales.

- Potenciar las habilidades emprendedoras de los participantes.

- Dominar la gestión de organizaciones que exploten los diferentes aspectos de la propiedad intelectual.

El programa académico ${ }^{36}$ se integra por los siguientes módulos:

1. Las industrias creativas

2. Innovación y creatividad

3. La nueva economía digital

4. El mercado global

5. Marcos institucionales y jurídicos

6. Comunicación y Marketing

7. Gestión económico-financiera

8. Habilidades directivas

9. Creación de organizaciones creativas

10. Diseño de proyectos creativos

11. Panorámicas, experiencias y debates

El cuerpo docente está integrado por profesores de diversas disciplinas (administración, economía, finanzas, derecho, publicidad) con especialización en Gestión Cultural principalmente de la Universidad de Barcelona y la Universidad Complutense de Madrid.

\footnotetext{
${ }^{36}$ Información tomada del sitio web de la universidad, para mayor información visitar: http://www.idec.upf.edu/master-en-gestion-de-industrias-creativas-y-culturales/contenidos-academicos
} 
Con base en la información anterior, se presenta el siguiente cuadro que permite ver la evolución a través de los años de dichos programas.

TABLA 3.1 PROGRAMAS DE FORMACIÓN EN EMPRENDIMIENTO CULTURAL Y CREATIVO EN IBEROAMÉRICA.

\begin{tabular}{|c|c|c|c|c|c|}
\hline PROGRAMA & PAÍS & UNIVERSIDAD & ÁREA & $\begin{array}{l}\text { AÑO DE } \\
\text { CREACIÓN }\end{array}$ & MODALIDAD \\
\hline $\begin{array}{c}\text { Licenciatura en } \\
\text { Emprendimiento Social } \\
\text { y Cultural }\end{array}$ & México & $\begin{array}{l}\text { ITESM, Campus } \\
\text { Santa Fe }\end{array}$ & $\begin{array}{l}\text { Ciencias Sociales } \\
\text { y Humanidades }\end{array}$ & 2011 & Presencial \\
\hline $\begin{array}{l}\text { Curso de Posgrado en } \\
\text { Gestión de } \\
\text { Emprendimientos } \\
\text { Creativos }\end{array}$ & Argentina & $\begin{array}{c}\text { Universidad Nacional } \\
\text { de Córdoba }\end{array}$ & $\begin{array}{l}\text { Facultad de } \\
\text { Ciencias } \\
\text { Económicas }\end{array}$ & 2012 & Virtual \\
\hline $\begin{array}{l}\text { Curso de Posgrado en } \\
\text { Gestión de Ciudades y } \\
\text { Emprendimientos } \\
\text { creativos }\end{array}$ & Argentina & $\begin{array}{c}\text { Universidad Nacional } \\
\text { de Córdoba }\end{array}$ & $\begin{array}{l}\text { Facultad de } \\
\text { Ciencias } \\
\text { Económicas }\end{array}$ & 2012 & Presencial \\
\hline $\begin{array}{c}\text { Maestría y } \\
\text { Especialización en } \\
\text { Administración de } \\
\text { Organizaciones del } \\
\text { Sector Cultural y } \\
\text { Creativo }\end{array}$ & Argentina & $\begin{array}{c}\text { Universidad Buenos } \\
\text { Aires }\end{array}$ & $\begin{array}{l}\text { Facultad de } \\
\text { Ciencias } \\
\text { Económicas }\end{array}$ & 2012 & Presencial \\
\hline $\begin{array}{l}\text { Máster en Gestión de } \\
\text { Industrias Culturales y } \\
\text { Creativas }\end{array}$ & España & $\begin{array}{l}\text { Universidad Nacional } \\
\text { de Educación a } \\
\text { Distancia (UNED) y la } \\
\text { Fundación } \\
\text { Alternativas } \\
\end{array}$ & Sin datos & 2012 & Virtual \\
\hline $\begin{array}{c}\text { Máster en economía } \\
\text { creativa, Gestión } \\
\text { Cultural y Desarrollo }\end{array}$ & España & $\begin{array}{l}\text { Universidad Rey Juan } \\
\text { Carlos }\end{array}$ & $\begin{array}{c}\text { Departamento de } \\
\text { Economía de la } \\
\text { Empresa } \\
\end{array}$ & 2012 & Presencial \\
\hline $\begin{array}{l}\text { Master en Innovación } \\
\text { Social e Industrias } \\
\text { Culturales y Creativas }\end{array}$ & España & $\begin{array}{l}\text { SPRI (Sociedad para } \\
\text { la Promoción y } \\
\text { Reconversión } \\
\text { Industrial) } \\
\text { y UPV/EHU } \\
\text { (Universidad del País } \\
\text { Vasco/EuskalHerriko } \\
\text { Unibertsitatea). }\end{array}$ & $\begin{array}{l}\text { Departamento de } \\
\text { Sociología }\end{array}$ & Sin datos & Presencial \\
\hline $\begin{array}{l}\text { Máster en Gestión de } \\
\text { Industrias Creativas y } \\
\text { Culturales }\end{array}$ & España & $\begin{array}{l}\text { Universitat Pompueu } \\
\text { Fabra }\end{array}$ & $\begin{array}{c}\text { Área de Gestión } \\
\text { Cultural }\end{array}$ & Sin datos & Presencial \\
\hline
\end{tabular}

Fuente: Elaboración propia 


\subsection{Eventos y Actividades realizados desde el ámbito académico, social y gubernamental para impulsar la difusión de emprendimientos culturales y creativos.}

Si bien, como sugieren DiMaggio y Powell (1999) en Retorno a la Jaula de Hierro: el isomorfismo institucional y la racionalidad colectiva en los campos organizacionales, son el Estado y las profesiones los que se han convertido en los grandes racionalizadores de la segunda mitad del siglo XX; en nuestro país (y el resto del mundo), en la última década el sector social (integrado tanto por organizaciones sin fines de lucro legalmente registradas como por colectivos "informales" e individuos que participan de manera activa en las actividades de su entorno inmediato), ha incrementado de manera importante su participación a través del impulso de iniciativas diversas en el tema cultural, con lo cual queda plenamente reconocido y confirmado su papel como actor relevante en este proceso de transformación de los últimos años del que hemos venido dando cuenta en los capítulos previos.

Por lo tanto, el objetivo de este apartado es fundamentalmente describir en términos gráficos, que en el periodo de tiempo que abarca el estudio (2003-2013) en México se incrementó la participación de este sector en la vida cultural, particularmente en años recientes, en lo que se refiere a la difusión del tema del emprendimiento cultural y creativo. 


\section{Antecedentes}

En México, precisamente en el año 2003 es posible ubicar el inicio de una etapa que se caracterizó por el impulso a la organización de eventos internacionales para introducir e institucionalizar la gestión cultural como profesión en nuestro país, vinculada directamente con un discurso de desarrollo, tanto económico como humano.

Así, desde el Consejo Nacional para la Cultura y las Artes (Conaculta) se organizó por tres años el Encuentro Internacional de Promotores y Gestores Culturales que, entre otras cosas, se realizaba para reunir a los Directivos de la Red Iberformat (Red de Centros y Unidades de Formación en Gestión Cultural) así como a promotores y gestores (tanto a nivel individual como colectivo). El primer encuentro se llevó a cabo en la ciudad de Zacatecas, el segundo en Querétaro y el tercero en Guadalajara.

De acuerdo con Mariscal (2011:14) "dichos encuentros no eran más que un desfile de expertos (generalmente instructores de los diplomados y especialistas extranjeros) relegando las experiencias de los gestores culturales mexicanos formados en la práctica y que tenían mucho que decir y compartir".

En los años siguientes ${ }^{37}$ se llevaron a cabo otros eventos más o menos siguiendo la misma línea, que integraban distintos términos para referirse a la acción cultural (promoción, gestión, difusión) y, de manera paulatina, los temas de la economía, el desarrollo y el emprendimiento fueron cobrando relevancia como parte de cada uno de éstos y, posteriormente, ya de manera protagónica.

\footnotetext{
37 Desde luego se han realizado múltiples actividades en el sector durante este periodo de tiempo, sin embargo, para la elaboración de la gráfica que se presenta a continuación fueron seleccionados los que seguían la línea que posteriormente desembocaría en el tema de la presente investigación. Asimismo, cabe mencionar que en los años 2006-2007 no se encontraron datos de un evento relacionado para ser incluido.
} 
Dado lo anterior, se puede afirmar que, con base en el isomorfismo normativo, estos eventos cumplieron su cometido que era facilitar un espacio para el intercambio entre profesionales y expertos de distintos países para impulsar la difusión de una idea, en ese caso, de la gestión cultural como profesión en nuestro país.

A partir del año 2011 se percibe que el tema de las industrias creativas y la cultura como elemento fundamental de desarrollo económico para las naciones es mucho más visible y recurrente en nuestro país. $Y$ desde ese año, la participación social ${ }^{38}$ en temas culturales es determinante en el curso que va tomando actualmente.

\footnotetext{
${ }^{38} \mathrm{Si}$ bien muchos de los eventos que se han identificado como del ámbito social tienen participación de los gobiernos local y federal así como algunos de universidades, la iniciativa y coordinación general ha recaído en una osc o un consejo de especialistas independientes, por lo tanto, se le ubicó como parte del sector social.
} 


\section{TABLA 3.2 EVENTOS Y ACTIVIDADES 2003-2013}

\begin{tabular}{|c|c|c|c|}
\hline AÑO & EVENTO & LUGAR & SECTOR CONVOCANTE \\
\hline 2003 & $\begin{array}{l}\text { Encuentro Internacional de Promotores y } \\
\text { Gestores Culturales }\end{array}$ & Zacatecas & Gubernamental \\
\hline 2004 & $\begin{array}{l}\text { Encuentro Internacional de Promotores y } \\
\text { Gestores Culturales }\end{array}$ & Querétaro & Gubernamental \\
\hline 2005 & $\begin{array}{l}\text { Encuentro Internacional de Promotores y } \\
\text { Gestores Culturales }\end{array}$ & Guadalajara & Gubernamental \\
\hline 2008 & Encuentro Nacional de Difusión Cultural & Ciudad de México & Social \\
\hline 2009 & Encuentro Nacional de Difusión Cultural & Ciudad de México & Social \\
\hline 2009 & $\begin{array}{l}\text { Primeras Jornadas ITESM de Vinculación } \\
\text { con los Gestores Culturales }\end{array}$ & Estado de México & Académico \\
\hline 2010 & Seminario Cultura y Desarrollo. Diseño de Indicadores & Ciudad de México & Gubernamental \\
\hline 2010 & Encuentro Nacional de Difusión Cultural & Ciudad de México & Social \\
\hline 2011 & Primer Encuentro Nacional de Gestores Culturales & Tijuana & Social \\
\hline 2011 & Seminario Cultura y Desarrollo. Diseño de Indicadores & Ciudad de México & Gubernamental \\
\hline 2011 & Foro de Economía y Cultura UACM/UNAM & Ciudad de México & Académico \\
\hline 2012 & Encuentro Internacional Arte y sustentabilidad & Ciudad de México & Social \\
\hline 2012 & Simposium Internacional Arte, Cultura y Negocios & Ciudad de México & Social \\
\hline 2012 & ConectaKultura, Foro de Emprendimientos Creativos & Ciudad de México & Social \\
\hline 2012 & Encuentro GDL & Guadalajara & Gubernamental \\
\hline 2012 & $\begin{array}{c}\text { Nodo, Primer Encuentro de Fomento a las Industrias } \\
\text { Culturales y Creativas }\end{array}$ & Ciudad de México & Social \\
\hline 2012 & 1:1 Encuentro Internacional de Industrias Creativas & Guadalajara & Social \\
\hline 2012 & $\begin{array}{l}\text { Seminario Cultura y Desarrollo. } \\
\text { Aplicación de Indicadores }\end{array}$ & Ciudad de México & Gubernamental \\
\hline 2012 & $\begin{array}{c}\text { Miradas Comunitarias: Encuentro de visiones para el } \\
\text { desarrollo cultural local }\end{array}$ & Ciudad de México & Gubernamental \\
\hline 2012 & Bonus Creative Week Mx & Ciudad de México & Social \\
\hline
\end{tabular}




\begin{tabular}{|c|c|c|c|}
\hline 2013 & Clúster de la Industria Creativa Roma/Condesa & Ciudad de México & Social \\
\hline 2013 & Paralelo 9MX & Nacional & Social \\
\hline 2013 & Coloquio Gestión Cultural desde lo local & Xalapa, Veracruz & Académico \\
\hline 2013 & Encuentro Internacional de Desarrollo Emprendedor & Ciudad de México & Académico \\
\hline 2013 & Foro de Economía y Cultura UACM/UNAM/UAM & Ciudad de México & Académico \\
\hline 2013 & Primer Encuentro Nacional de Gestión Cultural & Sonora & Académico \\
\hline 2013 & Deja tú lo guapo: isoy emprendedor! & Ciudad de México & Gubernamental \\
\hline 2013 & Abierto Mexicano de Diseño & Ciudad de México & Social \\
\hline 2013 & Bonus Creative Week Mx & Ciudad de México & Social \\
\hline 2013 & $\begin{array}{l}\text { El Tianguis de C.A.C.A.O Exposición-venta de } \\
\text { productores culturales independientes }\end{array}$ & Ciudad de México & Académico \\
\hline 2013 & $\begin{array}{c}\text { Feria Interdelegacional de Mipymes Culturales } \\
\text { Artísticas y Tecnológicas }\end{array}$ & Ciudad de México & Social \\
\hline 2013 & Encuentro Cultura + Desarrollo & San Luis Potosí & Gubernamental \\
\hline 2013 & Foro Desarrollo y Cultura (REJUC) & Ciudad de México & Social \\
\hline
\end{tabular}

Fuente: Elaboración propia 
FIGURA 3. EVENTOS Y ACTIVIDADES 2003-2013

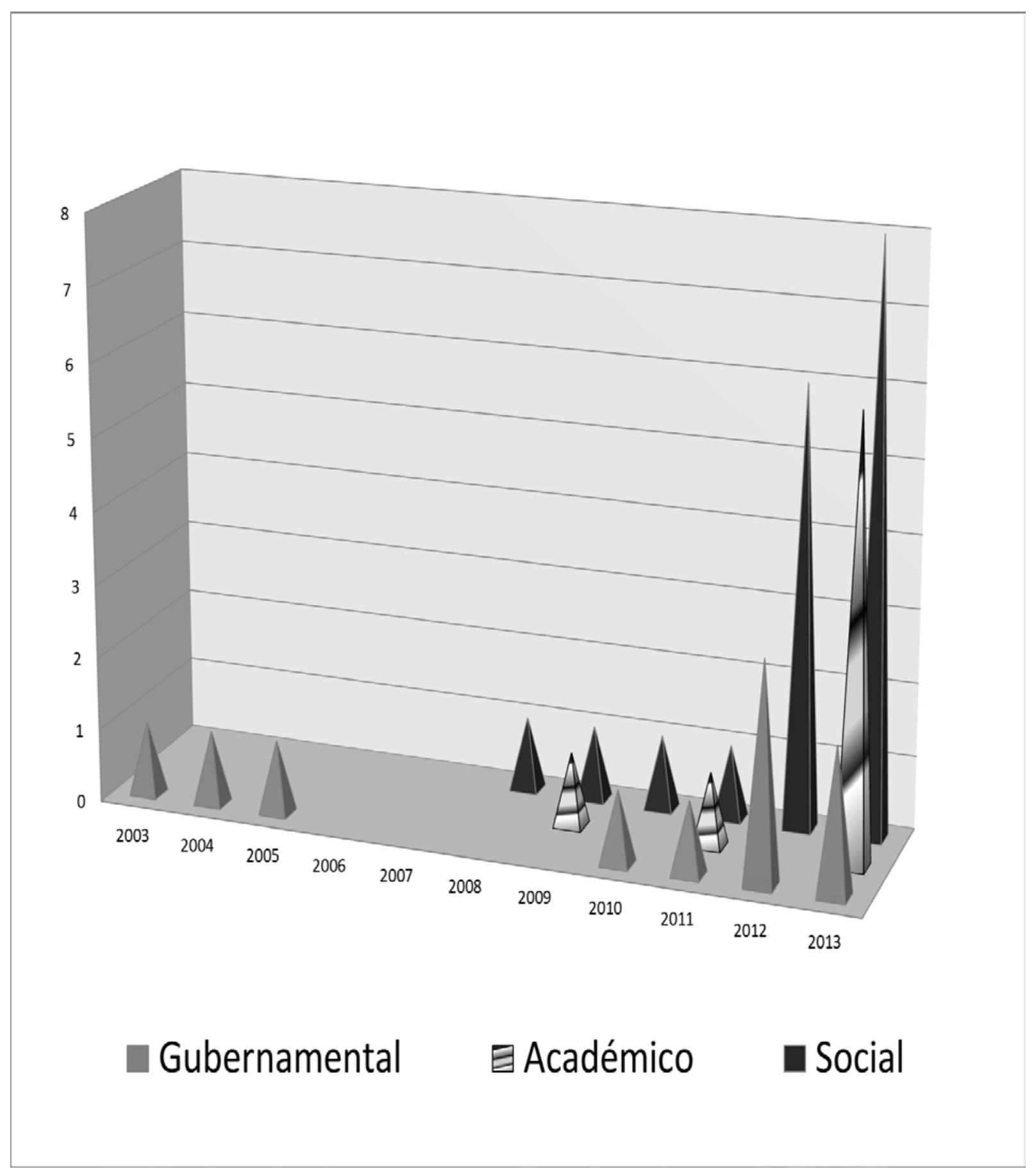

Fuente: Elaboración propia 
Entre estos eventos, resulta pertinente mencionar con más detalle aquellos que por sus características, dimensiones, vinculación con otros sectores así como por el impacto que han tenido o pudiesen llegar a tener en unos años. Entre éstos, ubicamos los siguientes:

En la Secretaría de Cultura de la Ciudad de México, en los años 2010, 2011 y 2012 se llevaron a cabo tres emisiones del Seminario Cultura y Desarrollo (Diseño y aplicación de indicadores) ${ }^{39}$, cuyo objetivo fue "analizar las herramientas que permitan medir el valor económico y social, así como el impacto de los programas culturales para contribuir al posicionamiento del tema en la agenda regional así como dimensionar la importancia que implica la evaluación de las políticas culturales y el uso de indicadores cuantitativos y cualitativos, para mejorar los programas en favor de los derechos culturales de la ciudadanía así como demostrar que la cultura es el cuarto pilar del desarrollo" (en concordancia con la Agenda 21 de la Cultura, a la que la Ciudad de México se adhirió en 2010). Dicho seminario contó con la participación de reconocidos especialistas, tanto extranjeros como nacionales representando a la UNESCO, a Colombia, a España, así como investigadores y servidores públicos de administraciones locales.

Desde el ámbito académico, en 2011 y 2013 se llevó a cabo el Foro Economía y Cultura UACM-UNAM ${ }^{40}$ que se ha ido posicionando como un espacio para el debate y la reflexión crítica de los principales ámbitos de interés en la relación entre la economía y la cultura desde la mirada no sólo de investigadores consolidados, sino también de jóvenes estudiantes así como profesionales de la cultura en activo para integrar su experiencia en el campo a las aportaciones teóricas en el área.

\footnotetext{
${ }^{39}$ Para más información visitar: http://vinculacionculturalcomunitaria.wordpress.com/2011/11/01/seminariocultura-y-desarrollo-diseno-de-indicadores/

${ }^{40}$ Para más información visitar: http://www.economiaycultura.org/
} 
Si bien, el tema es sumamente amplio y se puede abordar desde diversas perspectivas, a partir de su primera emisión este foro ha destinado un espacio importante para pensar lo que sucede en nuestro país con las industrias culturales y creativas, los emprendimientos y empresas culturales y creativas así como los modelos de incubadoras para el sector.

Durante 2012, la actividad se incrementa de manera significativa. Así, se lleva a cabo el Encuentro Internacional Arte y Sustentabilidad: Arte, Emprendurismo e Innovación Social ${ }^{41}$, organizado por el Consorcio Internacional Arte y Escuela A.C. (ConARTE) con el apoyo de organizaciones internacionales, la Secretaría de Cultura de la Ciudad de México así como otras dependencias y organizaciones locales. Se desarrolla bajo la idea de "reunir en un espacio a artistas, gestores culturales, emprendedores, inversionistas potenciales, investigadores, asociaciones, compañías, colectivos artísticos y/o culturales y redes sociales interesados en el emprendurismo, la innovación social y el desarrollo comunitario procedentes de países como: Colombia, Reino Unido, Estados Unidos, Brasil, además de ocho ciudades de la República Mexicana, para intercambiar información y metodologías a fin de fortalecer tanto sus capacidades empresariales como la participación social y comunitaria en las artes".

El Primer Simposium Internacional Arte, Cultura y Negocios ${ }^{42}$, organizado por Imaginaria arts\& show (agencia de promotoría, gestión y marketing cultural) se llevó a cabo con el objetivo principal de "crear un intercambio de conceptos e ideas entre los principales productores de la cultura y el público interesado en la sustentabilidad y rentabilidad, para generar así la integración y consolidación de la economía creativa en nuestro país, contribuyendo así al desarrollo comunitario a través del fomento a las empresas

\footnotetext{
41Para más información visitar: http://www.conarte.mx/inicio/hub-conarte/encuentro-internacional-arte-ysustentabilidad/

${ }^{42}$ Para más información visitar: http://dimecreatividad.wordpress.com/2012/10/02/1er-simposium-internacionalartecultura-y-negocios-ciudad-de-mexico-2012/
} 
culturales, el desarrollo de sus actividades y a la industria del pensamiento". Los temas que se abordaron fueron: economía cultural, institucionalidad, tendencias contemporáneas, medios de comunicación y empresas culturales.

ConectaKultura, Foros de Emprendimientos Creativos ${ }^{43}$, organizado por CLT Consultores, A.C. en coordinación con la Agencia Española de Cooperación Internacional para el Desarrollo (AECID) y la Fundación Interarts, fue un programa integrado por tres Foros de Emprendimientos Creativos en derechos culturales, género y emprendedurismo realizados en Atlixco, Puebla, Oaxaca, Oaxaca y la Ciudad de México, respectivamente, cuyo objetivo fundamental fue "vincular personas y proyectos a la economía creativa regional para promover ciudades creativas que al mismo tiempo fomentaran y fortalecieran la participación de los jóvenes en la vida cultural, a través de capacitaciones teóricas y prácticas, laboratorios artísticos, paneles y mesas de debate".

En 2012 y 2013 se llevó a cabo en Guadalajara, Jalisco 1:1 Encuentro Internacional de Industrias Creativas ${ }^{44}$ (en 2013 el país invitado fue Reino Unido), el cual es organizado por dicenJALISCO, que es el Consejo Promotor de Innovación y Diseño, integrado por más de 30 asociaciones (Industria, Gobierno y Academia), es definido como "un encuentro de mundos, de perfiles y de actores dentro y alrededor de las Industrias Creativas. Una oportunidad para diseñar el futuro de la economía y una cita con el presente en la que creadores, empresarios, académicos y gobernantes, a través de conferencias, charlas, talleres y conciertos se vinculan a destacadas personalidades de cada ámbito, en un espacio permeado por la creatividad, la innovación y el diseño, a fin de sentar las bases de nuevas formas y nuevos modelos de acción y asociación. 1:1 pretende ser un espacio de reflexión, conocimiento y reconocimiento del potencial de las Industrias Creativas para acelerar el desarrollo económico, cultural y social de Latinoamérica".

\footnotetext{
${ }^{43}$ Para más información visitar: http://www.conectakultura.org

${ }^{44}$ Para más información visitar: $\underline{\mathrm{http}: / / w w w .1 a 1 . m x /}$
} 
Bonus Creative Week ${ }^{45}$, que se autodefine como El Primer Foro de Industrias Creativas en América Latina, en sus dos emisiones (2012 y 2013) se ha consolidado como "una plataforma que promueve la creatividad y la innovación, que funciona como una incubadora y aceleradora de industrias creativas, que pretende a través de sus actividades reunir a los principales actores del sector creativo para crear sinergia y colaboración, abrir canales de comunicación, colocar temas de la economía creativa en la agenda pública y buscar soluciones a nuevos retos sociales y económicos. Al mismo tiempo pretende servir como un escaparate del talento y trabajo creativo mexicano a nivel nacional e internacional".

En 2013 se lleva a cabo por primera vez el Abierto Mexicano de Diseño ${ }^{46}$, un evento organizado por un consejo heterogéneo de diseñadores, arquitectos, curadores, promotores, académicos y comunicadores. Es presentado como "un festival internacional que consiste en una multiplicidad y variedad de eventos concentrados en una semana en la ciudad, con el Centro Histórico como epicentro. El objetivo es que el evento permita a diseñadores, empresas, organizaciones, embajadas y universidades concentrar esfuerzos y presentar de manera conjunta la producción reciente de las disciplinas creativas en un ambiente festivo de colaboración".

Durante el 2013, Reinventa. Incubadora de Ideas A.C. ${ }^{47}$, organizó dos eventos en el tema. El primero titulado Nodo, primer encuentro de Fomento a las Industrias Culturales y Creativas se llevó a cabo en el Instituto Tecnológico de Estudios Superiores Monterrey, Campus Ciudad de México, con el propósito de "diseñar una agenda definida para fomentar y fortalecer las industrias culturales, facilitando el encuentro entre emprendedores de la cultura e inversionistas, el acceso a programas de financiamiento, la introducción de nuevos productos culturales al mercado y la generación de sinergias

\footnotetext{
${ }^{45}$ Para mayor información visitar: http://bonusmx.com/

${ }^{46}$ Para mayor información visitar: http://www.abiertodediseno.mx/

${ }^{47}$ Para mayor información visitar: http://reinventa.mx/
} 
entre empresas culturales y creativas para la creación de nuevos encadenamientos productivos".

El segundo, se realizó a finales de año y fue la Primer Feria Interdelegacional de Mipymes Culturales Artísticas y Tecnológicas, la cual estuvo organizada en coordinación con el Instituto Nacional del Emprendedor (INADEM) y los gobiernos delegacionales en Xochimilco y Tlalpan. La idea fundamental es que este evento sea "el inicio de un trabajo colaborativo entre sociedad civil, gobierno y empresas, con el fin de impulsar la economía de la Ciudad de México a través de la capacitación (plan de negocios, asistencia financiera y jurídica especializada) a emprendedores del Distrito Federal".

Finalmente, es necesario mencionar el programa Paralelo $9 M X^{48}$, financiado por el Fondo Internacional para la Diversidad Cultural (IFCD) de la UNESCO, que se desarrolla en 9 municipios del país cubriendo las regiones Noreste, Centro Este, Centro, Suroeste, Sur y Sureste desde mediados de 2013 y finalizará en noviembre de 2014.

Dicho programa es coordinado por la Conferencia Nacional de Instituciones Municipales de Cultura A.C. (CONAIMUC) y tiene como objetivo "fortalecer las industrias culturales y creativas de México a través de procesos de capacitación a responsables de cultura y desarrollo económico municipales así como emprendedores creativos.

Está integrado por tres etapas:

1. Foros de capacitación presencial simultáneos: uno dirigido a emprendedores creativos y otro para funcionarios públicos municipales de las áreas de cultura y economía, partiendo de lo local hacia lo regional, nacional e internacional.

\footnotetext{
${ }^{48}$ Para mayor información visitar: http://www.paralelo9mx.com/
} 
2. Cursos de capacitación virtual: Capacitación tanto para emprendedores culturales y creativos como para tomadores de decisiones del ámbito público con el fin de otorgar herramientas concretas que vayan desde la integración de un plan de negocios, mercadotecnia cultural, integración de alianzas, financiación, construcción de política pública para ICC, corresponsabilidad hasta generación de estrategias innovadoras para el sector de la economía creativa y cultural.

3. Integración de la Red Mexicana de Economía de la Cultura y la Creatividad: Esta etapa se va construyendo gracias a una dinámica de cartografía georeferenciada sobre los emprendimientos culturales y creativos que se ha denominado Intersecciones".

Este programa, en concordancia con los parámetros de la Economía Creativa, integra emprendimientos y empresas de artes visuales y artesanías, libros y prensa, presentaciones artísticas y celebraciones, medios audiovisuales e interactivos, diseño en todas sus ramas y servicios creativos, incluyendo publicidad, mercadotecnia, gastronomía y cocina de autor. 


\subsection{Programas y políticas para el impulso a la creación de emprendimientos culturales y creativos}

En un interesante y particular análisis sobre la evolución histórica en nuestro país sobre la construcción de los nexos entre la economía y la cultura, Eduardo Cruz Vázquez refiere que "pocos podrán diferir en que a partir de la apertura comercial, la secuencia de tratados internacionales de libre comercio y del ajuste en sus alcances del Estado benefactor, se impone la necesidad de visualizar lo que significa la cultura en la riqueza económica del país. Ya no cuentan sólo los soportes simbólicos que el quehacer creativo o su mediación como producto prefigura para las nociones de identidad nacional o acervo patrimonial. Se torna fundamental su valoración como componente de un sistema económico" (Cruz, 2010: 21).

Así, a partir de este reconocimiento, tanto desde el ámbito federal como local, los últimos años hemos presenciado cambios importantes en la forma de visualizar y operar el sector $y$, si bien no se ha establecido una política integral y específica para atender las diversas demandas de la cultura en su nexo con la economía en nuestro país ${ }^{49}$, en el periodo del presente análisis, el trabajo interinstitucional ha iniciado y ha evolucionado de la siguiente forma:

\footnotetext{
49 Para complementar esta idea, se sugiere consultar "El ámbito de las empresas culturales y las políticas públicas de cultura" de Eduardo Nivón (2010), quien hace un interesante análisis de las experiencias en otros países para el impulso a las industrias culturales y creativas así como de la agenda de trabajo pendiente en nuestro país, el cual se puede revisar en: http://economiacultural.xoc.uam.mx/images/libro/libroeconomiacultural.pdf
} 
En 2007, en la Ciudad de México, surge el programa Imaginación en movimiento, empresas culturales y creativas $^{50}$, el cual cumple las siguientes funciones: "Orientación, asesoría, cursos, talleres y seminarios a artistas, creadores y gestores culturales para impulsar emprendimientos creativos independientes que fomenten la inclusión social y desarrollo comunitario en condiciones de equidad, propiciando que sean concebidos y producidos en el marco de los Derechos Culturales" ${ }^{\prime 51}$.

En esta misma línea, es importante mencionar que el Programa de las Naciones Unidas para el Desarrollo en México en coordinación con la Secretaría de Cultura del Gobierno del Distrito Federal, implementaron el proyecto titulado "Fortalecimiento y construcción de políticas culturales equitativas y diversas en el Distrito Federal" de Febrero 2008 a diciembre 2010 cuyo objetivo fue "contribuir al proceso de institucionalización de políticas públicas culturales en la Ciudad de México, a partir de la investigación aplicada y la sistematización de experiencias de construcción de ciudadanía y participación social en la cultura del Distrito Federal".

\footnotetext{
${ }^{50}$ De acuerdo con datos de la Secretaría de Cultura, a lo largo de este programa (2007-2011) se han realizado 5 seminarios que han contribuido a la profesionalización de casi 2,000 integrantes de colectivos artísticos y culturales, se impulsó la creación de 58 empresas culturales, las cuales han generado más de 500 empleos y más de 4,000 actividades que benefician a sus creadores y también a las comunidades que atienden. A través de los seminarios cuya duración es de 60 horas, los artistas, creadores y gestores culturales se han podido formar en: Elaboración y Gestión de Proyectos Culturales, Marketing Cultural, Economía Social, Plan de Negocios, Procuración de Fondos, entre otros. Fuente: ReDF, Arte, Cultura y Desarrollo. Imaginación en movimiento, empresas culturales y creativas. Resultados globales. Disponible en http://www.cultura.df.gob.mx/index.php/vinvulacion\#14, Consultado el 23-11-2011.

${ }^{51}$ Fuente: ReDF, Arte, Cultura y Desarrollo. Imaginación en movimiento, empresas culturales y creativas. Resultados globales, Disponible en http://www.cultura.df.gob.mx/index.php/vinvulacion\#14, Consultado el 6-07-2012.
} 
En el capítulo 2 dedicado a las Estrategias, el inciso C se titula "Estrategia de cadenas de valor en empresas creativas" en el que se establece que "se diseñarán metodologías para la creación de nuevas empresas creativas y el fortalecimiento de las existentes desde una perspectiva de integración de cadenas de valor y considerando mecanismos que potencien la integración de las mujeres en actividades productivas. Asimismo, se podrán desarrollar actividades relacionadas con la promoción de la economía de la creatividad" ${ }^{52}$.

Así, con base en lo anterior, en 2010 se nombró a la Ciudad de México ${ }^{53}$ Capital Iberoamericana de la Cultura, en 2011 adopta formalmente la Agenda 21 de la Cultura, en 2012 obtuvo la co-presidencia de la Comisión de Cultura de la Organización Mundial de Ciudades y Gobiernos Locales Unidos (CGLU) para la Agenda 21 de la Cultura, que fundamentalmente impulsa el reconocimiento de la cultura como el cuarto pilar del desarrollo sustentable.

\footnotetext{
${ }^{52}$ Fuente: ReDF, Arte, Cultura y Desarrollo. Imaginación en movimiento, empresas culturales y creativas. Resultados globales, Disponible en http://www.cultura.df.gob.mx/index.php/vinvulacion\#14, Consultado el 6-07-2012.

${ }^{53}$ La Ciudad de México ha sido un agente sumamente activo en el impulso del tema en los últimos años a través de diversos programas y publicaciones. Entre los documentos podemos destacar los siguientes: la serie Cultura y Desarrollo Humano. Aportes para la discusión publicada por el Programa de las Naciones Unidas para el Desarrollo, PNUD México, que incluye los títulos Economía y Cultura en la Ciudad de México de Ernesto Piedras (2010), Desarrollo y cultura en la Ciudad de México de Eduardo Nivón Bolán (2010) y De las Políticas a los Ciudadanos. Una reflexión crítica sobre los supuestos y definiciones que asumen las políticas culturales para conceptualizar sus acciones de desarrollo cultural de Rosalía Winocur que forman parte del proyecto Fortalecimiento y Construcción de Políticas Culturales Equitativas y Diversas en el Distrito Federal. Asimismo, el Libro Verde para la institucionalización del Sistema de Fomento y Desarrollo Cultural de la Ciudad de México (2010) coordinado por Eduardo Nivón Bolán, Rafael Mesa Iturbide, Carmen Pérez Camacho y Andrés López Ojeda.
} 
Tales acontecimientos han sido interpretados y difundidos por los funcionarios de la siguiente manera. En el contexto de la presentación del Libro Verde para la institucionalización del Sistema de Fomento y Desarrollo Cultural de la Ciudad de México ${ }^{54}$, Nina Serratos, Secretaria de Cultura, afirmó:

“...Es muy importante que la cultura en la Ciudad de México no deba verse con mentalidad cerrada, sino articulada con el resto del planeta y preguntarse cómo los creadores pueden desarrollarse con la participación del exterior... Únicamente redefiniendo la forma en que apreciamos la cultura en cada entorno determinado y caminando en una cooperación internacional como la de Agenda 21 de la Cultura, conseguiremos mantenerla viva y actuante, pues la historia nos enseña que las civilizaciones han realizado los mayores progresos gracias a su capacidad de tomar en consideración otras culturas y evolucionar..."

En el mismo evento, Marcelo Ebrard señaló que:

“...la idea de hacer de la cultura un motor de cambio social, determinó que la Ciudad de México ganara la Presidencia de las Ciudades del mundo, lo cual generó un consenso entre especialistas, que quedó plasmado en el texto presentado... además considero fundamental incorporar los programas y la terminología culturales a la vanguardia internacional..."

Para dar continuidad a esta labor desde la Secretaría de Cultura, se anunció que en 2014 "se pondrá en marcha la Incubadora de Empresas Culturales de la Ciudad de México, además de reforzar los programas ya establecidos. El proyecto fue aprobado por la Comisión Interdependencial para el Desarrollo, Fomento y Promoción del Desarrollo Económico de la Ciudad de México, con el cual se busca fomentar efectivamente la creación de empresas y establecer sinergias con otras dependencias del gobierno local" 55

\footnotetext{
${ }^{54}$ Fuente: http://www.cultura.df.gob.mx/sala-de-prensa/boletines/3811-675-10-6968. Consultado el_28-11-2012.

${ }^{55}$ Fuente: "Pondrán en marcha el proyecto Incubadora de Empresas Culturales en el DF", Agencia Notimex, 3-012014, Disponible en www.m-x.com.mx.
} 
También en la Ciudad de México, pero desde la Secretaría de Desarrollo Económico, a través del Fondo de Desarrollo Social (Fondeso) y, siguiendo la línea del impulso a la Economía Creativa, en marzo de 2010 se crea la Incubadora de Empresas Creativas ${ }^{56}$ (la primera en su tipo en el país) "con el propósito de ofrecer a la población nuevas opciones y oportunidades productivas que contribuyan a mejorar la situación económica, social, turística y cultural de la capital del país, que concentra la mayor parte de las actividades de la economía creativa... Lo anterior se dio en el marco de una línea de trabajo específica para identificar y apoyar nuevas actividades económicas emergentes así como en estrecha relación con la Secretaría de Cultura de la Ciudad para impulsar proyectos creativo-culturales en las áreas de creatividad tecnológica, creatividad artístico-cultural, creatividad social y creatividad en servicios; que al llevarse a cabo en Fondeso, facilita que los incubandos accedan a opciones de financiamiento y, por lo tanto, dejen de depender del financiamiento público y sean sustentables" (Navarrete, 2011).

Siguiendo con lo que se refiere a incubadoras, en el ámbito académico fueron identificadas las siguientes:

Incubadora de Empresas Artísticas y Culturales del ITESM

A partir de una entrevista ${ }^{57}$ realizada en 2011 a Ivón Aída Cepeda Mayorga, Directora del Departamento en Humanidades y Ética del Tecnológico de Monterrey, Campus Santa Fe, se pudieron extraer las siguientes citas respecto a la manera cómo conceptualiza el programa de incubación de dicha institución:

\footnotetext{
56 De acuerdo con datos proporcionados por Fondeso, hasta finales de 2012 de las 3 convocatorias que habían difundido (dos en 2011 y una en 2012), resultaron beneficiados 30 y 39 proyectos, respectivamente.

57 “Impulsa TEC de Monterrey incubación de empresas culturales”, publicado el 30 de marzo de 2011 y consultado el 2 de noviembre de 2012. Disponible en http://mx.globedia.com/impulsa-tec-monterrey-incubacion-empresasculturales
} 
"Con la finalidad de explotar por vez primera en México el fértil nicho de los proyectos llevados a cabo con profesionalización y sustentabilidad, se firmó una alianza estratégica para impulsar la incubación de empresas artísticas y culturales en el Instituto Tecnológico de Monterrey"

"Tratamos de atacar ese nicho que no se ha explotado en el país. Proyectos culturales que pueden ser desde una pequeña galería, una compañía de teatro, una editorial digital y hasta una empresa como

Cirque du Solei mexicana"

"Somos pioneros en el país, aunque las industrias culturales y creativas se desarrollan en Europa desde hace cinco años... el antecedente descansa en las propuestas usadas en Barcelona, Berlín y Reino Unido para tratar de sacar de la crisis financiera a algunas regiones de esos países; y sí lo lograron"

En la Universidad Nacional Autónoma de México, existe desde 2008 el programa denominado Innova UNAM ${ }^{58}$, cuyo objetivo principal es "apoyar la creación y desarrollo de empresas de valor agregado mediante procesos de incubación para la comunidad universitaria; así como, contribuir a la formación de empresarios y empresas competitivas en el ámbito nacional e internacional, con habilidades, actitudes y valores que contribuyan al crecimiento económico y al desarrollo social de su comunidad. La Coordinación de Innovación y desarrollo integra tres áreas fundamentales: transferencia de tecnología, servicios tecnológicos e incubadoras de empresas y parques tecnológicos. Es en este último apartado en donde la Universidad ha desarrollado en los últimos dos años una serie de capacidades en el tema de emprendimientos pasando de no contar con incubadoras de empresa en 2008 a tener 5 incubadoras con 37 proyectos en incubación para 2010 de las cuales 10 son de académicos, 6 de alumnos y 21 de egresados y a la apertura de 4 nuevas unidades de incubación en 2011 con lo que alcanza ya 9 incubadoras en total".

\footnotetext{
${ }^{58}$ Para mayor información consultar: http://www.incubadoras.unam.mx/
} 
De las 9 incubadoras con que cuenta el programa Innova UNAM (que funcionan bajo los parámetros de la Secretaría de Economía), en 2011 se diseñan dos que están dedicadas especialmente al estímulo de proyectos creativos, artísticos y culturales. Una ubicada en la Escuela Nacional de Artes Plásticas y la otra en la Facultad de Arquitectura (específicamente en el Centro de Investigación en Diseño Industrial).

Si bien la Universidad Autónoma Metropolitana no cuenta todavía con un programa de incubación formal ${ }^{59}$ y reconocido por la Secretaría de Economía, en el tema que compete a esta investigación cabe destacar su valiosa aportación como sede del Grupo de Reflexión sobre Economía y Cultura (GRECU), coordinado por Eduardo Cruz Vázquez, que desde el año 2009 tiene su sede en la Unidad Xochimilco, lo cual es un elemento importante a destacar pues muestra el interés de la universidad en el tema.

A partir de ese año, el trabajo del grupo ha sido constante y se ha manifestado a través de distintos medios:

- Publicaciones [Economía cultural para emprendedores (2010) y 1988-2012 Cultura y transición (2012)]

- Artículos de opinión en medios de comunicación nacional (Periódico El Economista)

- Portal institucional de internet para difundir el trabajo del grupo y el Programa de Monitoreo en Economía Cultural (http://economiacultural.xoc.uam.mx)

\footnotetext{
${ }^{59}$ No obstante cabe mencionar que desde hace algunos años, las distintas unidades que conforman el sistema UAM han iniciado la labor de vincular a sus alumnos con temas de emprendimiento como una opción de insertarlos en el ámbito profesional. En una entrevista que se realizó en mayo de 2013 con la Dra. Irene Guillén, Profesora del Departamento de Economía de la UAM Iztapalapa, comentó que "en la UAM Iztapalapa, ya desde hace algunos años existe un programa de impulso a emprendedores que se denominan tradicionales (con base en la clasificación de la Secretaría de Economía). Dicho programa surgió como resultado de la realización en 2009 del Diplomado Multidisciplinario de Emprendedores con Innovación Tecnológica, el cual además fue apoyado y reconocido por el Instituto de Ciencia y Tecnología".
} 
- Ofertas de formación, entre las que destaca en 2012 el Diplomado en Cultura y Negocios, que en 2013 derivó en lo que hoy es el Diplomado para la creación de empresas culturales, que se realiza en el marco de la División de Ciencias y Artes para el Diseño.

Desde el ámbito social, Reinventa, Incubadora de Ideas A. $C^{60}$ se presenta como una plataforma integral para el desarrollo de las industrias culturales y creativas a través de sus diversos programas de incubación para Emprendimientos Culturales, Creativos y Tecnológicos, los cuales tienen reconocimiento de la Secretaría de Economía y trabaja bajo los lineamientos de la Agenda 21 de la Cultura y la Convención sobre la Protección y Promoción de la Diversidad de las Expresiones Culturales de la UNESCO 2005.

De acuerdo a su página de internet, este programa surge, entre otras cosas, "por la escasez de programas sociales de desarrollo de empresas y cooperativas especializados en el sector cultural, siendo que la industria creativa es una de las de mayor crecimiento en los últimos años así como una gran oportunidad para el desarrollo de nuevos negocios, la reducción del desempleo, la pobreza así como la generación de riqueza en tres vías de forma simultánea: económica, social y cultural".

Su forma de operar integra un sistema de gestión de la calidad en el que vinculan los lineamientos de la Agenda 21 de la Cultura, las directrices sobre mejores prácticas de incubación definidas por el Fondo Pyme de la Secretaría de Economía y el modelo de gestión de la calidad EFQM 2010 (al que señalan hicieron modificaciones para adaptarlo al sector cultural).

\footnotetext{
${ }^{60}$ Para más información visitar: http://reinventa.mx/
} 
De manera general su propuesta de trabajo está integrada por cuatro grandes programas:

- Cecrea: Laboratorio de Innovación Social y creativa

- InCultura: Incubación de Iniciativas Culturales, Creativas y Tecnológicas

- Nodo: Encuentros y Eventos de las Industrias Culturales y Creativas (ICC's)

- Red: Integración de Agentes Estratégicos del Sector Cultural

Otra iniciativa en el tema impulsada desde el sector social es el Clúster Creativo Roma/Condesa, (que desde su nombre tiene una influencia clara de los principios de la Economía Creativa ${ }^{61}$ ), el cual fue presentado como Asociación Civil en el marco de la realización del Primer Foro Industrias Creativas en marzo de 2013.

Si bien la integración del clúster sucedió de manera natural en la zona, de acuerdo con Gabriel Grinberg, impulsor del proyecto:

"la idea es que sea un espacio de encuentro, donde se brindará capacitación, consultorías, servicios de cómputo, sistema de crowdfunding, asesoría legal y administrativa, apoyo en gestión y elaboración de proyectos, para obtener apoyos de organismos públicos y privados a costos que no sean altos...

El tema no es nuevo en el mundo, pero en México, apenas se está hablando de las industrias creativas y el gobierno federal y del DF comienza a entender su riqueza" (Gutiérrez, 2013, marzo 7).

\footnotetext{
${ }^{61}$ La palabra Clúster fundamentalmente se refiere a "conglomerados que concentran diversas iniciativas de carácter cultural capaces de producir diferentes sinergias debido a su proximidad espacial y generar interdependencias entre ellas debido a su complementariedad". Para mayor información sobre argumentos tanto a favor como en contra en el uso del término se puede visitar: http://clustercreativo.wordpress.com/
} 
Entre las primeras actividades a las que ha convocado como organización, se encuentra el Curso Superior de Gestión de Industrias Creativas y Organizaciones Culturales a realizarse en marzo de 2014 con el respaldo de la Secretaría de Economía y Nacional Financiera ${ }^{62}$.

Ahora bien, en lo que respecta a las iniciativas que han emanado del ámbito del Gobierno Federal, éstas comenzaron a hacer su aparición pública en 2012.

En septiembre de 2012 el Conaculta lanzó una iniciativa titulada Primer Concurso de Estímulo a la Creación de Micro y Pequeñas Empresas Culturales ${ }^{63}$ en coordinación con el Grupo Financiero Banorte y Nacional Financiera, a través del cual se anunció que se otorgaría un millón de pesos a 10 emprendedores mexicanos con proyectos individuales o colectivos dedicados a la creación, generación, producción, enseñanza, conservación, difusión, distribución o venta de bienes y servicios culturales. Asimismo, los proyectos ganadores se comprometían a recibir capacitación de Nacional Financiera para el desarrollo de empresas culturales en máximo cuatro meses después de recibir dicho recurso.

En octubre del mismo año se dieron a conocer los resultados de dicho concurso. En una entrevista realizada a Raúl Arenzana, Director General de Vinculación Cultural del Conaculta, éste señaló lo siguiente:

\footnotetext{
${ }^{62}$ Nacional Financiera (Nafinsa) es una banca de desarrollo cuya misión es promover el acceso de las Mipymes a los servicios financieros; impulsar el desarrollo de proyectos sustentables y estratégicos para el país; promover el mercado de valores y fungir como agente financiero del Gobierno Federal, con el fin de contribuir al crecimiento regional y a la creación de empleos. Más información en: http://www.nafin.com/portalnf/content/home/home.html

${ }^{63}$ La convocatoria completa se puede revisar en: http://www.conaculta.gob.mx/1er-concurso-empresas-culturales/
} 
"El objetivo es vincular la cultura y los negocios a través de propuestas creativas, innovadoras y sobre todo factibles. La cultura con su riqueza y tradición, sus componentes de creación e innovación, también pueden articularse con la economía y la generación a su vez de empleos... En México hay una gran tradición de mecenazgo y estímulos a creadores, pero carecía de un organismo específico para el impulso y creación de micro y pequeñas empresas culturales, pues se había establecido una política cultural para la inversión en infraestructura, a fin de estimular la creación artística y favorecer la formación de profesionales... Este primer concurso es el inicio de un cambio, instituciones públicas y privadas que han iniciado acciones y programas para el apoyo al sector cultural" ${ }^{64}$

Se informó que se recibieron 2,300 proyectos, de los cuales 524 pudieron ser evaluados y que participaron proyectos de las 31 entidades federativas. ${ }^{65}$

Por otro lado y de manera casi simultánea, con base en el Plan Nacional de Cultura 20072012, la Coordinación Nacional de Patrimonio Cultural y Turismo (CNPCYT) del Conaculta lanza el programa Mipymes Culturales, el cual se alineó con el Eje 8, que se centra en el tema de las Industrias Culturales. En este programa se define a las Mipymes Culturales ${ }^{66}$ como empresas que: se encuentran ligadas a actividades artístico-culturales, rescatan tradiciones, promueven la cultura local tangible o intangible y forman parte de la oferta cultural de la localidad. Hacen una clasificación de las Mipymes Culturales basada en la clasificación de Industrias Culturales del Ministerio de Colombia -que a su vez, cabe mencionar, se basa en la clasificación general de la UNCTAD 2010 que se presentó en la parte contextual de esta investigación-.

\footnotetext{
${ }^{64}$ “Conaculta premia a empresas culturales”, en El Universal, 24 de octubre de 2012, Disponible en: http://www.eluniversal.com.mx/notas/878694.html

${ }^{65}$ Se identifica que entre los proyectos seleccionados fueron los de las disciplinas que se integraron con la clasificación de la UNCTAD los que tuvieron más presencia (diseño, gastronomía, artesanía). Para consultar el listado completo se puede visitar: http://www.conaculta.gob.mx/detalle-nota/?id=23452\#.Uu3e1z15OSo

${ }^{66}$ [Información proporcionada por la Coordinación Nacional de Patrimonio Cultural y Turismo]. Es pertinente mencionar que este nombre se adoptó porque era el que estaba de moda o vigente en la Secretaría de Economía en ese entonces, incluso había una subsecretaría con ese nombre, por lo que una alianza interinstitucional tenía que reforzar el término.

En esta línea cabe señalar que si bien el concepto México Emprende surge en 2008, a partir de enero de 2013, que se creó el Instituto Nacional del Emprendedor (Inadem) -que asume las responsabilidades de la antes denominada Subsecretaría para la Micro, Pequeña y Mediana Empresa-se percibe que ahora todos los nombres de los programas (tanto públicos como sociales e incluso académicos) se refieren a esta figura de emprendedores y emprendimientos, al menos discursivamente.
} 
En una entrevista realizada en las instalaciones del Conaculta el 28 de mayo de 2013 con Marisol Vázquez, de la Coordinación Nacional de Patrimonio Cultural y Turismo, sobre el proceso de conceptualización de dicho programa, comenta que surge de unas reuniones con la Secretaría de Economía en 2011 con el propósito de dinamizar el turismo cultural en los pueblos mágicos.

En un inicio, explica, únicamente se llevaba la misma información que la Secretaría de Economía utiliza en todo tipo de empresas, sin ningún ajuste a las características del sector, por lo que no funcionó y entonces se llevó a cabo el proceso de capacitar de manera especializada a consultores, el cual se puede visualizar a través de las siguientes citas extraídas de aquella conversación:

"...la Coordinación se dio a la tarea de buscar empresas que estaban dedicadas al trabajo con empresas culturales y se trató de que fueran incluidas en las opciones de la Secretaría de Economía (SE). Así, se logró en 2012 que Espacio Empresarial, que era la empresa que se dedicaba a capacitar a todos los consultores de la SE a nivel nacional, capacitara a un grupo de 52 personas que ahora son Consultores Culturales..."

“... Al final del año pasado (2012) a la Coordinadora se le ocurre reunir a todos los que participaron en ese proyecto de capacitación a fin de conocer su opinión sobre las necesidades para homologar un programa de capacitación dirigido a este sector en particular, partiendo de los conocimientos que estaban adquiriendo así como de la experiencia de tantos años que cada uno tiene. Esto se hace con base en la demanda de capacitación que tenía el sector, ya que a finales de 2012 se tenía solicitud de 232 empresas registradas..."

“... Espacio Empresarial, tenía un recurso para capacitar consultores en general y proponen tomar parte de ese recurso para capacitar a consultores especializados en emprendimientos culturales y creativos. $Y$

lo que se hace es que se les dan los mismos módulos que se les dan a todos los consultores:

administración, finanzas, recursos humanos y mercadotecnia; y adicional a eso se hizo un consenso sobre qué temas eran necesarios en el área cultural, donde Conaculta iba a sugerir sus ponentes. Se solicitó ponente en temas de derechos de autor, historia del arte, antropología, cultura, estética, temas que están relacionados con los emprendimientos... Así, se formaron como consultores con reconocimiento de la SE y de Conaculta 52 personas con este perfil de Consultores Culturales. Eso fue en febrero de 2013..." 
En julio de 2013 se presentó el Programa Nacional de Fomento y Estímulo a las Industrias Culturales Creativas y a Empresas Culturales ${ }^{67}$, cuyo monto económico será de 120 millones de pesos a través de la banca comercial. Dicho programa cuenta con el apoyo del Fondo Nacional para la Cultura y las artes (Fonca), el Inadem y Nafinsa, caracterizándose por ser una oferta integral que consiste en capacitación, asistencia y financiamiento. Se explicó que los apoyos estarían encaminados a que las industrias creativas y empresas culturales (personas físicas con actividad empresarial, micro, pequeñas y medianas empresas) tengan la posibilidad de obtener un crédito de hasta cuatro millones de pesos, con plazos flexibles hasta por tres años para créditos de capital de trabajo y hasta cinco para adquisición de activo fijo.

Finalmente, en este proceso de institucionalización de los emprendimientos culturales y creativos, es necesario mencionar el papel de los medios de comunicación en esta construcción y legitimación de una idea.

En 2012 la Revista ProMéxico ${ }^{68}$, destinó un número especial a las Industrias Creativas, lo que implica el reconocimiento hacia el exterior de dicho sector como relevante para el desarrollo económico del país.

\footnotetext{
${ }^{67}$ Consultado en http://fonca.conaculta.gob.mx/programa/programa-nacional-de-fomento-y-estimulo-a-lasindustrias-creativas-y-a-empresas-culturales/

${ }^{68}$ ProMéxico "es el Organismo del Gobierno Federal encargado de coordinar las estrategias dirigidas al fortalecimiento de la participación de México en la economía internacional; apoyando el proceso exportador de empresas establecidas en nuestro país y coordinando acciones encaminadas a la atracción de inversión extranjera. Fue creado bajo la figura de Fideicomiso mediante Decreto Presidencial en junio de 2007". Para mayor información visitar http://www.promexico.gob.mx/es ca/promexico/Revistas 2012
} 
La revista Entrepreneur ${ }^{69}$, de gran tiraje y especializada en el tema emprendedor, desde 2012 tiene una columna que aborda temas relacionados con Economía Creativa y emprendimiento en el sector. Asimismo, de manera recurrente ha incluido casos de éxito en otras secciones relacionados con las disciplinas que integran las industrias creativas $^{70}$.

En el monitoreo que se llevó a cabo entre 2011 y 2013, en un ejercicio de búsqueda rápida se verificó que en el sitio web del periódico El Economista el día 21 de septiembre de 2013 los tópicos relacionados con la Economía Creativa están presentes de manera importante, lo cual permite corroborar que el tema es cada vez más visible y forma parte del debate actual en el sector.

\begin{tabular}{|c|c|}
\hline Búsqueda & Resultados encontrados \\
\hline Industrias Creativas & 859 \\
\hline Economía Creativa & 1,860 \\
\hline Economía Cultural & 4,820 \\
\hline Industria Cultural & 1,050 \\
\hline Emprendedor cultural & 348 \\
\hline
\end{tabular}

Como se puede observar a partir de la revisión de los diversos programas que se han diseñado para impulsar la actividad emprendedora en el sector cultural y creativo, tanto a nivel nacional como local y desde la plataforma de diversos sectores, se reafirma la idea que todavía éste es un proceso en construcción del que, sin embargo, resulta importante dar cuenta en este momento para contribuir a sentar las bases contextuales que permita que futuras investigaciones, ya sea desde los Estudios Organizacionales $u$ otras disciplinas, puedan profundizar en el estudio de las prácticas y modelos de gestión implementados teniendo como referente todos estos elementos.

\footnotetext{
${ }^{69}$ Además desde 2013 el área de redacción de la revista es la encargada de la generación de contenidos para emprendedores en la página de internet del Inadem, donde el tema de la economía creativa también está presente. http://www.soyentrepreneur.com/1-home.html

${ }^{70}$ Se sugiere revisar: http://www.soyentrepreneur.com/26208-galeria-de-emprendedores-2013.html
} 
Asimismo, atendiendo a las palabras de los responsables del diseño de estas políticas y programas como testimonio, se puede observar claramente el proceso a partir del cual se ha ido estructurando el traslado institucional de la idea empresarial/emprendedora al sector cultural y creativo, quedando claro que desde la conceptualización de éstos existe una clara referencia a experiencias y documentos internacionales que han sido referidos en esta investigación al tiempo que se han podido identificar los argumentos empleados para la legitimación de dichos programas y acciones, los cuales constituyen uno de los factores detonantes en el surgimiento de un campo organizacional, en este caso, de emprendimientos en el sector cultural y creativo de la Ciudad de México.

La diversidad de enfoques en su concepción es evidente. Así, de manera simultánea en los últimos años hemos sido testigos de la convivencia de diversos términos asociados para referirse al tipo de organizaciones que han emergido como consecuencia de la fusión de la cultura, el desarrollo, la economía y la creatividad y cuyo nombre refleja la plataforma desde la cual han sido impulsados. Entre éstos identificamos los siguientes:

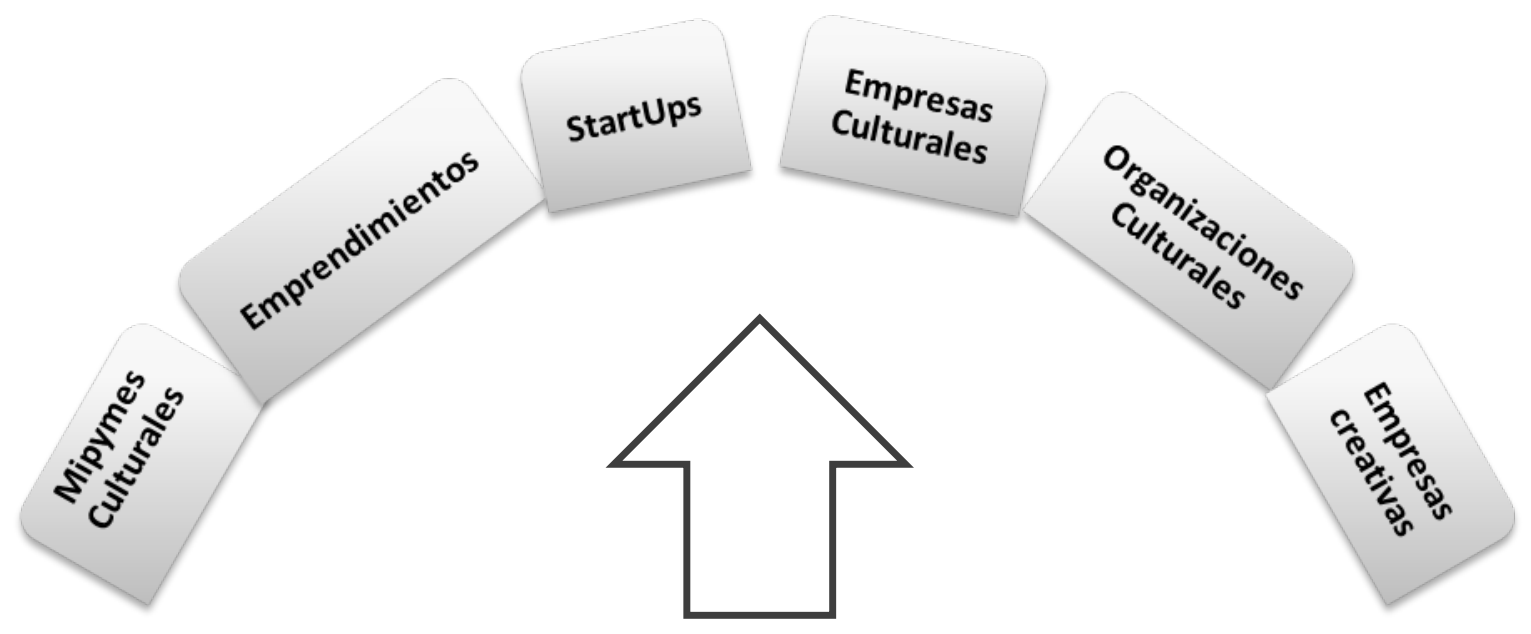


TABLA 3.3 PROGRAMAS IDENTIFICADOS POR SECTOR DE ACTIVIDAD (2003-2013)

\begin{tabular}{|c|c|c|c|c|}
\hline PROGRAMA & NIVEL & AÑO & INSTANCIA & SECTOR \\
\hline $\begin{array}{c}\text { Imaginación en movimiento, } \\
\text { empresas culturales y } \\
\text { creativas }\end{array}$ & Local & 2007 & Secretaría de Cultura & Gubernamental \\
\hline $\begin{array}{c}\text { Incubadora de Empresas } \\
\text { Creativas }\end{array}$ & Local & 2010 & $\begin{array}{l}\text { Secretaría de Desarrollo } \\
\text { Económico/Fondo de } \\
\text { Desarrollo Social }\end{array}$ & Gubernamental \\
\hline $\begin{array}{l}\text { Incubadora de Empresas } \\
\text { Artísticas y Culturales }\end{array}$ & Local & 2011 & $\begin{array}{c}\text { Instituto Tecnológico de } \\
\text { Estudios Superiores } \\
\text { Monterrey, Campus } \\
\text { Santa Fe } \\
\end{array}$ & Académico \\
\hline $\begin{array}{l}\text { Innova UNAM para } \\
\text { Proyectos Creativos, } \\
\text { Artísticos y Culturales }\end{array}$ & Local & 2011 & $\begin{array}{l}\text { Universidad Nacional } \\
\text { Autónoma de México } \\
\text { (Facultad de Arquitectura } \\
\text { y Escuela Nacional de } \\
\text { Artes Plásticas) }\end{array}$ & Académico \\
\hline $\begin{array}{l}\text { Grupo de Reflexión sobre } \\
\text { Economía y Cultura }\end{array}$ & Local & 2009 & $\begin{array}{c}\text { Universidad Autónoma } \\
\text { Metropolitana Unidad } \\
\text { Xochimilco } \\
\end{array}$ & Académico \\
\hline $\begin{array}{l}\text { InCultura, Incubación de } \\
\text { Iniciativas Culturales, } \\
\text { Creativas y Tecnológicas }\end{array}$ & Local & 2011 & $\begin{array}{c}\text { Reinventa Incubadora de } \\
\text { Ideas A.C }\end{array}$ & Social \\
\hline $\begin{array}{l}\text { Clúster Creativo } \\
\text { Roma/Condesa }\end{array}$ & Local & 2013 & $\begin{array}{c}\text { Clúster Creativo } \\
\text { Roma/Condesa A.C. }\end{array}$ & Social \\
\hline $\begin{array}{c}\text { Primer Concurso de Estímulo } \\
\text { a la Creación de Micro y } \\
\text { Pequeñas Empresas } \\
\text { Culturales }\end{array}$ & Federal & 2012 & Conaculta & Gubernamental \\
\hline $\begin{array}{c}\text { Programa Mipymes } \\
\text { Culturales }\end{array}$ & Federal & 2012 & Conaculta & Gubernamental \\
\hline $\begin{array}{c}\text { Programa Nacional de } \\
\text { Fomento y Estímulo a las } \\
\text { Industrias Culturales, } \\
\text { Creativas y a Empresas } \\
\text { Culturales } \\
\end{array}$ & Federal & 2013 & Conaculta & Gubernamental \\
\hline $\begin{array}{l}\text { Incubadora de Empresas } \\
\text { Culturales de la Ciudad } \\
\text { de México }\end{array}$ & Local & $\begin{array}{c}2014 \\
\text { (próximamente) }\end{array}$ & Secretaría de Cultura & Gubernamental \\
\hline
\end{tabular}

Fuente: Elaboración propia. 


\subsection{Traducción e Isomorfismo en la conformación de un contexto institucional para el emprendimiento en el sector cultural y creativo de la Ciudad de México}

A lo largo del desarrollo del presente capítulo en donde se llevó a cabo el mapeo y análisis de los programas de formación profesional en Emprendimiento Cultural y Creativo, de las políticas y programas que desde los ámbitos gubernamental, académico y social, tanto a nivel local como federal, se han implementado en los últimos años, así como la realización de eventos y actividades diversas en el tema; se puede observar la manera cómo los mecanismos de cambio institucional isomorfo (mimético, normativo y coercitivo) se han hecho presentes en el proceso de institucionalización de una idea, tal es el caso de la noción de Emprendimiento Cultural y Creativo.

Así, desde el Nuevo Institucionalismo Sociológico, y con base en la información desarrollada previamente, se puede afirmar que existen elementos de isomorfismo coercitivo, mimético y normativo en los tres ámbitos analizados (programas de formación profesional, políticas-programas y eventos) a través de estrategias de legitimación como la profesionalización, la participación e intercambio de profesionales reconocidos en el sector (los que han escrito los libros más emblemáticos en el tema, son algunos de los principales impulsores de la profesionalización, al tiempo que participan de manera activa con gobiernos de distintos países en seminarios, programas de capacitación y como asesores en el diseño de políticas y programas públicos), así como en la concentración de recursos económicos a través del establecimiento de políticas y programas de estímulo entre entidades gubernamentales para la coordinación interinstitucional de las organizaciones del sector. 
Ahora bien, hablando específicamente del tema de la profesionalización, retomando lo que ha sucedido en el caso de la Gestión Cultural, Mariscal (2011) identifica cinco elementos que considera cruciales, dos de los cuales coinciden con lo que actualmente sucede con el surgimiento de los denominados emprendimientos culturales y creativos (derivados de la Economía Creativa) y son los siguientes:

- “La implementación del modelo económico neoliberal en México que influyó en la disminución del financiamiento púbico a la cultura, la implementación en el sector cultural de ideologías y modos de administración provenientes de las empresas privadas (Nivón, 2006), así como una menor participación e intervención del Estado en el sector y un aumento de la iniciativa privada en los circuitos culturales (Berman y Jiménez, 2006).

- Una mayor demanda por parte de la ciudadanía por participar en la generación de acciones culturales desde la asociatividad, lo cual ha requerido que los ciudadanos o grupos de ciudadanos tengan las competencias suficientes para diseñar e implementar proyectos culturales, así como la gestión de recursos en fuentes de financiamiento púbicas, privadas y comunitarias" (Mariscal, 2011: 21-22).

Desde lo trabajado en esta investigación en particular, se agregarían dos elementos más:

- La economía creativa integra disciplinas que antes no se consideraban parte del sector, lo que hace necesarias nuevas maneras de aproximarse a la gestión de este tipo de actividades que tienen requerimientos muy específicos.

- El periodo de crisis económica a nivel mundial ha intensificado el vínculo entre la economía y el sector cultural y creativo. Por un lado, desde las políticas públicas se busca la manera de hacer que estas actividades generen desarrollo económico y, por otro lado, la falta de empleo (no sólo en el sector cultural, sino en general) ha ocasionado que tanto los artistas y creativos se interesen por conocer y formarse en esta área como una opción de procurarse ingresos económicos (cabe mencionar que no sólo son artistas, individuos provenientes de otras profesiones han considerado viable incursionar también en este tipo de emprendimientos). 
Como se puede observar, entre los programas de formación aquí presentados existen diferentes enfoques: desde los más críticos y reflexivos hasta los más funcionales e incluso se podría decir que algunos sólo se adhieren al nombre de emprendimiento y creatividad para ingresar en el campo y aprovechar el impulso que se está dando al tema desde distintas esferas. No obstante, es importante dar cuenta de su existencia.

El conocer su contenido académico nos ha permitido visualizar el enfoque que tienen a partir de los temas que incluyen. Por otro lado, identificar el área dentro de las universidades que impulsan dichos programas ayuda tener clara la visión desde la cual se enmarca el rol de la cultura y la creatividad en cada instancia (si es más reflexiva, crítica, adminsitrativa).

Lo mismo ha sucedido con las políticas, programas y eventos, muchos de ellos se adhieren a los términos para seguir una tendencia que se considera legítima y es bien vista por los pares en el espacio profesional.

Así, lo que se intentó con la descripción de los programas es demostrar que la idea de Economía Creativa ha viajado y transitado desde diversos ámbitos (gubernamental, académico y social) en los cuales se confirma que los actores al interior de las organizaciones han sido sumamente activos en la búsqueda de modelos y formas de operar para lograr que su organización sobreviva.

Aún están en proceso de estructuración y formalización, la información es reciente y los procesos están llevándose a cabo de manera simultánea, será en unos años cuando se pueda evaluar el impacto real de todas estas iniciativas en el sector. Lo que es un hecho es que al concentrarse los recursos económicos en el impulso de ciertas formas de organización y de gestión se está promoviendo claramente el isomorfismo ${ }^{71}$.

\footnotetext{
${ }^{71} \mathrm{O}$ posiblemente sólo se esté adoptando el mismo nombre, fenómeno que se ha denominado como Isonomismo.
} 
De esta manera, el proceso de traducción, tal como lo describe Czarniawska (2005), se puede identificar claramente: una idea (Economía Creativa), viaja a través de documentos (informes, libros, acuerdos internacionales), se materializa (en programas universitarios, políticas, programas de estímulo y eventos) para finalmente llegar a los actores del sector, quienes seleccionarán e interpretarán la información recibida, con base en su experiencia y las características de su entorno específico, para después de un tiempo de asimilación, traducir dicho conocimiento en una práctica concreta en su organización, con lo que se supera el universo de interpretación institucionalista que sólo reconocía el papel del Estado y las profesiones en esta labor y se agrega el importante rol de los actores en esta construcción, tanto de manera individual como colectiva.

Si bien la estructuración de un campo puede darse en todos los sectores, afirman desde la teoría institucional que "en el sector no lucrativo, donde no existen barreras legales para la colusión, la estructuración puede proceder incluso más rápido, ya que la competencia entre organizaciones no se da tanto en términos económicos o de eficiencia sino en búsqueda de estatus y legitimidad social en donde el prestigio y los recursos organizacionales son elementos clave para atraer profesionales. Este proceso favorece la homogeneización a medida que las organizaciones procuran proporcionar los mismos beneficios y servicios que sus competidores" (DiMaggio y Powell, 1999: 116117). Por lo tanto, en dicho sector, incluso, se estimula el trabajo coordinado entre las organizaciones que forman parte del campo y eso es considerado positivamente. Finalmente, todos estos elementos permiten comprender el proceso de institucionalización que se ha llevado a cabo los últimos años en el sector cultural y creativo, el cual da lugar y enmarca el tema que se estudiará en el siguiente capítulo que se refiere a la formación de un campo organizacional a través del análisis de los campos de imitación como traducción, fenómeno que se aterrizará en el estudio de los Bazares de Arte y Diseño Independiente de la Ciudad de México. 


\section{CAPÍTULO 4.}

\section{BAZARES DE ARTE Y DISEÑO INDEPENDIENTE EN LA CIUDAD DE MÉXICO: EL SURGIMIENTO DE UN CAMPO ORGANIZACIONAL.}

\subsection{La Ciudad de México: dinamismo y centralización cultural}

De acuerdo con datos del Censo de Población y Vivienda 2010 publicados en el sitio web del INEGI ${ }^{72}$, la población nacional está integrada por 112336538 individuos, de los cuales, 8851080 se ubican en el Distrito Federal.

Ahora bien, debido a la cercanía e intercambio entre habitantes de municipios cercanos, en sentido amplio se tiende a hablar más bien de la Zona Metropolitana del Valle de México (integrada por las 16 delegaciones del Distrito Federal, 59 municipios del Estado de México y uno de Hidalgo), la cual actualmente está formada por una población total de 20 millones de habitantes, por lo tanto, es de suponer que constituye un centro de actividad económica, política, social y cultural fundamental para el país.

En lo que se refiere a la actividad cultural, "por densidad demográfica, la capital del país concentra el mayor mercado cultural: va del teatro y el cine a las librerías, a los restaurantes de autor, disqueras, la radio y televisión, a las galerías y empresas creativas desarrolladoras de software que, en el eje Roma-Condesa, son alrededor de 150 unidades económicas... Las delegaciones Benito Juárez, Cuauhtémoc, Coyoacán, Miguel Hidalgo y Tlalpan concentran casi toda la movilidad de la economía cultural" (Cruz y Romo, 2012, diciembre 4). No obstante lo anterior, existen delegaciones con mayor concentración poblacional como Gustavo A. Madero e Iztapalapa.

\footnotetext{
${ }^{72}$ Fuente: http://www.inegi.org.mx/ consultado el 20 de diciembre de 2013.
} 
Por otro lado, de acuerdo con Ernesto Piedras (2010: 28) "el DF constituye un imán para los creadores del país y de la región debido a su gran tamaño, concentración de consumidores potenciales y la existencia de prácticamente todos los medios necesarios para la actividad cultural. Por esto, la ciudad se ha constituido como el principal generador de bienes y servicios culturales del país".

Lo anterior tiene una arista positiva y, a partir de la cual, se justifican una serie de programas y presupuesto para el impulso de la actividad cultural y creativa; aunque por otro lado también resulta problemática debido a que se sigue reproduciendo y estimulando la centralización de la actividad cultural, con lo que quedan fuera numerosas propuestas, áreas y, por lo tanto, ciudadanos que no pueden acceder a este tipo de oferta cultural.

Como ejemplo, baste mencionar que:

De acuerdo con datos de 2012 "la Comisión de Cultura recibió este año más de cinco mil propuestas de proyectos culturales, pero sólo fue posible apoyar poco más de mil iniciativas, que fueron seleccionados a consideración de los diputados... De la suma destinada para etiquetados, más de 987 millones fueron asignados a proyectos estatales, siendo el Estado de México el principal beneficiado, con 259 millones 900 mil pesos, para 52 proyectos. En el caso de los proyectos municipales, la Ciudad de México obtuvo más de 216 millones de pesos, a pesar de contar sólo con 16 delegaciones, mientras que Oaxaca, que cuenta con más de 500 municipios, apenas obtuvo 30 millones 900 mil pesos" ${ }^{\prime 73}$. Los datos anteriores permiten visualizar el complejo panorama del contexto que rodea a las organizaciones del sector cultural y creativo.

\footnotetext{
${ }^{73}$ “Concentran DF y Edomex presupuesto para proyectos culturales” publicado y consultado el 07 de enero de 2013. Disponible en http://www.excelsior.com.mx/node/878015
} 
Por un lado, la Ciudad de México ofrece un sinnúmero de posibilidades a los creadores al concentrar la mayor parte de la infraestructura cultural del país, lo cual le confiere un dinamismo sumamente valioso para el impulso y desarrollo artístico y creativo. Por otro, la centralización de recursos que, además cabe señalar, son cada vez más reducidos (y su reparto es muchas veces discrecional) impide la diversidad en la oferta cultural y el rezago de numerosos sectores.

Finalmente, lo que además nos vincula directamente con el surgimiento de los Bazares de Arte y Diseño Independiente, es la conjunción de ambos elementos, es decir, en un mismo espacio (Ciudad de México) se encuentran al mismo tiempo numerosos artistas, colectivos y asociaciones con iniciativas para la realización de proyectos, pero al estar todo concentrado, la demanda de recursos excede los presupuestos destinados, lo que trae, a su vez, como consecuencia, que en este momento ya no sea suficiente el financiamiento público para el sector, razón por la cual los creadores se han dado a la tarea de buscar y diseñar estrategias que se traducen en formas de organización innovadoras para lograr los objetivos de creación, circulación y consumo de su producción cultural y creativa aprovechando el marco de acción que establece la clasificación de las industrias creativas.

En este punto, la figura del emprendedor $y$, en sentido amplio, de los emprendimientos en el sector cultural y creativo constituye hoy por hoy un campo organizacional que está emergiendo con fuerza en este contexto, fenómeno que como ya se revisó en el capítulo previo, ha ido conformándose institucionalmente con las acciones conjuntas de diversos sectores: académico, gubernamental y social. 


\subsection{Algunas premisas sobre los emprendedores culturales y creativos}

Antes de adentrarnos en el universo organizacional de los Bazares de Arte y Diseño Independiente, resulta necesario identificar de manera clara algunas características que, de acuerdo a la bibliografía en el tema, definen a los emprendimientos del sector cultural y creativo:

\section{TABLA 4. CARACTERÍSTICAS DE LOS EMPRENDIMIENTOS CULTURALES Y CREATIVOS}
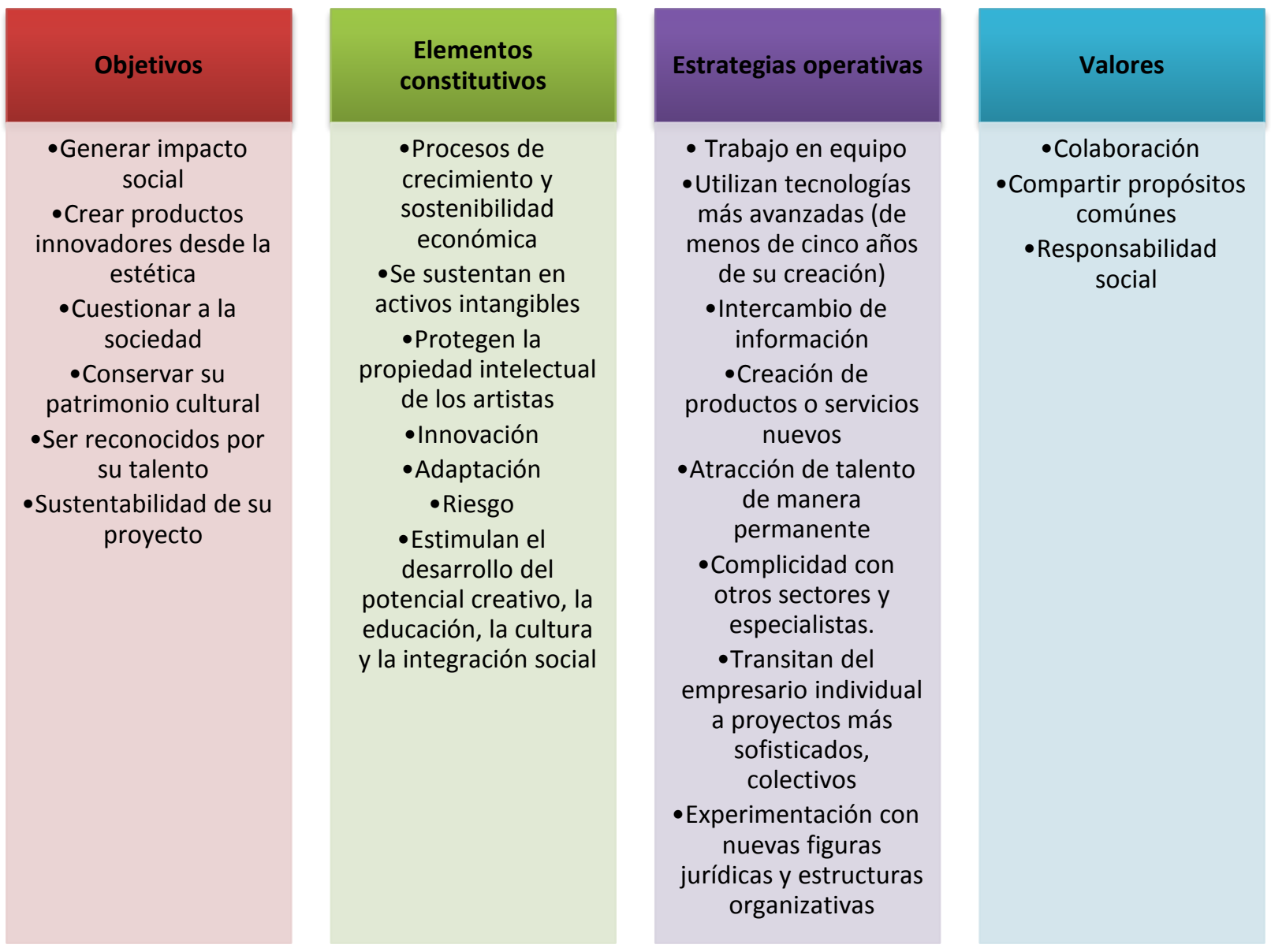

Fuente: Elaboración propia con base en Holguín (2010), Ruiz (s/f), Pallarés (2012), Ruz (2012). 
Dado lo anterior, si bien no existe una definición única de emprendimiento en el ámbito cultural y creativo, una propuesta que integra los diversos elementos que caracterizan a este sector y coincide con el objeto de estudio de esta investigación puede ser la siguiente:

"Es una actividad (individual o colectiva) de apropiación de los valores simbólicos -de origen tangible e intangible- de una sociedad que tiene como propósito crear y recrear diversas formas de representación plasmadas en bienes y servicios culturales [y creativos], mediante procesos económicos y sociales -vinculados o no al mercadobasados en el riesgo, la creatividad y la innovación. Estas actividades aspiran en su conjunto a la consolidación de una vocación, una idea de negocio, empresa o colectividad identitaria" (Espinosa et al., 2012: 17).

De esta manera, de acuerdo con Pallarés (2010: 47) se sugiere que "la mejor estructura organizativa es la de una "agrupación de industrias culturales y creativas", es decir, un conjunto concentrado de industrias reactivas y adaptables. En la mayor parte de los casos, estas agrupaciones funcionales se basan en una intensa colaboración entre diferentes instituciones y actores de la innovación interrelacionados. En estos entornos, los competidores emprenden frecuentemente cooperaciones entre empresas".

En este punto hacen su aparición los Bazares de Arte y Diseño Independiente como forma organizacional emergente en el sector cultural y creativo de la Ciudad de México y, debido a su dinamismo y crecimiento acelerado en los últimos años, constituye un referente interesante para el estudio del surgimiento de un campo organizacional en un contexto que es permanentemente incierto que implica retos y transformaciones constantes. 


\subsection{Aproximaciones a la Configuración organizacional de los bazares de Arte y Diseño Independiente de la Ciudad de México}

Este apartado tiene como propósito delimitar algunos elementos clave referentes a la configuración organizacional de los Bazares de Arte y Diseño en la Ciudad de México que posibilite trazar ciertas líneas que permitan la identificación de características específicas que comparten este tipo de organizaciones con la intención de contribuir a su tipificación.

\subsubsection{Notas sobre el estudio de la estructura}

Si partimos de la idea de que la definición de estructura es compleja pues depende de muchos factores, podemos aproximarnos a su estudio con una mirada un poco más abierta e integradora de las diversas concepciones y metodologías. Existe una cantidad considerable de autores que trabajan el tema y que ofrecen numerosas definiciones de estructura organizacional los cuales enfatizan distintos elementos y, entre otras cosas, algo en lo que coinciden es que la estructura está en surgimiento continuo.

Por ejemplo, Hall (1996a:53) afirma que "las estructuras organizacionales sirven a tres funciones: 1) tienen la intención de elaborar productos organizacionales y alcanzar objetivos organizacionales, 2) se diseñan para minimizar, o por lo menos regular, la influencia de las variaciones individuales sobre la organización, 3) las estructuras son el ambiente donde se ejercita el poder, donde se toman decisiones y donde se desarrollan las actividades de las organizaciones. Así, la estructura es la arena para las acciones organizacionales". 
Para Daft (1998: 202), los tres componentes claves en la definición de la estructura de la organización son:

I. La estructura de la organización designa las relaciones formales de reporte, incluso el número de niveles en la estructura jerárquica y el tramo de control de gerentes y supervisores. 2. La estructura de la organización identifica el agrupamiento de individuos en departamentos y de éstos en la organización total. 3. La estructura de la organización incluye el diseño de sistemas para asegurar la comunicación, coordinación e integración efectivas de esfuerzos en todos los departamentos.

De acuerdo con Mintzberg (1989: 116), "la estructura de una organización se puede definir como las maneras en que su trabajo se divide en diferentes tareas y luego se logra la coordinación entre las mismas".

Siguiendo con Hall (1996b: 93), el autor afirma que "existen dos categorías principales de factores que afectan la estructura. La primera está constituida por el contexto donde operan las organizaciones. Los factores contextuales incluyen el tamaño de la organización, la tecnología, la cultura interna (o clima organizacional), el ambiente y factores de cultura nacional. Aquí el contexto significa la situación donde opera una organización. La segunda categoría de las explicaciones de la estructura es el diseño, las elecciones efectuadas en una organización acerca de cómo se va a estructurar la misma. Los enfoques principales aquí son la selección estratégica y los modelos institucionales de estructura". 
Por lo tanto, de acuerdo con esta tendencia, las organizaciones (entendidas además como sistemas abiertos) son influenciadas y están determinadas en su diseño y estructura por el entorno en el cual se ubican, al tiempo que otros elementos como su tamaño, sector, actividad, etc. también inciden en su conformación.

Así, para llevar a cabo la caracterización de los Bazares de Arte y Diseño Independiente se tomará como referente la propuesta de Pugh, et al., (1973) a partir de la identificación y descripción de las seis dimensiones de la estructura de la organización: Especialización, Estandarización, Formalización, Centralización, Configuración y Tradicionalismo.

El autor defiende la idea de que "estas dimensiones hacen que sea posible elaborar perfiles característicos de las organizaciones particulares" (Pugh, et al., 1973:459). Asimismo, dicho enfoque facilita el análisis multifactorial en el diseño estructural de las organizaciones y permite, de alguna manera, el desarrollo de una clasificación taxonómica.

Si bien el citado autor sugiere que para realizar un análisis formal de la estructura organizacional primero se debe decidir las características a medir, y para ello propone las seis variables o dimensiones de la estructura organizacional que se mencionaron arriba, para facilitar la lectura y comprensión del lector de la presente investigación, se ha optado por primero identificar y desarrollar las dimensiones contextuales, para posteriormente con esta información, responder a las preguntas sobre cada una de las dimensiones de la estructura de los Bazares de Arte y Diseño Independiente. 


\subsubsection{Dimensiones Contextuales}

\section{- Origen e historia.}

En la Ciudad de México el fenómeno de los Bazares de Diseño Independiente inició en 2003 con la organización del Bazar Fusión, una iniciativa coordinada por un par de creadores argentinos radicados en México, que retomaron la idea de las Ferias de Diseño ${ }^{74}$ que se realizaban en Argentina como consecuencia, entre otras cosas, de la crisis económica y política que enfrentó aquel país en diciembre de 2001, la cual impactó notablemente el sector cultural.

De acuerdo con la Real Academia Española ${ }^{75}$ una feria es "una instalación donde con periodicidad determinada se exponen los productos de un solo ramo industrial o comercial, como libros, muebles, juguetes, etc., para su promoción y venta", definición que permite identificar las características que comparten con el esquema de los bazares, los cuales se definen como "un mercado, muchas veces cubierto, típicamente encontrado en áreas de la cultura persa, hindú e islámica, análogo al árabe zoco. La palabra deriva de la palabra persa bāzār, cuya etimología viene del antiguo dialecto pahlavi baha-char (رأجاهب) que significa "el lugar de los precios"76.

Así, en una entrevista realizada en 2011 a Carolina Kopeloff ${ }^{77}$, co-fundadora del Bazar Fusión comenta:

74 Para mayor información visitar: http://fido.palermo.edu/servicios dyc/publicacionesdc/vista/detalle articulo.php?id libro=118\&id_articulo $=140$

${ }^{75}$ Fuente: http://lema.rae.es/drae/srv/search?id=qsP6MUYUEDXX2UD8Q0wF

${ }^{76}$ Fuente: http://es.wikipedia.org

77 Fuente: Programa Central 11, junio de 2011 consultado en https://www.facebook.com/photo.php?v=10150223111051851\&set=vb.207920780643\&type=3\&theater 
"La idea del Bazar Fusión surgió de Manuel Sekkel, que es mi socio, y yo. Manuel hace zapatos y yo accesorios. Entonces [el bazar] empieza por una necesidad propia de tener un espacio donde vender directo al público. Empezamos en una casa con solo 10 y ahorita estamos 80 diseñadores... la idea es difundir el diseño, la moda, el arte, el ámbito editorial, toda esa corriente que es independiente en donde la gente pueda venir a comprar directamente al diseñador sin intermediarios, pueda conocer al creador y llevarse piezas únicas".

Integrando ambas definiciones y el testimonio que dio lugar a su surgimiento, para los propósitos de esta investigación se entiende que los Bazares de Arte y Diseño Independiente de la Ciudad de México, debido a sus objetivos, constituyen una actividad económica, social y cultural que se realiza de forma periódica e itinerante, que reúne a creadores de disciplinas relacionadas en torno a una temática, los cuales además comparten algún propósito en común, que en este caso, es impulsar, difundir y comercializar su trabajo creativo directamente.

De esta manera, a partir de 2003 en parques y plazas públicas de las colonias San Miguel Chapultepec, Roma, Condesa y Coyoacán, de manera periódica, Bazar Fusión organizó eventos que difundían propuestas en todas las ramas del diseño -incluyendo editoriales- así como ventas de arte. De acuerdo con los datos obtenidos en el seguimiento del tema que se realizó para esta investigación, en el periodo comprendido entre 2003-2009 no existen registros del surgimiento de un bazar similar, $^{78}$ por lo que durante seis años Bazar Fusión ${ }^{79}$ fue prácticamente la única opción de este tipo en la Ciudad de México, razón por la cual constituye hoy en día un referente fundamental.

\footnotetext{
78 “... desde entonces, Bazar Fusión ha servido de modelo para la creación de propuestas similares, algunas no perduraron más de un año, como fue el caso de Bazar Simple que inició en 2009 y cuyo último registro de actividad en su página web fue en diciembre de ese año". Muciño Rangel, Krizia (2013, junio 27). La otra cara del diseño: el lado independiente. Disponible en www.aunamnoticias.blogspot.mx.

${ }^{79}$ Hay que mencionar que este proyecto ha evolucionado. Desde inicios de 2013 dejó de ser itinerante, para ubicarse en una locación fija en la Colonia Juárez en donde se unieron algunas marcas que formaron por años parte del bazar para tener una tienda. No obstante, mantiene una dinámica itinerante o de bazar, debido a que en una zona de la casa, los fines de semana se presentan proyectos invitados que cambian de manera constante.
} 
Fue a partir del año 2009, con la aparición de Tráfico Bazar y, en 2010, de La Lonja Mercantil e InCubus Visual con eventos mensuales o bimestrales en las delegaciones Cuauhtémoc y Coyoacán, que la presencia de los bazares se fue haciendo cada vez más cotidiana como parte de la oferta impulsada por los creadores, artistas, diseñadores para estimular el consumo cultural y creativo en la ciudad.

2011, con cuatro bazares nuevos (DIM, El Perchero. Mujeres Emprendedoras, Vanitas y Bazar Ambulante), puede considerarse un año clave y determinante que detonó el crecimiento de esta forma de organización colectiva que ha tenido su punto más alto en 2013 y que se enmarca perfectamente en las actividades derivadas de la Economía Creativa y las políticas y programas que desde distintos ámbitos se han venido impulsando tanto a nivel local como nacional para institucionalizar el emprendimiento en el sector cultural y creativo. 
TABLA 4.1 BAZARES DE ARTE Y DISEÑO INDEPENDIENTE EN LA CIUDAD DE MÉXICO (2003-2013).

\begin{tabular}{|c|c|c|c|}
\hline NÚMERO & BAZAR & UBICACIÓN & $\begin{array}{l}\text { AÑO DE } \\
\text { CREACIÓN }\end{array}$ \\
\hline 1 & FUSIÓN & CUAUHTÉMOC & 2003 \\
\hline 2 & TRÁFICO & CUAUHTÉMOC/COYOACÁN & 2009 \\
\hline 3 & LONJA MERCANTIL & CUAUHTÉMOC & 2010 \\
\hline 4 & INCUBUS VISUAL & CUAUHTÉMOC/COYOACÁN & 2010 \\
\hline 5 & $\begin{array}{l}\text { DISEÑADORES INDEPENDIENTES MEXICANOS } \\
\text { (DIM) }\end{array}$ & CUAUHTÉMOC & 2011 \\
\hline 6 & EL PERCHERO. MUJERES EMPRENDEDORAS & CUAUHTÉMOC & 2011 \\
\hline 7 & VANITAS & CUAUHTÉMOC/COYOACÁN & 2011 \\
\hline 8 & BAZAR AMBULANTE & TLALPAN & 2011 \\
\hline 9 & MEXICANITAS & CUAUHTÉMOC & 2012 \\
\hline 10 & BAZAR LA CIRUELA & CUAUHTÉMOC & 2012 \\
\hline 11 & GARAGE ART & CUAUHTÉMOC & 2012 \\
\hline 12 & BAZAR DE BARRIO & CUAUHTÉMOC & 2012 \\
\hline 13 & PÚRPURA BAZAR & CUAUHTÉMOC & 2012 \\
\hline 14 & PABELLÓN DE DISEÑO MEXICANO & CUAUHTÉMOC/BENITO JUÁREZ & 2012 \\
\hline 15 & ART DISTRICT & MIGUEL HIDALGO & 2012 \\
\hline 16 & FACTOR MODA & TLALPAN & 2012 \\
\hline 17 & MEXICANISIMO & COYOACÁN & 2013 \\
\hline 18 & EDAM DF (ESPACIO ARTESANAL MEXICANO) & COYOACÁN & 2013 \\
\hline 19 & CREE\&CREA & CUAUHTÉMOC & 2013 \\
\hline 20 & MAHONIA & CUAUHTÉMOC & 2013 \\
\hline 21 & NÓMADA & CUAUHTÉMOC & 2013 \\
\hline 22 & FOOD TRUCK BAZAR & CUAUHTÉMOC & 2013 \\
\hline 23 & LIBRE LIEBRE BAZAR & CUAUHTÉMOC & 2013 \\
\hline 24 & RETRO BAZAR & CUAUHTÉMOC & 2013 \\
\hline 25 & ARTE Y DISEÑO MEXICANO 13 & CUAUHTÉMOC / COYOACÁN & 2013 \\
\hline 26 & LI-ARTE BAZAR CREATIVO & MIGUEL HIDALGO & 2013 \\
\hline 27 & MEXICO DISEÑA. BAZAR-GALERIA & CUAUHTÉMOC & 2013 \\
\hline 28 & BAZAR DE NADIE & CUAUHTÉMOC & 2013 \\
\hline
\end{tabular}

Fuente: Elaboración propia 
FIGURA 4. EVOLUCIÓN DEL SURGIMIENTO DE BAZARES DE ARTE Y DISEÑO EN LA CIUDAD DE MÉXICO 2003-2013.

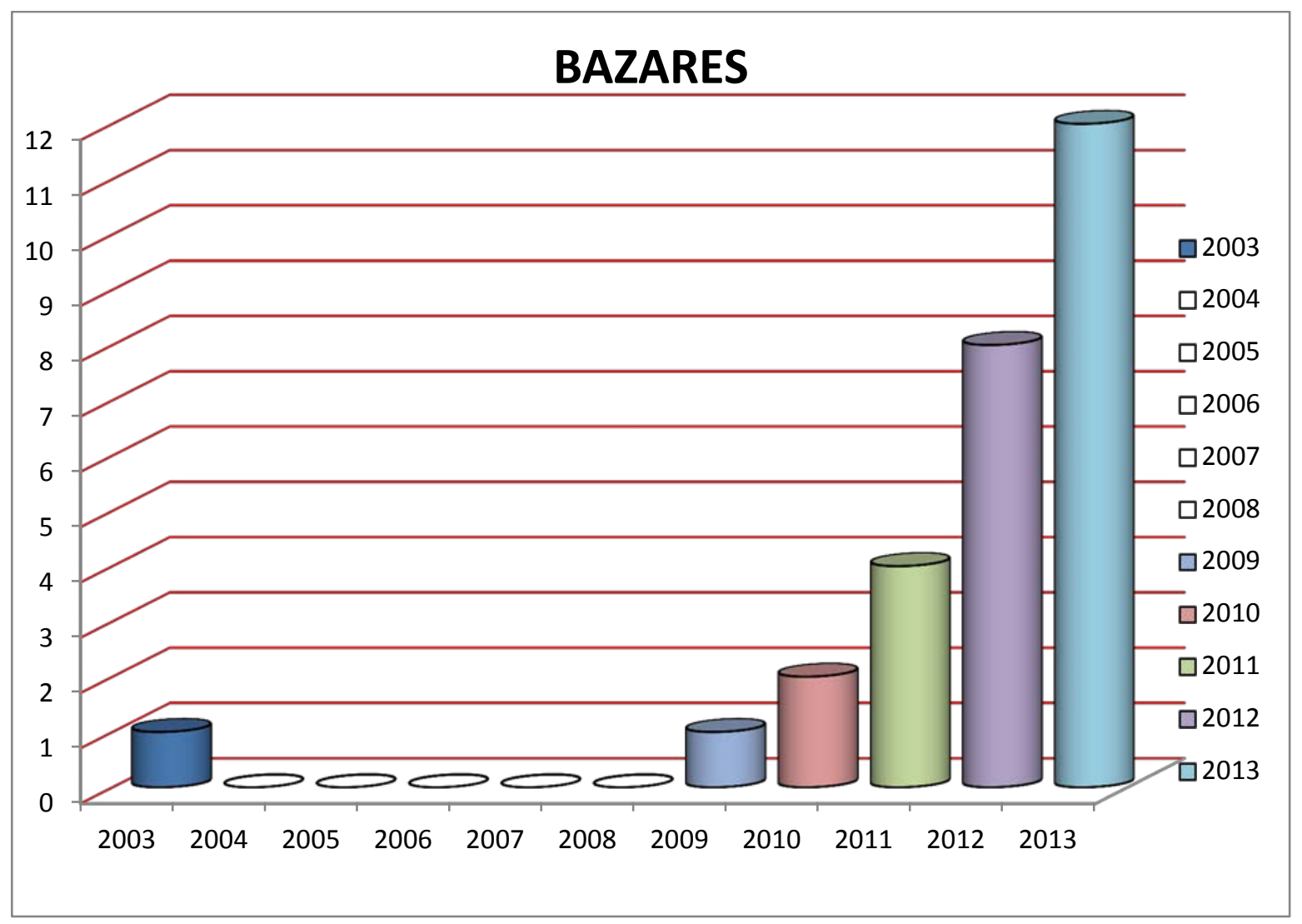

Fuente: Elaboración propia

NOTA: Se identificó que desde el gobierno local en 2013 se crearon dos bazares siguiendo este mismo modelo. Uno es el Bazar Capital que organiza el Instituto de la Juventud en el Museo Interactivo de Economía el cual tuvo dos emisiones durante el año. Por su parte, la Delegación Cuauhtémoc organiza los fines de semana el Bazar Capital en su explanada. Sin embargo no fueron incluidos en esta investigación porque no cumplían con la característica distintiva de ser independientes. 


\section{- Propiedad y control.}

Todos los bazares que forman parte del objeto de estudio de esta investigación son independientes. Esto quiere decir que surgen de la iniciativa de creadores (individuales) en diversas disciplinas que, para promover su trabajo, se coordinan con otros que de manera complementaria, pueden contribuir a través de actividades colaborativas al reconocimiento de objetivos comunes. En este sentido, se puede decir forman parte del ámbito privado ${ }^{80}$.

Existen otros, que si bien, han sido creados desde la plataforma antes mencionada, debido a diversos objetivos sociales que integran en su actividad cotidiana, deciden registrarse como Asociación Civil y es la manera a partir de la cual operan.

\section{- Tamaño.}

Si partimos de una visualización del sector cultural a través de sus organizaciones y, con base en las observaciones y estudio realizado para esta investigación, se ha identificado que el campo organizacional de los Bazares de Arte y Diseño Independiente se ubica en la intersección entre el denominado subsector de organismos asistenciales y de cooperación, coproducción internacional y el subsector de las micro y pequeñas empresas. Por lo tanto, esta imagen constituye un referente gráfico del lugar donde se insertan las organizaciones objeto de estudio:

\footnotetext{
${ }^{80}$ La mayoría están registrados ante la SHCP como Persona Física con Actividad Profesional.
} 


\section{FIGURA 4.1 UBICACIÓN DEL CAMPO ORGANIZACIONAL DE BAZARES DE ARTE Y DISEÑO INDEPENDIENTE EN EL SECTOR CULTURAL EN MÉXICO.}

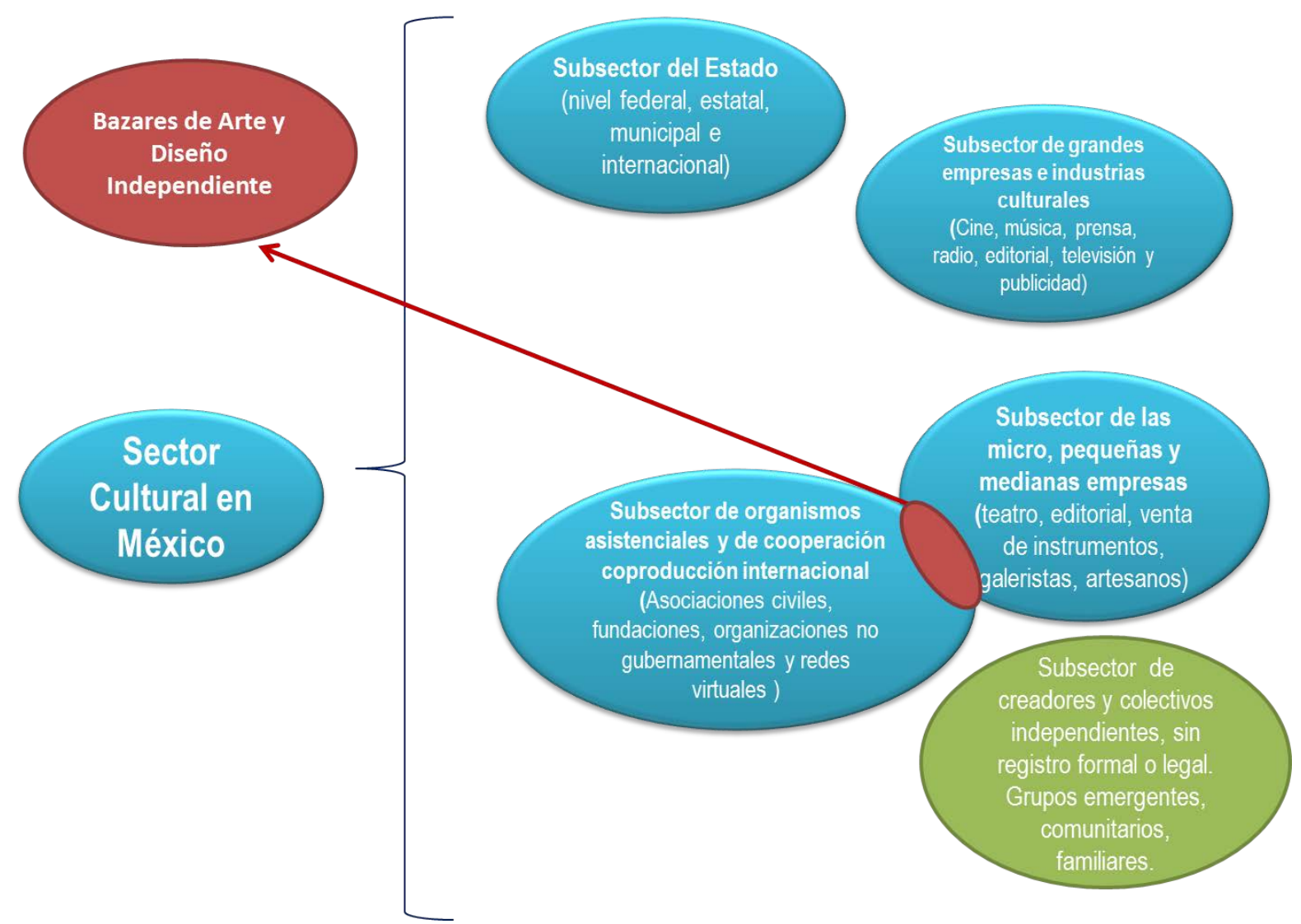

Fuente: Elaboración propia con base en información del Grupo de Reflexión sobre Economía y Cultura de la UAM-Xochimilco (2009).

NOTA: El subsector de colectivos y grupos independientes ha sido agregado en este esquema pues sin duda tiene una presencia sumamente importante en la dinámica creativa y cultural de la Ciudad de México aunque es difícil identificarlos debido a que no poseen una figura legal formalizada.

A nivel interno, los bazares son coordinados por un equipo o también llamado comité organizador integrado entre 1 y 4 personas (cabe mencionar que en todos los casos, los coordinadores son también creadores, es decir, tienen un proyecto en alguna disciplina que forma parte de la oferta del bazar). 
Para la operación del bazar (logística y montaje) cuentan con un staff de apoyo integrado por 2 o 4 personas generalmente, pero la coordinación general está a cargo de ese equipo o comité central.

Cada bazar puede ser entendido como un proyecto. Así, en promedio por evento presentan 60 propuestas/expositores (dependiendo del espacio), por lo que los responsables tienen que coordinar y dar seguimiento a todo el proceso del desarrollo de la actividad con este número de personas involucradas.

FIGURA 4.2 ORGANIGRAMA BÁSICO DE UN BAZAR DE ARTE Y DISEÑO INDEPENDIENTE

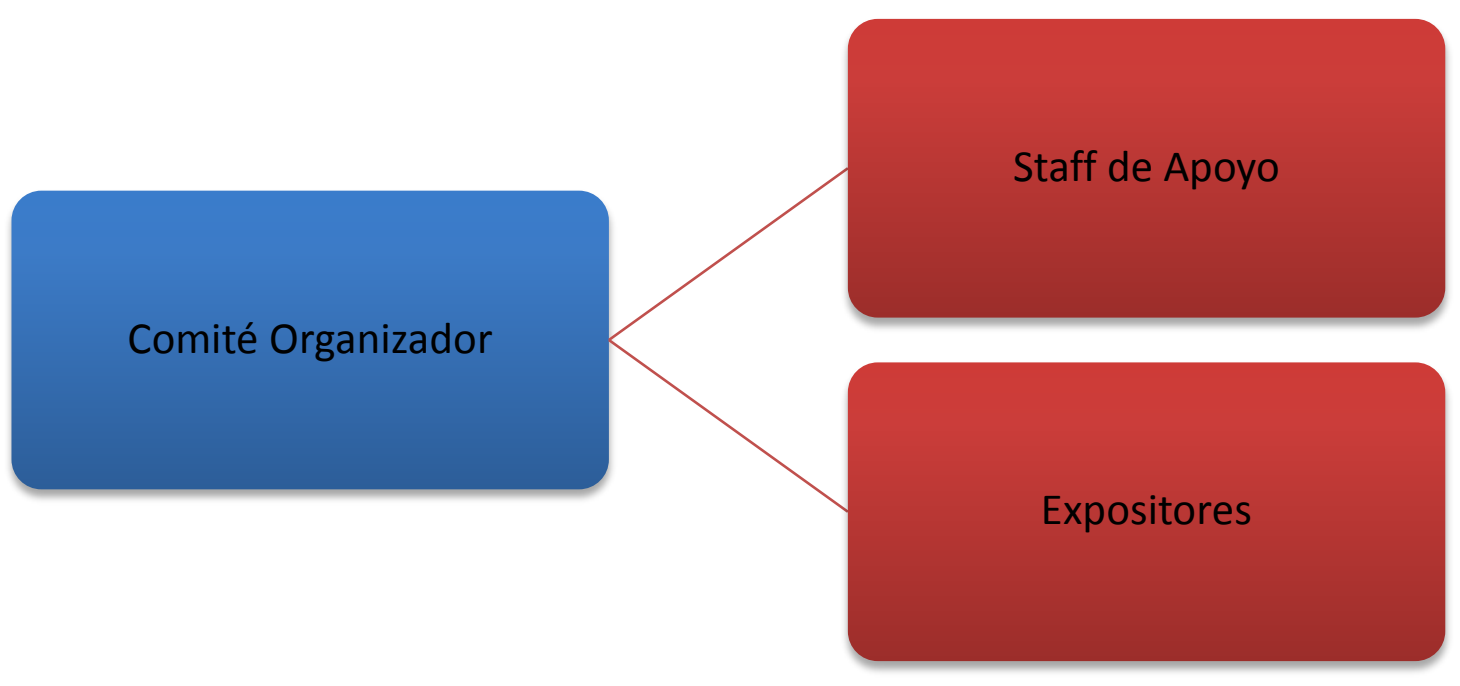

Fuente: Elaboración propia. 


\section{- Constitución.}

Como se mencionó, los Bazares de Arte y Diseño Independiente surgen de la necesidad de artistas, diseñadores -creativos en general- de difundir y comercializar su trabajo

directamente. Así, para tener una idea más clara de la manera cómo estas organizaciones visualizan y ejercen su labor, se comparten a continuación algunas presentaciones y la misión que publican en sus sitios web o redes sociales como Facebook:

Este nuevo espacio [Casa Fusión] busca ser una plataforma de proyección y difusión que impulse a los diseñadores y artistas independientes en México.

Desde el 2009, Tráfico Bazar ha sido una plataforma para la compra venta de arte y diseño mexicano, en la que jóvenes Diseñadores y emprendedores Mexicanos dan a conocer productos innovadores y nuevas tendencias de lo "Hecho en México"

Libre Liebre Bazar es un espacio de difusión y socialización de propuestas de diseño en sus diferentes vertientes que tomando en cuenta la necesidad actual de fomentar el desarrollo y fortalecimiento de un mercado que permita la vinculación directa entre consumidores y productores, identificamos que es importante un crecimiento compartido y colaborativo entre los distintos proyectos para generar redes autogestivas que permitan un crecimiento económico sano y justo.

Lonja Mercantil pretende crear comunidad ofreciendo un espacio de comercio que acerque a creativos y productores emergentes con un público diverso. El rol de la Lonja Mercantil es impulsar el diseño mexicano a nivel nacional e internacional. Cada temporada reunimos a ingeniosos cocineros, diseñadores, músicos y creativos, generando un espacio de consumo consciente y diverso. Valoramos lo mexicano, creativo, funcional, estético, responsable y de excelente calidad.

La misión de DIM consiste en ser un movimiento incluyente de artesanos y diseñadores independientes, en lucha por el reconocimiento de nuestra importancia como medio de desarrollo económico.

Vanitas es un bazar de diseño que promueve desde 2011, el trabajo de los nuevos creadores mexicanos. Impulsados por la necesidad de crear espacios que sirvan de escaparate para el talento mexicano, buscamos promover en cada edición, y de manera original y divertida, el acercamiento entre diseñadores, público y profesionales del sector.

El Perchero es una iniciativa que comenzó a partir de un sueño de 4 emprendedoras y amigas que vieron la necesidad de crear un espacio para poder potenciar sus emprendimientos.

Bazar La Ciruela es una iniciativa que promueve la cultura del consumo a artistas y talleres locales, en cuya selección se favorece a proyectos que buscan incorporar criterios de responsabilidad social y ambiental a sus procesos. El proyecto se caracteriza por estar en constante búsqueda de nuevas propuestas creativas y por conectar a los creadores con su público en un ambiente relajado, propicio para platicar sobre su trabajo, acompañado de buena comida, bebida y música, también a cargo de artistas y productores locales.

ArtDistrict, Bazar de arte, diseño e ilustración, es una plataforma que busca difundir y apoyar el trabajo de creadores de distintas disciplinas mediante la organización de talleres, bazares, conferencias y exposiciones conviviendo en un mismo recinto con la finalidad de generar una comunidad donde los creadores y público en general puedan intercambiar experiencias y conocimientos que los ayuden a potencializar el ejercicio de su trayectoria en el ámbito profesional.

Li-ARTE Bazar obedece a una iniciativa para fortalecer los puentes existentes entre los diseñadores, el arte, la moda y el público a quien van dirigidos. Buscamos ofrecer un nuevo espacio para las propuestas de creadores. 
FIGURA 4.3 BIENES Y SERVICIOS CULTURALES Y CREATIVOS QUE OFRECEN LOS BAZARES DE ARTE Y DISEÑO INDEPENDIENTE EN LA CIUDAD DE MÉXICO.

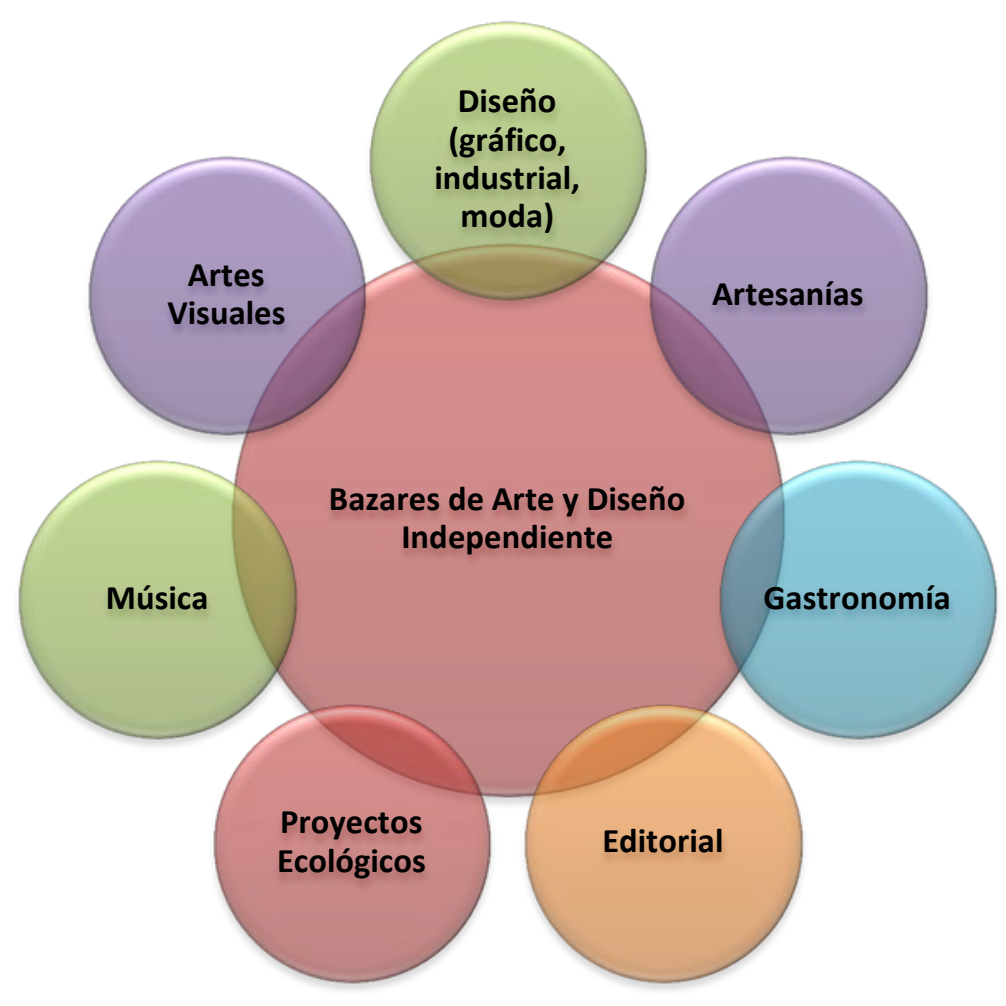

Fuente: Elaboración propia

NOTA: Se identificó además que algunos bazares han incorporado en su cartelera de actividades talleres cortos, los cuales están relacionados tanto con técnicas de producción artesanal, creativa, ecológica, como con elementos empresariales, de gestión, herramientas de difusión, etc.

De esta manera, como se puede observar, en la misión de estas organizaciones se ven reflejados y claramente asimilados los elementos de los que se ha venido discutiendo a lo largo de esta investigación. La figura (a partir de la utilización del término) del emprendedor cultural y creativo se identifica en el discurso que manejan los integrantes de los bazares. La conciencia que tienen de la relación que existe entre la actividad que llevan a cabo y el desarrollo económico y cultural es evidente. 
También se percibe un exaltación clara de lo local a partir del impulso y compromiso con lo "hecho en México", lo cual justifica y enmarca su existencia, elementos que además contribuyen en su legitimación. Finalmente, a partir de la identificación de las actividades que promueven, se puede ver que éstas forman parte del esquema ampliado de las industrias creativas propuesto desde la UNCTAD (2010).

\section{- Ubicación}

\section{FIGURA 4.4 UBICACIÓN POR DELEGACIÓN DE LOS BAZARES DE ARTE Y DISEÑO INDEPENDIENTE EN LA CIUDAD DE MÉXICO.}

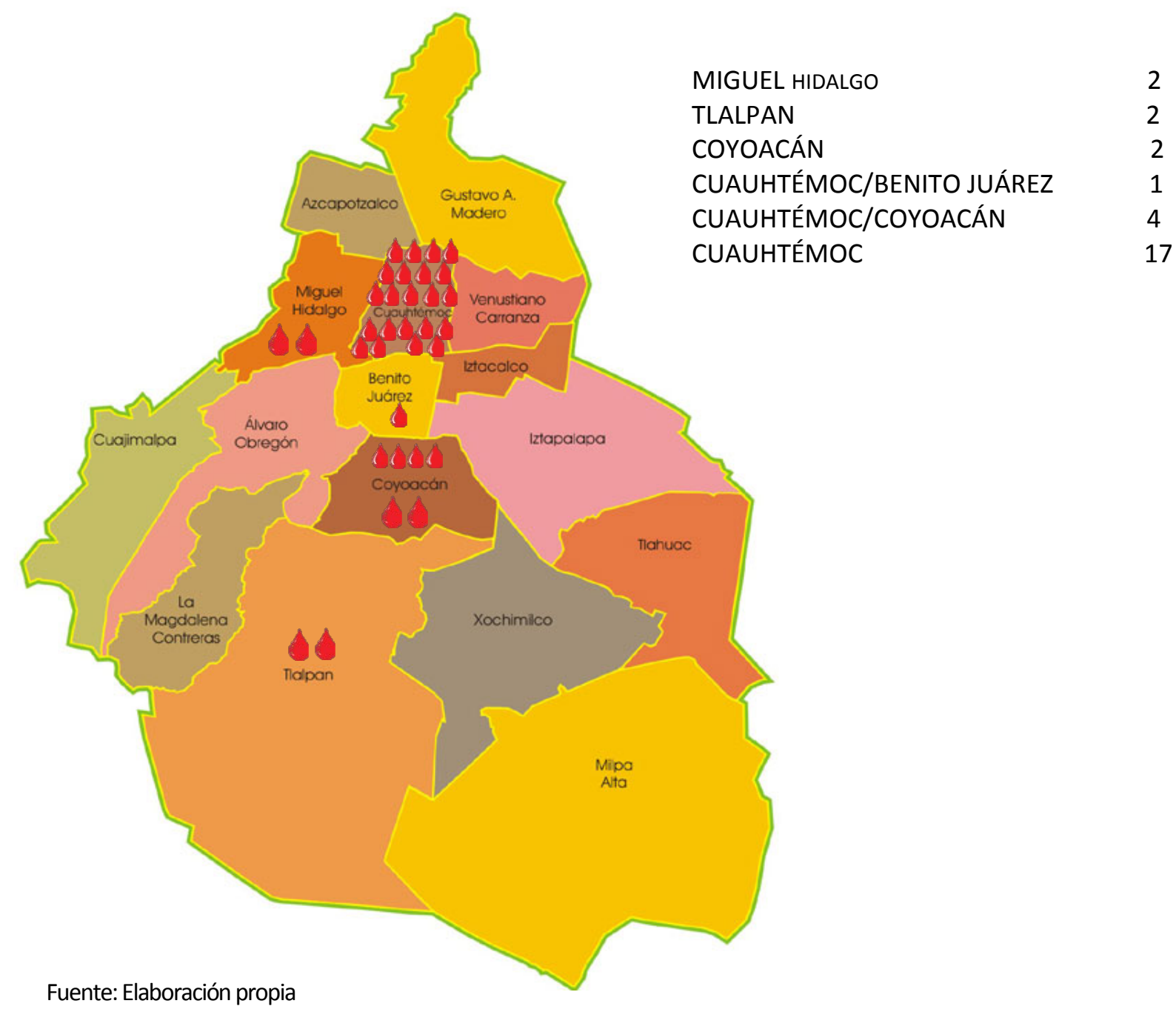


Este mapa permite visualizar que existe una alta concentración de Bazares de Arte y Diseño Independiente en la delegación Cuauhtémoc, siendo puntos estratégicos las colonias Roma y Condesa (plazas públicas, parques, espacios culturales, universidades e incluso casas particulares), así como la zona del Centro de la Ciudad (cantinas, pasajes comerciales, museos). Coyoacán, a través de las casas de cultura, también constituye un punto de encuentro importante y es una zona que tradicionalmente ha acogido este tipo de proyectos. En las otras demarcaciones, los sitios elegidos para la organización de los bazares han sido parques e instalaciones privadas.

\section{- Interdependencia.}

Para la organización de los Bazares, son fundamentales las relaciones de vinculación que se establecen con individuos y organizaciones de diversos sectores para alcanzar tanto el éxito del evento como su continuidad.

Como se señaló, muchos bazares son organizados en espacios públicos, razón por la cual las relaciones con el gobierno delegacional que corresponda son indispensables por todo lo que tiene que ver con permisos y licencias. El ámbito de la iniciativa privada participa principalmente como patrocinador (lugar, materiales, publicidad, equipo, etc.). La relación con el sector social es importante por el trabajo de vinculación entre organizaciones con objetivos complementarios así como por el soporte que dan a alguna causa en particular como parte del evento. Asimismo, el apoyo de los habitantes de la zona donde se lleva a cabo el bazar es fundamental debido a que este tipo de actividades contribuyen al rescate del uso del espacio público al tiempo que generan comunidad a través de ese punto de reunión. Los medios de comunicación también son aliados estratégicos para difundir las actividades que se realizan y constituyen instrumentos claros de legitimación del trabajo realizado. Finalmente, el público que asiste y consume estos productos es necesario para completar el ciclo de producción cultural. 
Lo anterior queda reflejado en el siguiente esquema.

FIGURA 4.5 RELACIONES DE VINCULACIÓN DE LOS BAZARES DE ARTE Y DISEÑO INDEPENDIENTE CON DIVERSAS ORGANIZACIONES Y SECTORES.

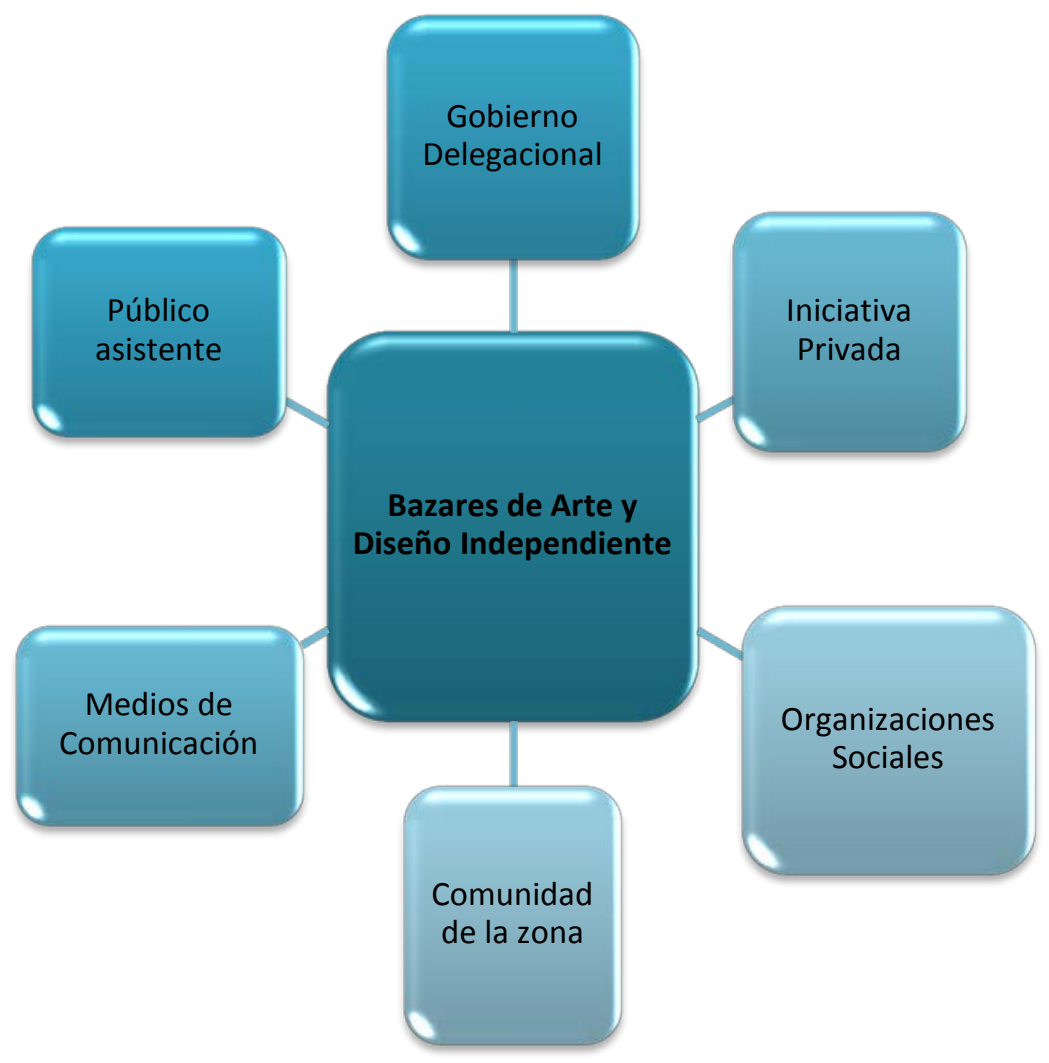

Fuente: Elaboración propia.

Obviamente esto se refiere a las relaciones con el entorno inmediato, sin embargo, resulta claro que también requieren de un contexto más amplio que les sea favorable con políticas públicas para el reconocimiento e impulso de esta actividad. 


\subsubsection{Dimensiones de la estructura organizacional}

\section{- Especialización}

Si bien existe un alto grado de especialización y profesionalización de los individuos que forman parte de los Bazares de Arte y Diseño Independiente, -la mayoría de los coordinadores y expositores tienen estudios universitarios en diversas áreas, las cuales no son únicamente artísticas sino que son recurrentes disciplinas como la administración, diseño, arquitectura, ingeniería, mercadotecnia, publicidad y comunicación por mencionar algunas-, como otras organizaciones del sector cultural, se caracterizan más bien por la polivalencia o multifuncionalidad de las acciones que sus integrantes llevan a cabo, debido a que son organizaciones sumamente pequeñas y, por ende, una misma persona debe desarrollar más de una actividad.

De esta manera, con base en la observación de las actividades realizadas por los coordinadores de los bazares así como por el seguimiento que se hizo al trabajo y trayectoria de algunos creadores que forman parte de éstos como expositores, se divide en dos la descripción de estos procesos:

1. Los coordinadores (independientemente de la formación profesional que tengan) realizan de manera simultánea las siguientes actividades: logística para la realización del bazar (trámite de permisos y autorizaciones, pago de derechos a la delegación, renta de tablones, sillas, lonas, elaboración del material de difusión, etc., supervisión de montaje y desmontaje); administración de recursos financieros; difusión en medios de comunicación y redes sociales (Facebook y Twitter principalmente), tanto de la convocatoria como del evento; seguimiento de la convocatoria para la selección de proyectos participantes, búsqueda y establecimiento de alianzas con otros actores y organizaciones (patrocinios, impartición de talleres, realización de alguna conferencia, etc.) para la sostenibilidad y crecimiento del bazar. 
2. Los expositores (hay que recordar que los coordinadores de bazares también participan como expositores) además de llevar a cabo todo el proceso de creación de su producto o servicio creativo -el cual obviamente es diferente en cada caso- se encargan también de manera simultánea de la administración de sus recursos financieros; la búsqueda de convocatorias para participar en los diversos bazares y programar su agenda mensual; identificación de nuevos puntos de venta, difusión de su marca en medios de comunicación, redes sociales, eventos, por mencionar las más importantes y que se realizan de manera cotidiana.

De tal manera, se puede afirmar que la especialización de funciones es mínima en este tipo de organizaciones, sin embargo, en la medida en que más personas se van integrando a la organización (las cuales tienden a contar con formación profesional especializada) se podría pensar que esto de la multifuncionalidad puede reducirse en algún momento de la vida de la organización.

\section{- Estandarización}

Con base en el seguimiento de la actividad de los Bazares de Arte y Diseño Independiente, se pudo identificar que si bien muchas de las actividades que realizan son similares entre éstos, las convocatorias para seleccionar a los participantes en los bazares, son uno de los procedimientos más estandarizados y que comparten las mismas características y requerimientos en prácticamente todos los bazares.

Para tal efecto, la utilización de tecnologías de la información es una herramienta fundamental en dicho proceso, ya sea a través del diseño de un formulario que se llena en línea o a partir del envío de documentación y demás requisitos a través de correo electrónico o redes sociales. 
Los requisitos para la selección de los productos y servicios que formarán parte de los bazares son los siguientes:

- Elaborado en México

- Originalidad

- Innovación en términos de diseño

- Calidad (materiales, acabados, tecnologías, procesos)

- Nivel de producción (para cubrir la demanda de los bazares)

- Enviar entre 5 y 8 fotografías de los productos

- Descripción general del concepto de la marca

El proceso de realización de un bazar, desde la publicación de la convocatoria hasta la exposición ante el público se muestra en la siguiente figura

FIGURA 4.6 PROCESO DE REALIZACIÓN DE UN BAZAR

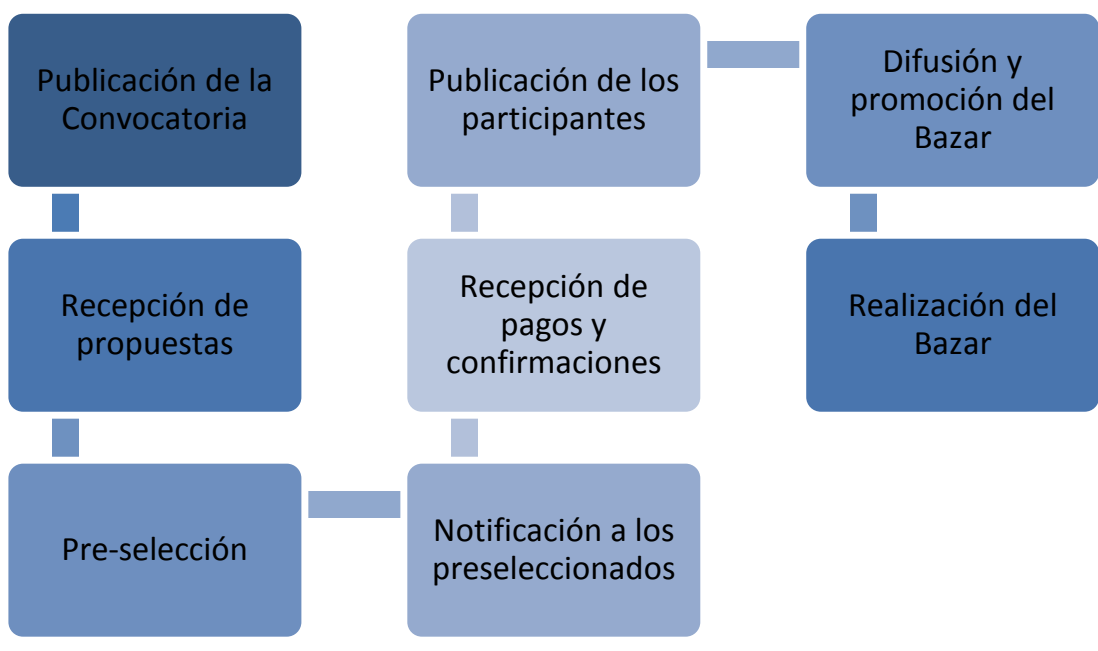

Fuente: Elaboración propia

NOTA: Bazar Fusión es la única organización en donde se identificó que posterior a la preselección se realiza una entrevista personal con los creadores para hacer la selección final. 


\section{- Formalización}

El nivel de formalización en los Bazares de Arte y Diseño Independiente se puede considerar bajo $^{81}$. Si bien, como se mencionó anteriormente, la convocatoria para participar es el procedimiento más estandarizado y, en ese sentido, está escrito formalmente, los demás temas referentes a la participación de los creadores en el evento se van atendiendo en el momento en que surgen ${ }^{82}$.

En conversaciones con creadores y coordinadores de bazares, éstos mencionaron que la manera a partir de la cual se resuelven dudas, algún problema o inconformidad, es a través del contacto directo con el organizador (vía telefónica, mail, redes sociales). Asimismo, prácticamente todos los Bazares, de cada evento crean un "grupo en Facebook" para compartir información que pudiese resultar de interés para la mayoría de los participantes en ese evento en particular. En ese mismo espacio se realiza frecuentemente al final una evaluación del evento.

\section{- Centralización}

Los coordinadores de los bazares se encuentran al centro de la toma de decisiones importantes en torno al evento y la dirección que tomará el desarrollo del bazar en el tiempo. Son ellos los que determinan las fechas, la sede, los requerimientos para participar, los precios del espacio. Asimismo, son responsables antes, durante y después del evento de todas las actividades del mismo.

\footnotetext{
${ }^{81}$ Con base en la información a la que se tuvo acceso, solo DIM cuenta con Manuales propiamente dichos (Manual de Expositor, Manual de Logística, Reglamento para el Expositor), los cuales se envían a los participantes en formato PDF por correo electrónico al ser confirmada su participación.

${ }^{82}$ Se identificó que posterior a la confirmación de los expositores, los organizadores envían de manera escrita el procedimiento: horarios de montaje, las características del espacio que ocuparán, etc. pero no es un documento formal.
} 
En algunos casos, la centralización en la toma de decisiones y resolución de conflictos se divide por áreas de acuerdo a las disciplinas que integra, por ejemplo, existe la figura de coordinación de moda, coordinación de gastronomía, coordinación de artesanías, coordinación de arte, etc.

\section{- Tradicionalismo}

Si bien la rotación de propuestas de diseño entre los bazares es uno de sus elementos característicos a fin de tener siempre opciones nuevas y, en esa medida, ofrecer dinamismo al sector, existen proyectos que de manera casi permanente participan en las diversas ediciones que se organizan durante el año o que incluso tienen ya varios años colaborando con algún bazar en específico. En este sentido, su participación aunque no esté escrita o firmada en ningún lugar, se empieza a "normalizar" o hacerse costumbre pues el creador ya conoce los procedimientos, las formas de organización, etc. y esto no sucede únicamente respecto a un bazar sino prácticamente con todos, pues funcionan de manera similar.

\section{- Configuración}

Esta variable se desarrolla de manera un poco más amplia recurriendo las aportaciones de diversos autores que desde la perspectiva institucional abordan los determinantes en la configuración organizacional.

Sobre las configuraciones se dice que éstas "pueden representarse en tipologías desarrolladas conceptualmente 0 capturadas en taxonomías derivadas empíricamente" (Meyer, Tsui, y Hinings 1993: 1175). Pero, siguiendo con estos autores, ¿Qué limita el número de configuraciones organizacionales? Si bien, dado el dinamismo del ámbito de lo organizacional las posibles combinaciones pueden ser numerosas, para los teóricos que asumen la perspectiva configuracional, "esta variedad de atributos tiende a caer en patrones coherentes" (Meyer, Tsui, y Hinings 1993: 1176). 
Así, los autores arriba mencionados sugieren que existe una diversidad de fuerzas que determinan la forma que toman las organizaciones en diversos contextos. De esta manera, "la perspectiva institucional considera al diseño organizacional no como proceso racional basado en metas organizacionales, sino más bien como proceso de presiones, tanto externas como internas, que lleva a las organizaciones en un campo a asemejarse unas con otras con el paso del tiempo. En esta perspectiva se percibe a las opciones estratégicas como proviniendo del orden institucional donde se inserta una organización" (Hall, 1996b: 116). Entonces, se puede ver que las organizaciones van adaptando su diseño en función de las características del ambiente en el que están insertas con el propósito de tener mayores posibilidades de sobrevivir.

De aquí deviene la pertinencia de la postura configuracional, ya que "representa una postura holística, una afirmación de que las partes de una entidad social toman su significado del conjunto y no se puede entender de forma aislada" (Meyer, Tsui, y Hinings 1993: 1178), por lo tanto, resulta claro, como se ha afirmado previamente, que de manera constante los actores organizacionales están a la búsqueda de innovaciones para poder insertarse en los entornos altamente complejos y dinámicos.

Greenwood y Hinings (1988, citados en Demers, 2007:54) "adoptan la explicación neo-institucionalista y llaman la atención sobre los orígenes sectoriales de los esquemas interpretativos. En su opinión, las organizaciones se integran en un marco institucional que legitima sólo un número limitado de los arquetipos de diseño y, por lo tanto, los esquemas interpretativos".

De esta manera y, de acuerdo con las críticas en torno a que las categorizaciones y generalizaciones pueden limitar la diversidad organizacional, también es cierto que la identificación de características puntuales en distintos tipos de organizaciones facilita el trabajo de aproximarnos a su estudio. 
Desde luego, el objetivo final (al menos de esta investigación) no será establecer condiciones inalterables para describir un campo organizacional, sin embargo, la perspectiva configuracional ofrece una guía útil desde la cual iniciar su estudio en esta primera etapa.

\subsection{Elementos clave en la Configuración Organizacional de los Bazares de Arte y Diseño Independiente de la Ciudad de México.}

Para continuar con al análisis de la configuración organizacional de los Bazares de Arte y Diseño Independiente y, con base en las características básicas que se definieron anteriormente, debido a que la mayor parte de éstos son de reciente creación -24 de ellos surgieron entre 2011-2013-, lo que coincide con lo establecido por Mintzberg (1989: 139), "la mayoría de las organizaciones de las áreas empresariales, gubernamentales y no lucrativas pasan por la configuración empresarial durante sus años de formación, durante la puesta en marcha" debido a que requieren de un liderazgo muy específico que las impulse en un inicio.

En este sentido, además de la juventud que los caracteriza, se puede identificar además otra particularidad de los Bazares de Arte y Diseño Independiente y es "su sentido de misión" en donde los participantes se identifican con ésta y constituye una de las razones principales por las cuales se interesan en formar parte de la organización. Esta cualidad también puede relacionarse en parte con la configuración de tipo misionero, ya que "se considera que una ideología es un rico sistema de valores y creencias sobre una organización, compartido por sus miembros que lo distingue de otras organizaciones... la característica clave de tal ideología es su poder unificador: ata al individuo a la organización, generando un "esprit de corps", un "sentido de misión", en realidad una integración de objetivos individuales y de la organización que puedan producir la sinergia" (Mintzberg, 1989:261). 
Si bien en la dinámica cotidiana de los Bazares este sentido de pertenencia no es tan estricto, sin duda, la manera como cada bazar a través de la redacción de su misión como organización pretende distinguirse del resto, es un elemento fundamental para que las personas busquen formar parte y permanecer en éste. En esta misma línea, también se identificaron los siguientes argumentos:

"Entre las ventajas que encuentro es que en DIM son muy organizados, son transparentes y a pesar de que no hay nada firmado ni formal son muy derechos y eso se valora mucho. Hay mucha planeación detrás de cada evento, difusión. Incluso durante el evento te apoyan, te rentan la terminal de tarjeta de crédito. Además se mueven muchísimo para conseguir otros eventos y cursos para los expositores. A pesar de no estar formalizada la relación en el bazar, hay mucho compromiso por parte de todos"

[Beu Moda y Accesorios]

"Hay gente que piensa que Tráfico Bazar es un <<mercadito >> o un $<<$ bazarcito >> pues nooo. Es un evento en donde participan alrededor de 70 expositores de marcas mexicanas, súper lindas, de excelente calidad, con mucha creatividad y auténticas" [Deseare Accesorios]

Al mismo tiempo, no hay que olvidar que "los individuos que se juntan no lo hacen al azar, sino que coalescen porque comparten algunos valores correspondientes a la organización en ciernes. Como mínimo ven algo en ella para sí mismos. Pero en algunos casos, además de la misión per se hay un <<sentido〉>" (Mintzberg, 1989:263).

"La gran mayoría de las marcas que participan en eventos como los bazares lo hacemos porque no podemos tener una tienda propia y más cuando vas empezando. Una de las primeras ventajas es que te contactan de otras tiendas en donde puedes vender tu producto" [Beu Moda y Accesorios]

"Participar en Vanitas nos gusta por varias razones. La organizadora tiene un trato muy personal con cada uno de los expositores así que el flujo de comunicación es más colectivo y uno se siente apoyado durante todo el proceso de organización del Bazar. Además, tenemos amigos de los bazares, incluso se han hecho reuniones con ellos, de hecho se puede decir que hay mucha confianza entre los expositores" [Mowteville]. 
Al hablar de organizaciones cuyo objetivo central es la comercialización de productos y de servicios culturales y creativos, lo que identifican de inicio como benéfico para su iniciativa es la posibilidad real de difundir y obtener ingresos por sus creaciones, sin embargo, ese no es el único motivo para que decidan formar parte de un bazar, también es fundamental para ellos la congruencia y responsabilidad del bazar tanto con los creadores como con el entorno.

Así que, con las debidas limitantes, se podría identificar también este tipo de organizaciones con las misioneras reformadoras, las cuales "se proponen cambiar el mundo directamente" (Mintzberg, 1989:271), los bazares en específico (como se observó en sus presentaciones) pretenden posicionar y legitimar el trabajo creativo hecho en México y ese argumento les ha servido para además integrar el campo de los Bazares, en donde más allá de la competencia obvia que existe por tener el mejor lugar, las mejores marcas, el posicionarse como proyecto; esta tarea de compromiso conjunto por el reconocimiento del trabajo creativo hecho en México constituye un eje transversal que de alguna manera los integra como comunidad.

Por otra parte, la denominada organización Innovadora o Adhocrática también constituye un referente interesante y útil en la tarea de caracterizar a los Bazares de Arte y Diseño Independiente. En palabras de Mintzberg (1989: 231), "la innovación sofisticada requiere una configuración que sea capaz de fusionar a expertos procedentes de diferentes disciplinas en equipos para proyectos ad hoc que funcionen apaciblemente".

Así, "tenemos una estructura altamente orgánica, con poca formalización del comportamiento... Innovar quiere decir romper con los patrones establecidos. Así pues, la organización innovadora no puede depender de ninguna forma de normalización para su coordinación. Por encima de todo tiene que ser flexible" (Mintzberg, 1989: 233). 
Para tal efecto, "los directivos de la Adhocracia tienen que ser maestros en las relaciones humanas, ser capaces de usar la persuasión, negociación, coalición, reputación y armonía para fusionar a los expertos individualistas en equipos de funcionamiento fluido. También tienen que dedicar mucho tiempo a vigilar los proyectos. Quizá el papel más importante de la alta dirección de esta configuración sea el enlace con el entorno exterior" (Mintzberg, 1989: 241). Los elementos previos se identificaron plenamente en la manera de operar de los Bazares de Arte y Diseño Independiente, ya que si bien en la organización existe centralización en la toma de decisiones, no se percibe que éste sea un proceso que se imponga, así que más que dar órdenes, la tarea es coordinar ${ }^{83}$.

"No es fácil pero tratamos de establecer vínculos con cada una de las marcas. Para nosotros es muy importante el trabajo de cada uno de ellos y lo sabemos puesto que también somos expositores y eso sin duda marca la diferencia. Tratamos de crear empatía y estamos disponibles siempre.

Hay ocasiones que a mi me han hablado a las 11 de la noche porque tienen una duda del evento. $Y$ eso es parte del compromiso que asumimos desde que lanzamos el proyecto y no nos vamos a echar para atrás. Así, creamos vínculos con las marcas, estamos al pendiente. Cuidamos ese lado humano que es importantísimo y tratamos de tenerlo siempre presente, escuchamos, tenemos juntas frecuentemente" [Diseñadores Independientes Mexicanos]

En esta manera de trabajar, se percibe un cambio de paradigma que implica la transición del dominio del trabajo individual al trabajo en equipos, el cual de acuerdo con los estudiosos del tema se da a partir de la década de los ochenta y entre otros factores, surge por "las múltiples innovaciones de carácter tecnológico y la complejidad que conllevan hacen necesaria la participación de las personas en equipos, de modo que puedan unir los conocimientos y habilidades que ellas requieren, trabajar a distancia, etc. lo que a su vez permite a las organizaciones dar respuesta a la necesidad de estructuras flexibles capaces de movilizar recursos con rapidez para adaptarse a entornos cambiantes" (Alcover de la Hera, 1998).

\footnotetext{
${ }^{83}$ Esto se afirma desde una mirada externa, para determinar en cada caso cómo es la dinámica en el proceso de gestión de recursos humanos se tendría que hacer un estudio particular en una organización para incluso identificar zonas de tensión y conflicto entre los involucrados, pero eso excede los límites y objetivos de esta investigación, por lo que es uno de los rubros que quedan pendientes para futuras investigaciones en el tema.
} 
Vinculando esta información con la dinámica operacional de los Bazares de Arte y Diseño Independiente, vemos que cada evento es equiparable a un proyecto en otro tipo de organización (con unas características y temporalidad determinada), entonces para entender su forma de operar, resulta de utilidad lo que propone el modelo matricial (Daft, 1998) el cual promueve un enfoque orgánico en donde para la eficacia o eficiencia de la organización se valora el desempeño colectivo sobre el individual, puesto que las decisiones y los ajustes son producto de la implementación de estrategias de colaboración.

Esta circunstancia, nos lleva a revisar lo referente a los límites organizacionales y las consecuencias que tienen en el funcionamiento, tanto de los equipos de trabajo como de las organizaciones en su conjunto, aspecto que es fundamental y determina la diferencia entre los Bazares de Arte y Diseño Independiente con otro tipo de organizaciones.

En opinión de Guzzo (1996 citado en Alcover de la Hera, 1998: 43) uno de los probables ámbitos donde se podrán apreciar los cambios a los que se verán sometidos en el futuro los equipos en las organizaciones es el relativo a la creciente erosión de los límites de los grupos de trabajo. Según el autor, los aspectos fundamentales son los siguientes:

1. Utilización de tecnologías informáticas

2. Miembros que pertenecen simultáneamente a múltiples equipos

3. Prácticas de trabajo flexibles 
Este tema de la erosión de los límites organizacionales es sumamente pertinente porque hay que destacar el hecho de que este tipo de organizaciones, al no tener un espacio físico de manera estable al que se pueda llamar oficina, empresa, etc., han aprovechado esta circunstancia que, seguramente en otro entorno con una lógica de funcionamiento distinta sería un gran problema, pero para estas organizaciones más que un obstáculo ha resultado una forma de optimizar recursos y, con el paso del tiempo, han demostrado que puede funcionar y han logrado desarrollar equipos de trabajo con un amplio sentido de pertenencia aunque no estén en el mismo lugar.

En esta tarea, la utilización de tecnologías informáticas constituye un eje crucial que ha facilitado que esta forma de organización exista ya que, como se revisó, gran parte de su gestión, coordinación, seguimiento y evaluación se lleva a cabo a través del uso de TIC's en donde por medio de estrategias diversas logran generar comunidad, tanto con los expositores que forman parte de los bazares como con el público que asiste a éstos.

De hecho, en las redes sociales es reiterado el uso del término "bazareños", "comunidad bazareña de la Ciudad de México" (así como nombres específicos de cada bazar), por lo que se logra identificar que hay un reconocimiento entre ellos mismos como parte de un conjunto de profesionales que se desarrollan en un área particular.

Por otro lado, la movilidad y participación simultánea de los creadores en otros bazares le imprime un sello característico y favorece de manera importante el proceso de definición institucional del campo de acuerdo a lo que establecen (DiMaggio y Powell, 1999: 106), ya que aumenta el grado de interacción entre las organizaciones, al tiempo que la colaboración y el intercambio constante de información permite que se estrechen los vínculos mientras que facilita que la comunidad entera se identifique como parte de un grupo con un proyecto en común, lo cual constituye una de sus grandes fortalezas. 
Finalmente, como se pudo observar a lo largo de este apartado, el tema de la configuración organizacional no es para nada simple. A medida que la relación con el entorno es cada vez más compleja y dinámica, "las dimensiones se agregan para aumentar la congruencia con la realidad, las configuraciones necesariamente se vuelven más complejas y difíciles de manejar. Sería ingenuo pensar que la taxonomía perfecta es la que reproduce perfectamente la realidad" (Meyer, Tsui, y Hinings 1993: 1182).

En este sentido, el diseño configuracional constituye sobre todo un ejercicio reflexivo al tiempo que debe facilitar la coordinación y estimular la participación de los individuos que forman parte de la organización. Así, vemos que lo que caracteriza a las organizaciones contemporáneas en general es su capacidad de gestión con base en la coordinación del trabajo interdisciplinario y colaborativo, como en el caso de los Bazares de Arte y Diseño Independiente, en donde a partir de lo limitado de los recursos y lo adverso del entorno, se hace imprescindible asumir riesgos y los obstáculos convertirlos en oportunidades, en donde la creatividad para innovar y aprender ha resultado fundamental. 
FIGURA 4.7 ELEMENTOS CLAVE DE LA CONFIGURACIÓN ORGANIZACIONAL DE LOS BAZARES DE ARTE Y DISEÑO INDEPENDIENTE DE LA CIUDAD DE MÉXICO:

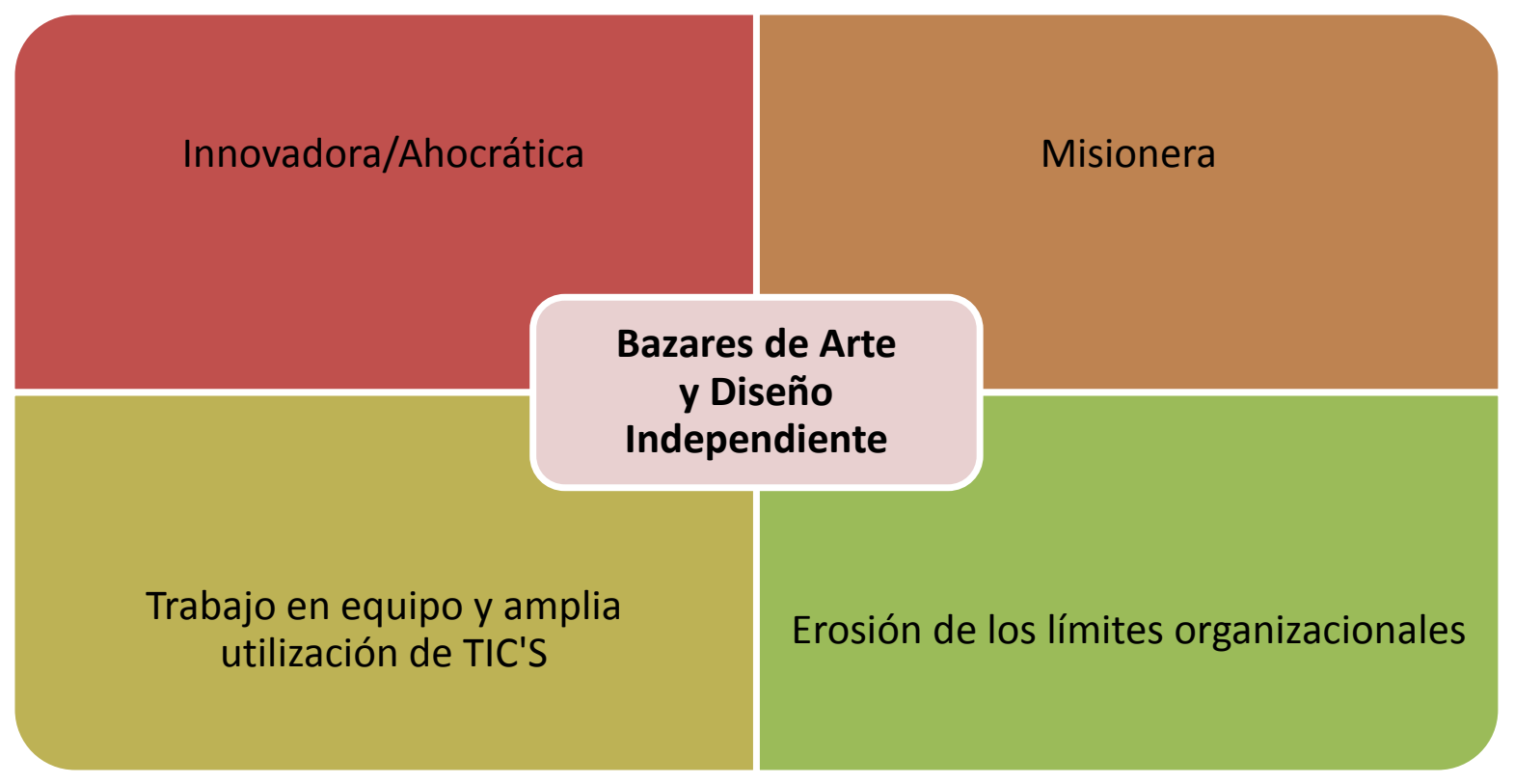

Fuente: Elaboración propia

4.5 Los campos de imitación como traducción: el surgimiento de un campo organizacional de Bazares de Arte y Diseño Independiente en la Ciudad de México.

Coincidiendo con lo que proponen Hedmo et al. (2005) respecto de que la imitación es una forma social básica, "no resulta sorprendente que los actores se imitan unos a otros, se recomiendan unos a otros y se reconocen como modelos referenciales importantes". 
Así, después de desarrollar en el marco teórico las características de los modos de imitación, ahora toca describir cómo se han manifestado en el terreno de los Bazares de Arte y Diseño Independiente de la Ciudad de México para verificar que el campo ha surgido al ser un área institucional reconocida, que además cumple con las características establecidas por los estudiosos institucionalistas ${ }^{84}$.

Sugieren tres modos de imitación: el de Transmisión, la Cadena de Imitación y el Mediado. El Modo de Transmisión, recordemos tiene las siguientes características:

- Se basa en un modelo específico o un conjunto central de ideas elegidas por los actores en diversos ámbitos.

- Surge un modelo central único que se convierte en un prototipo para ser imitado.

- La imitación es dirigida por la participación activa, iniciativa y motivos de aquellos que hacen la imitación.

- Tanto los imitados como los imitandos son formadores activos del proceso

Ahora bien, en el caso de lo que ha sucedido con los Bazares de Arte y Diseño Independiente, en términos gráficos el fenómeno puede representarse de la siguiente forma

\footnotetext{
${ }^{84}$ Como se explicó a detalle en el apartado previo de este capítulo, existe un aumento en el grado de interacción entre las organizaciones en el campo; se ha dado el surgimiento de estructuras interorganizacionales de dominio y patrones de coalición claramente definidos; existe un incremento en la carga de información de la que deben ocuparse las organizaciones que participan en un campo y también se ha dado el desarrollo de la conciencia entre los participantes de un conjunto de organizaciones de que están en una empresa común (DiMaggio y Powell, 1999: 106).
} 
FIGURA 4.8 MODO DE TRANSMISIÓN PRESENTE EN EL SURGIMIENTO DEL CAMPO ORGANIZACIONAL

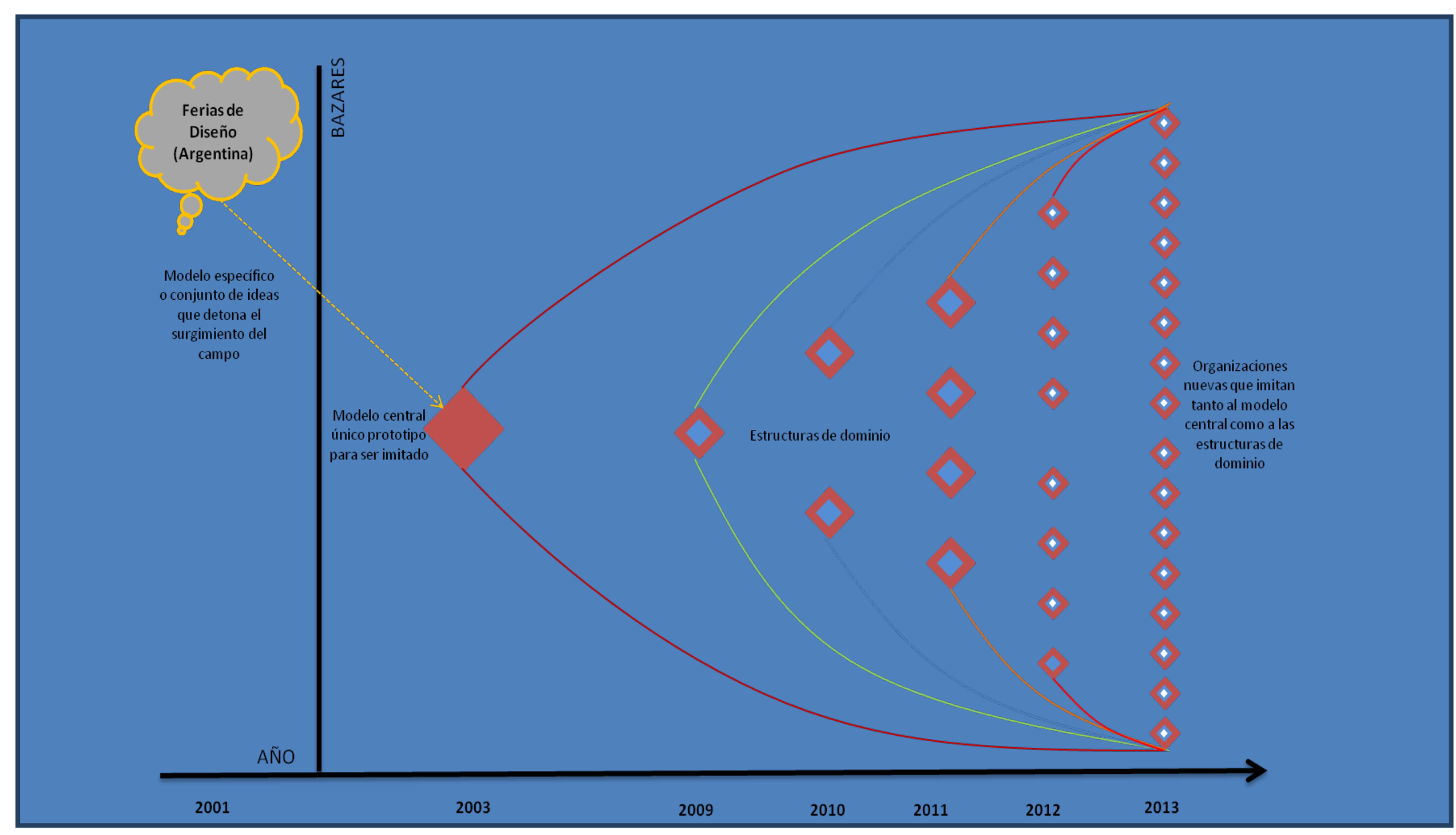

Fuente: Elaboración propia. 
Como se ha señalado, la imitación es dirigida por la participación activa, iniciativa y motivos de aquellos que hacen la imitación. En el caso del surgimiento de los Bazares de Arte y Diseño Independiente, muchos de ellos emanaron de la decisión de las marcas o proyectos que participaron previamente en algunos bazares $y$, a partir de ahí, identificaron tanto un área de oportunidad como negocio así como problemas o deficiencias que detonaron que se organizaran con otros emprendedores con ideas similares para, con ese referente, iniciar su propio bazar.

En palabras de sus organizadores, se encontraron los siguientes argumentos o razones del porqué de su creación:

"Nuestra misión es crear una educación y cultura del consumo de lo hecho en México, de crear conciencia de nuestra economía y ser el sujeto responsable de su mejoría. Apoyen a los pequeños productores, a los emprendedores, lo hecho en México está bien hecho" [Tráfico Bazar]

"Tomando en cuenta la necesidad actual de fomentar el desarrollo y fortalecimiento de un mercado que permita la vinculación directa entre consumidores y productores, identificamos que es importante un crecimiento compartido y colaborativo entre los distintos proyectos, para generar redes autogestivas que permitan un crecimiento económico sano y justo" [LIBRE Liebre Bazar]

"El Perchero es una iniciativa que comenzó a partir de un sueño de 4 emprendedoras y amigas que vieron la necesidad de crear un espacio para poder potenciar sus emprendimientos"

[EI Perchero. Mujeres Emprendedoras]

"Lonja mercantil surge en 2010 con el objetivo de promover y enaltecer lo hecho en México. Es una plataforma inspirada en los tradicionales mercados sobre ruedas que ha cambiado la manera de consumir diseño nacional al ofrecer una experiencia única de compra. Cada edición de La Lonja Mercantil es diferente, somos un evento comercial itinerante que promete siempre presentar a nuevos diseñadores"

"Bazar de Barrio es un mercado local organizado por polen diseño vivo, que promueve y reúne lo mejor del diseño innovador mexicano. Un espacio para convivir y conocer a la gente del barrio, la gente de nuestra tradicional Colonia Roma, para formar una comunidad en donde se podrá comprar piezas únicas, degustar ricos platillos, una cerveza o un mezcal, compartir y difundir el diseño mexicano emergente".

"La intención de Art District es propiciar la interacción y la construcción de relaciones entre diseñadores, publicaciones, creadores y personas en general, en un ambiente informal de fiesta y convivencia". 
Si bien muchos de los Bazares de Arte y Diseño Independiente han surgido con base en el referente de Bazar Fusión, esto no quiere decir que lo imitan del todo, es claro que los actores pasan por un proceso de edición y selección de lo que quieren imitar, de hecho, muchos han surgido bajo la premisa de "ser diferentes", "ser inclusivos".

En esta línea se puede destacar de manera prioritaria el discurso de los nuevos proyectos de impulsar y defender el diseño mexicano, hecho por creadores mexicanos, ya que al ser Fusión un espacio coordinado por extranjeros y que de manera constante presenta propuestas de creadores de otros países residentes en México, lo cual ha generado reservas en parte del campo organizacional que en algún momento se ha sentido fuera de ese círculo denominado por algunos como $<<$ elitista $\gg$, no obstante, se reconoce el lugar clave que desempeña al interior del campo.

"Participar en Bazar Fusión es carisimo. Además son súper elitistas, es un bazar de cuates. Los organizadores son argentinos así que la mayoría de los participantes son argentinos o extranjeros y los productos que venden son súper caros" [Beu Moda y Accesorios].

"Bazar Fusión si exige exclusividad con sus expositores, si estás ahí no puedes estar en otro. Se supone que es un bazar más profesional, con mejor calidad y representa lo mejor del diseño. Los coordinadores son unos argentinos muy serios, muy profesionales, no puedes chacotear con ellos.

Enseñan con un ejemplo de tenacidad, ya que tener un bazar por 10 años es un logro de gran magnitud porque siempre han tenido una visión de negocio muy clara... Sí, hay ciertas divisiones, se da cierta prioridad a los extranjeros por ser ellos extranjeros, pero no te importa tanto esa forma de trabajar porque este bazar siempre ha sido considerado un oasis donde tu marca despega"

[Los Hipersensibles].

"Si bien es caro y hay algo de discriminación si no eres extranjero, Bazar Fusión tiene una ventaja muy grande porque en redes sociales Moda Reforma difunde todos los eventos, desde los más caros hasta algunos bazares, y Fusión se asoció con ellos o algo y de manera constante los publican, retuitean información del bazar y eso ha sido sumamente benéfico para el bazar" [Mowteville]. 
Entonces, los actores identifican que esa forma de organización funciona y deciden imitarla bajo la premisa de hacerlo de una manera diferente:

"La idea de Retro Bazar surgió hace poco más de un año, nosotros tenemos 2 proyectos (pequeñitas marcas) que queríamos comercializar, nos encontramos con que ningún bazar nos quería aceptar, siempre sentíamos nuestro trabajo desvalorizado y juzgado, después de un año de darle vueltas decidimos crear nuestro bazar. Es por eso que el objetivo de Retro Bazar es dar a conocer $e$ impulsar marcas que están escondidas esperando que alguien les dé un lugar para comenzar a lograr su sueño de despegar su trabajo. En nuestros bazares siempre se encontrarán con marcas de las que quizá jamás habían oído, marcas que en ningún bazar habían visto"

"El evento DIM surgió de la necesidad manifestada por nuestros amigos diseñadores y artesanos de encontrar un espacio donde promover su marca y vender sus productos. DIM es un evento organizado por diseñadores y artesanos mexicanos para diseñadores y artesanos mexicanos. iQueremos marcar la diferencia!" [Diseñadores Independientes Mexicanos]

"Cree y Crea es el espacio ideal para los diseñadores, artistas y creativos mexicanos, con el fin de exponer la diversidad de talentos que hay en nuestro país. En Cree y Crea México apoyamos a los nuevos emprendedores mexicanos".

"No es solo comprar por comprar hay un porque. Cada pequeño acto repercute en el sistema económico" [Libre Liebre Bazar]

"Es en medio de la crisis cuando las mejores ideas surgen. Es una pena que haya quien no respeta el trabajo, la dedicación, el tiempo y el empeño de los artesanos y diseñadores independientes, es triste ver que mientras unos buscamos un espacio y oportunidad para vender, dar a conocer nuestras marcas y salir adelante de manera honesta hay quienes toman ventaja de esa necesidad y nos roban. Que esto no nos detenga, ilas piedras hay que utilizarlas para construir!"

[Diseñadores Independientes Mexicanos]

"Bazar de Nadie... de todos, para todos. Artistas y Productores unidos para un comercio justo"

Entre otros elementos, el seguimiento de la tendencia se ubica también en la selección de espacios ${ }^{85}$ y desde que Bazar Fusión cambió a Fusión, Casa de Diseñadores, estableciéndose en una locación definitiva, en algunos casos, los bazares han tendido a buscar también un lugar más estable para la realización de los eventos (espacios culturales, universidades, casas particulares) que les brinde mayor

\footnotetext{
${ }^{85}$ Hay lugares que han sido determinantes y han trazado una ruta en el desarrollo de los Bazares de Arte y Diseño Independiente, tal es el caso del Parque México en la Colonia Condesa, la Plaza Luis Cabrera y la Río de Janeiro en la Colonia Roma, el Casino Metropolitano y el Pasaje América en el Centro Histórico, la Casa de Cultura Jesús Reyes Heroles y el Museo Nacional de Culturas Populares en Coyoacán, por mencionar algunos de los espacios emblemáticos que han sido sede de los principales Bazares de la ciudad. Actualmente, la tendencia también incluye cantinas, casas, restaurantes, etc.
} 
comodidad, tanto para los expositores como los visitantes, sin estar a disposición del clima y otros factores que complican la logística de los eventos.

Por ejemplo, en junio de 2013 a partir de la apertura de un nuevo espacio cultural titulado Artissimo en la Colonia Portales de la Delegación Benito Juárez, surgió el proyecto México Artesano y Creativo (MAC), impulsado por una de las coordinadoras de $D I M$, el cual ya no tiene la dinámica de Bazar pues se ubica de manera permanente al interior del Centro Cultural y funciona como una pequeña tienda cuyo objetivo es "la promoción y venta de productos y artículos de diseño mexicano y manufactura artesanal”.

Por otro lado, nuevamente al ser Bazar Fusión un modelo tan imitado y al incrementarse la competencia en los últimos años, ha buscado de forma constante la manera de reinventarse para mantenerse vigente incluyendo otras características (exposiciones, zona de comida, la rotación de los creadores invitados, inclusión de la denominada Zona Verde con proyectos ecológicos, etc.).

Lo anterior se ha visto reflejado en un mosaico de propuestas y actividades que involucran diversas disciplinas y en el que se aprecia esta identidad "Bazareña" de la Ciudad de México 


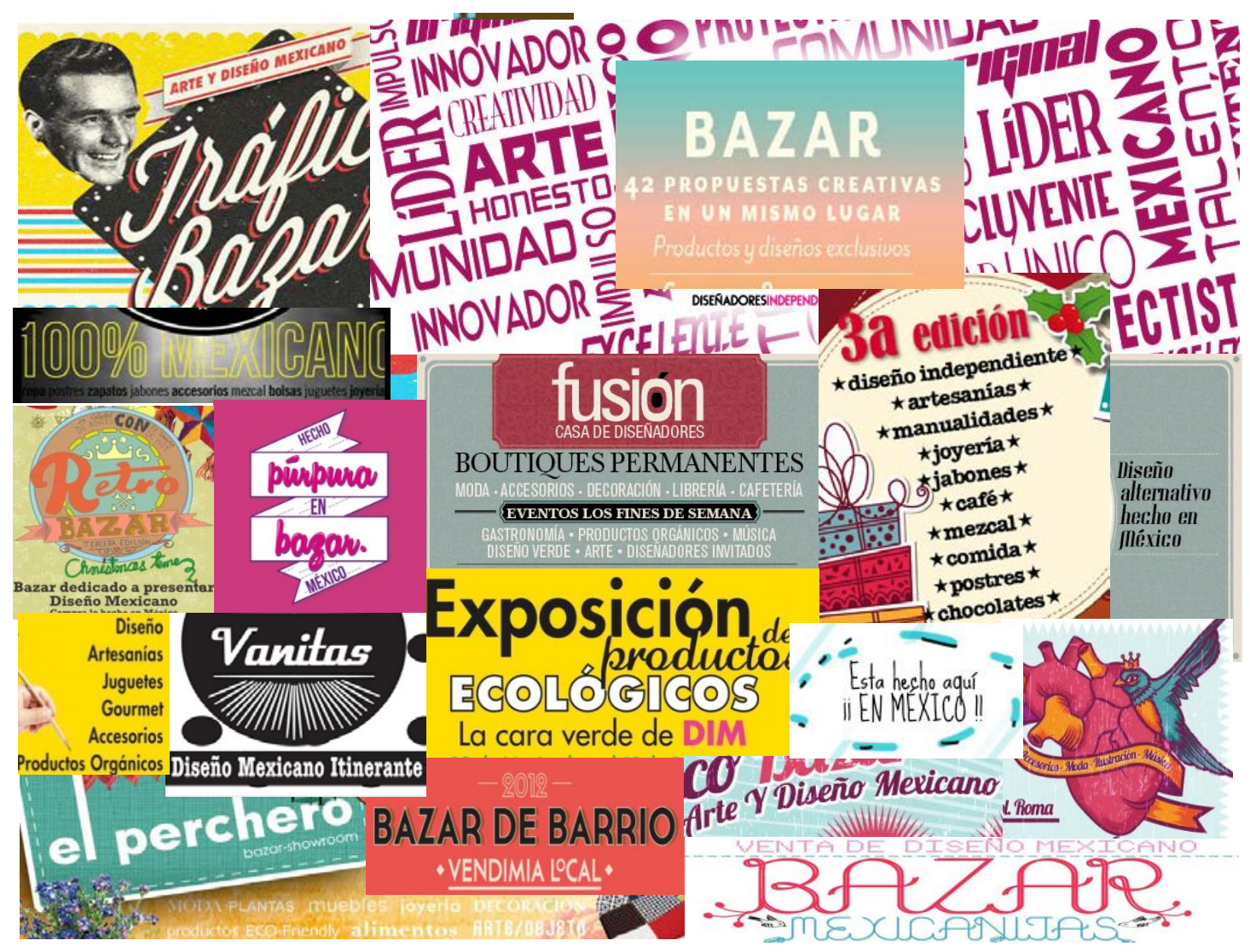

Fuente: Elaboración propia con imágenes obtenidas de los sitios web y redes sociales de los Bazares.

De esta forma, se puede identificar que uno de los principales canales a partir de los cuales ha ocurrido la imitación en el Modo de Transmisión, ha sido la motivación de los actores por formar parte de un movimiento, de un ámbito reconocido de la vida social y económica de la ciudad a través de la realización y reconocimiento de su trabajo creativo. 
El modo denominado Cadena de Imitación, no se encuentra presente de manera tan evidente en el surgimiento de los Bazares de Arte y Diseño Independiente debido a que el fenómeno es reciente y se ubica en un ámbito local bien definido como es la Ciudad de México, por lo que si bien se reconoce la inevitable cadena de imitación en este fenómeno, el referente primario está muy cerca (geográficamente), es sumamente activo y visible públicamente, por lo que es difícil que las organizaciones que imitan no identifiquen el origen de este modelo ${ }^{86}$.

El modo Mediado, de acuerdo con Hedmo et al. (2005) se caracteriza de la siguiente manera:

- Personas y organizaciones actúan como portadores y/o mediadores en la imitación.

- La identidad del portador a menudo se reduce a una entidad que sólo informa sobre lo que está ocurriendo en varios lugares, pero no es en sí mismo una entidad de activación ni un actor con influencia (investigadores, medios de comunicación, comités de expertos y organizaciones internacionales.

- Estos editores no sólo reportan y/o transmiten ideas y experiencias, también las enmarcan y reformulan en el proceso.

- Enseñan -más o menos directamente- a otras organizaciones cómo actuar a fin de ser reconocidas y legitimadas.

\footnotetext{
${ }^{86}$ En unos años más es posible que si se presente este modo de imitación de manera más contundente. De hecho, podría suponerse, que en los estados del país donde han comenzado a surgir Bazares de Arte y Diseño con las mismas características (Guanajuato, Querétaro, Michoacán, Oaxaca, Puebla) el referente sea otro y se esté dando una cadena de imitación pero debido a que no forman parte de la delimitación de esta investigación no se tienen los elementos para afirmarlo.
} 
En este modo, "existen mediadores pasivos que sólo pasan ideas y modelos. John Meyer $(1994,1996)$ los Ilama "Otros" para distinguirlos de los "Actores" que se asumen para perseguir sus propios intereses y políticas y son considerados responsables de sus acciones. Aunque los "Otros" pueden presentarse a sí mismos como mediadores neutrales, se involucran en actividades que son cruciales para la circulación y la traducción de ideas" (Meyer, 1996: 244 citado en Hedmo, et al., 2005: 197).

Este modo se desarrolló de manera amplia en el Capítulo 3 donde se describió a detalle la forma cómo se ha llevado a cabo durante la última década el proceso de institucionalización de la noción emprendedora en el sector cultural y creativo de la Ciudad de México, en donde quedó sumamente claro este proceso mediado a partir del cual ciertas ideas son identificadas como prioritarias (debido a influencias globales y cuestiones de legitimación política, económica y social muy importantes) y entonces a partir de ahí se diseñan mecanismos complejos desde las políticas públicas a nivel federal y local para la implementación de programas de financiamiento e impulso a dichas actividades estableciendo así (y no precisamente sin intención e interpretación previa) la certificación y legitimación de ciertas formas o modelos que se consideran mejores al concentrar los recursos económicos en determinados temas y formas de organización.

En términos concretos en el caso de nuestro país, lo que ha sucedido es que la figura de mecenazgo cultural que fomentó el Estado durante décadas, ha sido cuestionada $y$, en su lugar, se ha impulsado un programa amplio de estímulo para la formación de empresas y emprendedores en el sector cultural y creativo para transformar esta manera de operar de las organizaciones e individuos, lo cual se ha llevado a cabo a través del trabajo de diversas instancias gubernamentales -en términos del Modo de Imitación Mediada, hablamos de los "Otros"- 
Las universidades a partir del diseño de programas de formación profesional, en este caso, en Emprendimiento Cultural y Creativo, así como los expertos e investigadores también cumplen una función importante en este Modo Mediado. "Sahlin-Andersson (1996: 2000 citada en Hedmo, et al., 2005: 197) los conceptualiza como Editores, que no sólo reportan o transmiten ideas y experiencias, también las formulan y reformulan y, por lo tanto, las enmarcan y forman de nuevo en el proceso. Además, enseñan más o menos directamente a otras organizaciones cómo actuar con el fin de ser reconocidas como legítimas".

Ahora bien, es muy importante identificar que éste no ha sido un proceso unidireccional en el cual los actores culturales esperan inmóviles estas ideas y transformaciones. Como se revisó, debido a la complejidad del contexto actual caracterizado por constantes influencias globales, al tiempo de ubicarse en momentos de transición y crisis profundas (tanto en términos económicos como sociales), éstos han participado de manera sumamente activa en el proceso de traslado y traducción de ideas a través de la organización de numerosos eventos y su trabajo como organizaciones de la sociedad civil interviniendo entre los actores individuales y el gobierno en el diseño de estos programas. 
FIGURA 4.10 MODO MEDIADO PRESENTE EN EL SURGIMIENTO DEL CAMPO ORGANIZACIONAL

Organismos Internacionales [UNESCO, UNCTAD, PNUD]
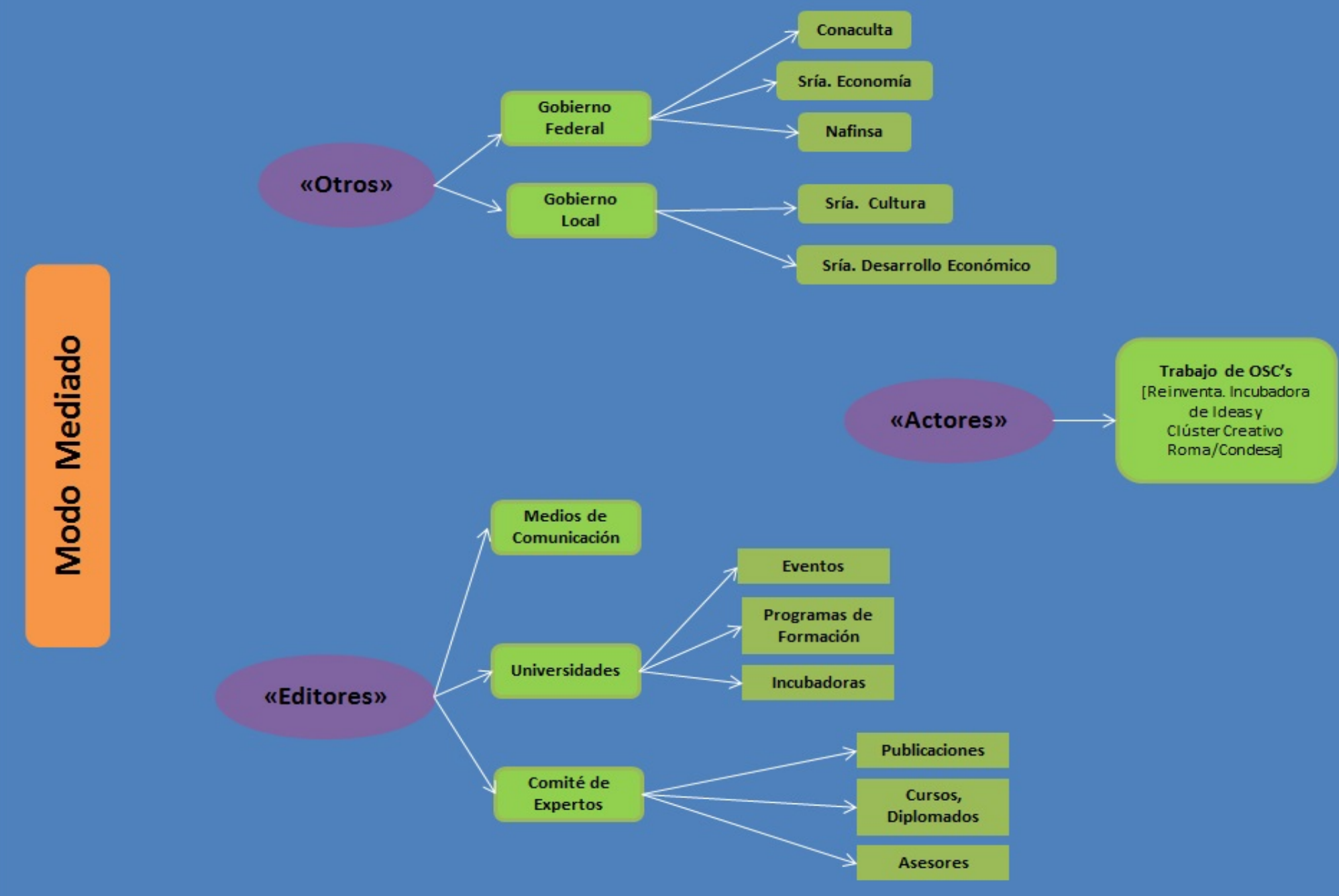

Fuente: Elaboración propia 
Este sintético esquema del proceso de mediación permite visualizar diversos elementos que han sido determinantes en el surgimiento del campo organizacional:

- En muchos casos se identifica que existe una referencia explícita a las ideas que están siendo imitadas a través de utilizar el mismo nombre o uno relacionado, con el propósito de compartir la legitimación que éstas pudiesen llegar a tener (términos como emprendimientos creativos o empresas culturales aparecen de manera constante -en un inicio eran más bien Mipymes en concordancia con los parámetros gubernamentales del momento- que, en sentido amplio, vinculan estos programas con la Economía Creativa).

- El proceso de edición en la formulación de los programas gubernamentales y en la información que difunden los medios de comunicación se relaciona con la utilización de clasificaciones que permiten destacar ciertos temas. Tal es el caso de la promoción que ha tenido el primer lugar que ocupa México a nivel mundial en Economía Creativa de acuerdo con la UNCTAD ${ }^{87}$ o la referencia a datos sobre las aportaciones que la cultura y la creatividad hacen al PIB ${ }^{88}$, en donde las artesanías constituyen el principal rubro económico cultural en el país. En esta misma línea, la Secretaría de Economía, a través del Inadem, identifica el diseño y la moda entre los sectores estratégicos con mayor futuro para el Distrito Federal ${ }^{89}$, datos que se han empleado para el sustento de políticas y programas en el tema.

\footnotetext{
${ }^{87}$ Algunas notas periodísticas al respecto: http://www.informador.com.mx/economia/2011/281666/6/mexico-primera-economia-creativa-deamerica-latina-onu.htm, http://economiacultural.xoc.uam.mx/index.php/lara/207-lider, http://www.soyentrepreneur.com/mexico-ocupa-el-primer-lugar-en-economia-creativa-en-americalatina.html, http://eleconomista.com.mx/entretenimiento/2012/02/19/mexico-debe-reconocer-e-impulsarsu-potencia-cultural, http://vivirmexico.com/2011/04/la-economia-creativa-una-zona-de-oportunidadespara-mexico, http://eleconomista.com.mx/entretenimiento/2013/11/17/mexico-nuevo-paraiso-creativo ${ }^{88}$ Fuente: http://eleconomista.com.mx/infografias/2014/01/22/produccion-gasto-empleo-culturales ${ }^{89}$ Fuente: https://www.inadem.gob.mx/sectores estrategicos.html
} 
- En el ambiente del campo organizacional de los Bazares de Arte y Diseño Independiente $-\mathrm{y}$ del sector cultural y creativo en general- se perciben también ciertos tópicos que han permeado de manera importante la actividad cotidiana de las organizaciones del sector $\mathrm{y}$, en particular de los Bazares de Arte y Diseño Independiente, al establecer como necesario el fortalecer las habilidades empresariales de los creadores para lograr acceder a créditos bancarios a fin de tener un emprendimiento o una empresa rentable y sustentable. Sirvan como referente las dos imágenes a continuación para mostrar de qué forma se ha comenzado a traducir esta idea en el campo:

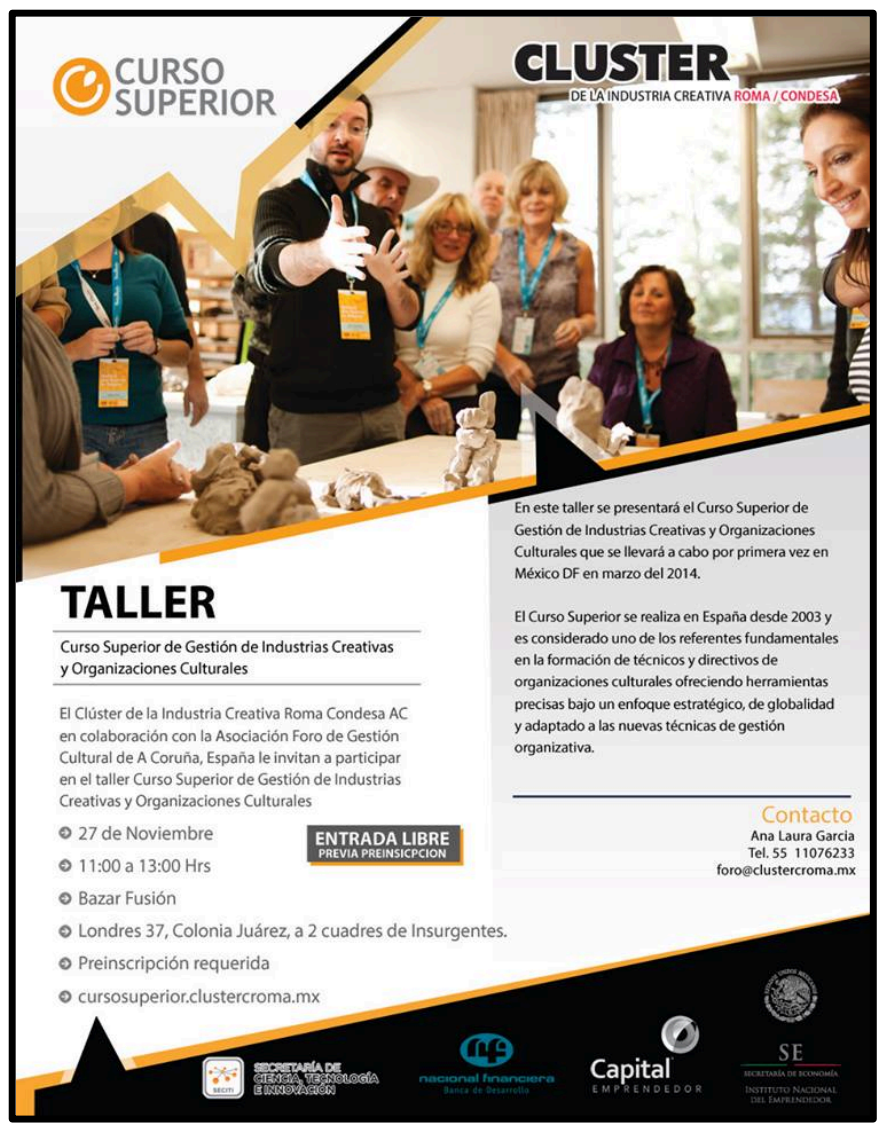

"Se realizará en el Bazar Fusión en la calle Londres 37, Colonia Juárez, a dos cuadras de Insurgentes. El cambio de sede obedece a lo siguiente: Fusión es un proyecto emblemático del Clúster de la Industria Creativa Roma Condesa. Se trata de una "fábrica" de emprendedores de la industria creativa que dará mucho que hablar en un futuro próximo. Por este motivo consideramos que es más atractivo trabajar el taller del Curso superior de gestión de industrias creativas y empresas culturales en un espacio que pertenece al sector" [Clúster Creativo Roma Condesa].

Fuente:

https://esla.facebook.com/clustercreativomx 


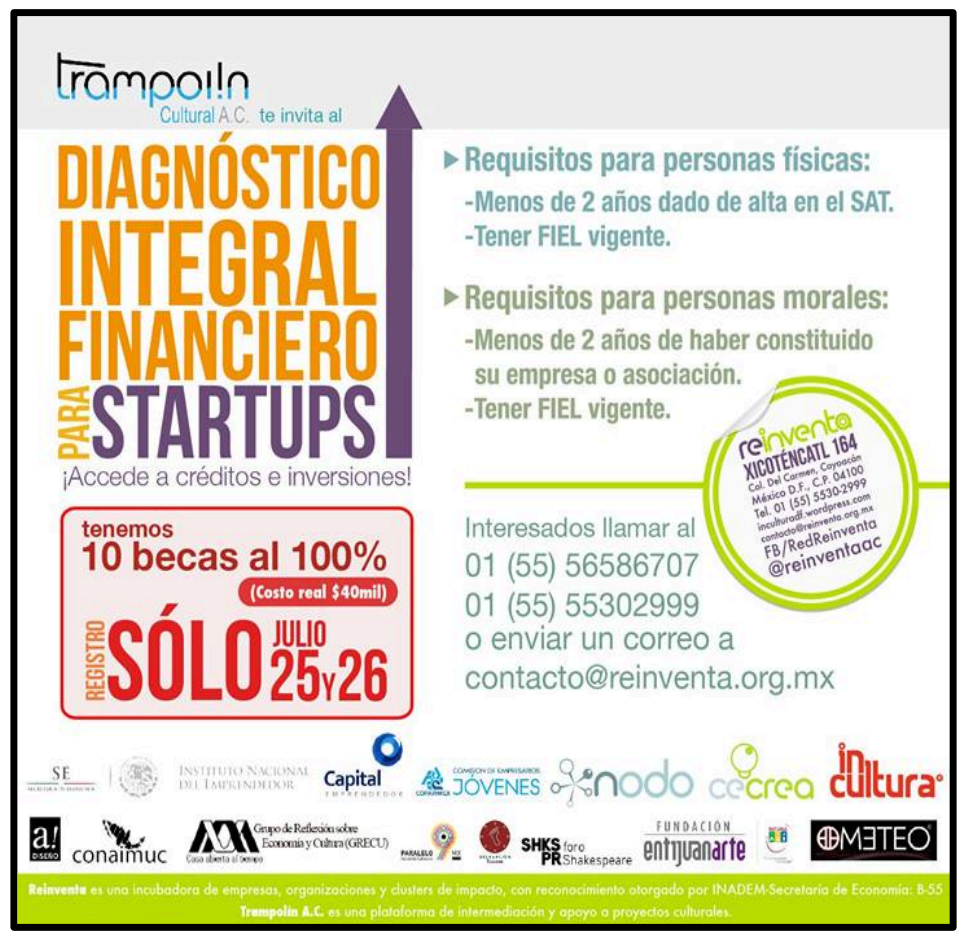

Fuente: http://reinventa.mx/

Ambas imágenes son altamente representativas del grado de integración entre instancias gubernamentales, sociales y actores del campo organizacional de Emprendimientos Culturales y Creativos en la Ciudad de México (Bazares de Arte y Diseño Independiente). En los dos casos, desde el enfoque del tema, el título de la actividad así como las organizaciones aliadas para el desarrollo de la actividad, se refleja la interconectividad de todos los temas que se han desarrollado en esta investigación. En donde además queda claro el rol destacado que han tenido los mediadores en el proceso de difusión e imitación de la figura del emprendedor en el sector cultural y creativo ubicándola como un área de oportunidad legitima y con potencial de desarrollo, por lo cual, en estos tiempos de globalización, resulta muy importante monitorear a las organizaciones y los medios que fungen como mediadores y editores en la formación de campos organizacionales. 
FIGURA 4.11 EL CAMPO DE IMITACIÓN PRESENTE EN EL SURGIMIENTO DEL CAMPO ORGANIZACIONAL DE BAZARES DE ARTE Y DISEÑO INDEPENDIENTE EN LA CIUDAD DE MÉXICO

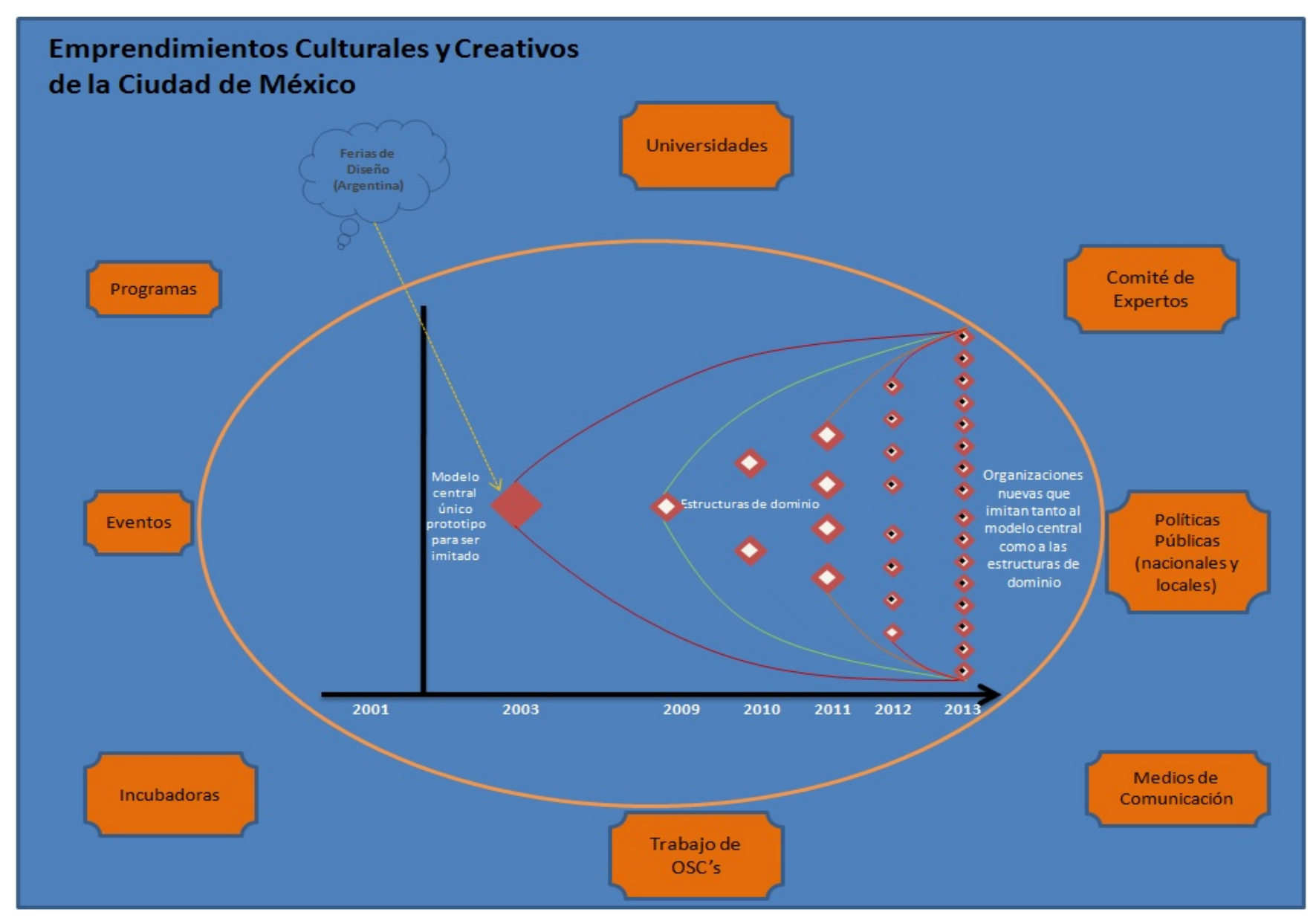

Fuente: Elaboración propia 
Finalmente, se ha confirmado, tal como señalan Hedmo, et al. (2005: 210):

"con la imitación sigue la emergencia de plataformas comunes, categorizaciones e identidades, de manera que el proceso de imitación llevado a cabo colectivamente condujo a la formación de un campo organizacional... Este proceso de imitación involucra contacto directo entre organizaciones así como la imitación de los modelos y significados más difundidos. Para comprender cómo un campo organizacional es formado, hemos defendido la necesidad de investigar y comprender no sólo que las organizaciones imitan y son imitadas, también a los actores y organizaciones que crean, modifican y promueven las ideas, plataformas y modelos usados para la imitación".

Lógicamente, no todos los bazares son iguales, si bien comparten características generales, si se estudiasen uno a uno a detalle se podrían identificar seguramente sus diferencias. Los límites de esta investigación han establecido desde un inicio que ese no es el objetivo en este momento debido a que este fenómeno es muy reciente y se encuentra en ebullición. Hace falta un proceso de asimilación por parte de las organizaciones y los actores culturales y creativos.

No obstante, se espera que este primer paso para su identificación como un área concreta y reconocida de la actividad cultural y creativa de la Ciudad colabore para sentar algún precedente que permita que estudios posteriores identifiquen las variaciones en la forma de traducir esta noción de la Economía Creativa y el fenómeno del emprendimiento en el sector. 


\section{CONCLUSIONES Y CONSIDERACIONES FINALES}

Una de las premisas básicas que dio lugar a la realización de esta investigación es considerar a las organizaciones como un sistema abierto en constante relación con el entorno en el que están ubicadas.

Así, ante la percepción de numerosas transformaciones e influencias globales en el sector cultural en general y, de la Ciudad de México en particular, se decidió analizar de qué manera han impactado éstas a las organizaciones del sector, ya que, coincidiendo con Scott (2005: 444), actualmente "las fuentes de innovación e ideas respecto a nuevas maneras de organizar pueden llegar por Internet desde el otro lado del mundo".

De tal manera que el impulso que se ha dado las últimas décadas a la difusión de los vínculos entre economía y cultura ha dado lugar a nuevas aproximaciones al tema. Desde una mirada organizacional, las transformaciones en el sector cultural, producto de la dinámica globalizadora que caracteriza a los tiempos actuales, se reflejan claramente en la trayectoria que ha seguido una idea (en este caso la Economía Creativa) y su reflejo en el surgimiento de un campo organizacional.

Así, el Nuevo Institucionalismo Sociológico (NIS), a través del estudio de los mecanismos de cambio institucional isomórficos, ha aportado elementos sumamente valiosos para interpretar los procesos a través de los cuales una idea logra legitimarse en un contexto determinado a través de la implementación de procesos miméticos, normativos y coercitivos -de los cuales se ha dado cuenta detalladamente en el tercer capítulo de esta investigación- a partir de lo siguiente: 
- La descripción y análisis de los programas de formación profesional que han sido creados para posicionar e introducir un nuevo paradigma al sector cultural -ahora denominado también creativo como resultado de esta integración de nuevas disciplinas-.

- La identificación de la temática de los eventos realizados para estimular el contacto e intercambio de información entre profesionales así como de las políticas y programas que desde distintos ámbitos (gubernamental, social y académico) han sido llevados a cabo para encuadrar este complejo proceso de cambio institucional isomórfico (cabe mencionar que se percibió también en algunos casos sólo como una copia del nombre para ser partícipes del impulso legitimador) que ha logrado colocarse cabalmente en el sector cultural y creativo de la Ciudad de México, en donde si bien se aprecia un predominio de los mecanismos normativos y miméticos al ser un sector caracterizado tradicionalmente por el trabajo de organizaciones de la sociedad civil, en donde más que la competencia entre organizaciones es la colaboración e intercambio entre éstas lo que las define; a través de la concentración de recursos económicos para impulsar las nuevas formas de organización que se amolden a las ideas que se quieren implantar en el sector, se reconocieron también elementos coercitivos que han cumplido con una función crucial.

No obstante, como se hizo evidente desde la construcción del marco teórico, dada la complejidad de la sociedad contemporánea y la velocidad con la que ocurren simultáneamente todos los procesos arriba descritos y, sobre la base del reconocimiento pleno del rol activo de los individuos que integran las organizaciones del sector, un solo paradigma teórico resultaba limitante para intentar comprender este fenómeno, sobre todo, el identificar cómo se da el proceso a través del cual las ideas fueron trasladadas a "objetos" tales como libros, documentos, programas, etc. 
En este sentido, la noción de Traducción resultó sumamente útil y enriquecedora, al tiempo que complementó acertadamente la perspectiva histórica que desde la plataforma neo institucionalista tenía ya el estudio.

Como ejemplo, baste mencionar lo que sucedió con la Economía Creativa, que se tradujo en diversos documentos internacionales que, en años recientes, han viajado a nivel mundial promoviendo el impulso y legitimación de la actividad emprendedora en el sector cultural, lo cual dio origen a nuevos actores, en este caso, la figura del emprendedor cultural y creativo que, con referencia a lo que ha sucedido particularmente en la Ciudad de México, se ha materializado en el surgimiento de un conjunto de organizaciones que comparten características comunes como son los Bazares de Arte y Diseño Independiente, los cuales, como se demostró, han tenido un crecimiento y visibilización destacable los últimos años, al tiempo que se han definido a partir de elementos muy específicos que los distinguen de otro tipo de organizaciones más "tradicionales" al integrar diferentes proyectos individuales en un esquema de colaboración temporal que no posee elementos formales de adhesión a la organización en cuestión y, sin embargo, logran unificar los objetivos individuales y los colectivos en una dinámica operativa en la que los límites organizacionales están completamente erosionados (los miembros de una organización pertenecen simultáneamente a otras organizaciones del mismo tipo; no existe una periodicidad ni un espacio físico determinado y estable para llevar a cabo las actividades y en donde las tecnologías de la información y comunicación han jugado un papel crucial en su funcionamiento).

El estudio del proceso a partir del cual se logró identificar que estaba emergiendo un campo organizacional, fue llevado a cabo a través del reconocimiento de la cadena de actores que han participado en éste. 
Con base en el estudio de los Campos de Imitación -tema desarrollado ampliamente en el cuarto capítulo de este trabajo- se reconoció la imitación como un proceso activo en el que además de las instituciones de gobierno, agentes y consultores internacionales, los académicos, los medios de comunicación y los mismos integrantes de las organizaciones son mediadores activos del proceso de imitación, a través de la selección y edición de los contenidos y formas que deciden repetir, ello con base en su interpretación de lo que es necesario para formar parte de un área legítima de su entorno inmediato.

Una manera para lograr que todo lo descrito anteriormente cobre sentido y se identifique como relevante para el sector, es enmarcándolo en el ámbito de acción de las políticas públicas, en este caso, en cultura. Así, de acuerdo con Coelho (2009), "las formas ideológicas de las políticas culturales según sus perspectivas son tres: 1) Políticas de dirigismo cultural (tradicionalismo patrimonialista y estatismo populista), 2) Políticas de liberalismo cultural y 3) Políticas de democratización cultural (principios consensuales para crear condiciones de acceso igualitario a la cultura para todos)".

Con base en la revisión de la literatura y de la sistematización de los datos producto de esta investigación, el fenómeno del emprendimiento cultural y creativo que ha dado lugar al surgimiento del campo organizacional de los Bazares de Arte y Diseño Independiente, coincide con el impulso de una política de liberalismo cultural que, de acuerdo con Coelho (2009: 246-247), entre otros elementos, se caracteriza por lo siguiente: 
- No entienden necesariamente que sea un deber del Estado promover la cultura y ofrecer opciones culturales a la población.

- Entre sus subtipos están las políticas culturales adeptas del mecenazgo liberal: el apoyo a la cultura depende en mayor grado de la iniciativa privada o de fundaciones privadas o semiprivadas en las cuales el poder público participa poco.

- El objetivo es uno solo: encuadrar a la cultura en las leyes del mercado. En este caso se entiende que la cultura debe ser una actividad lucrativa al grado de poder, por lo menos, sustentarse a sí misma.

- Sus principios son en general los de la globalización y apoya no a grupos comunitarios sino a individuos y empresas culturales.

Cada uno de estos elementos ha podido ser identificado, tanto en el discurso como en las características de las políticas y programas que se han implementado los últimos años en nuestro país con el referente directo de la Economía Creativa y las aportaciones que puede hacer al desarrollo -proceso del que se ha dado cuenta en esta investigación-.

No obstante, no todo es tan simple e ideal como suena en primera instancia y algunos autores han señalado los riesgos del predominio del tema económico en el ámbito cultural.

En este sentido, Throsby (2008: 72) es contundente al afirmar que "en el amplio debate sobre la cultura que se sostiene en los escenarios económicos contemporáneos, debe resistirse la tendencia al dominio de una interpretación económica del mundo, derivada de la omnipresencia y poderío del paradigma económico moderno. Si se toma en serio el intento de formular una teoría completa con validez operativa en la toma de decisiones, es esencial que el valor cultural figure junto al valor económico en el análisis del valor total de los bienes y servicios culturales". 
En esta misma línea, "Santiago Niño Morales - profesor de la Facultad de Artes de la Universidad Distrital Francisco José de Caldas, en Colombia- refiere que el actual modelo socioeconómico que prevalece en los países latinoamericanos tiene poca capacidad de generar mercados internos y de proteger eficazmente la microempresa vinculada a la cultura. Por lo tanto, no favorece aspectos claves necesarios para los emprendimientos del sector" (García, 2013 octubre 2).

A pesar de este tipo de advertencias sobre los posibles riesgos de la implementación no adecuada de este conjunto de ideas, la noción de Economía Creativa ha viajado rápidamente alrededor del mundo sin mayor cuestionamiento por parte de los gobiernos que la trasladan a entornos completamente distintos de los lugares donde se originó.

Así, "en varios países europeos, donde los gobiernos han desplegado programas de apoyo a los emprendedores, pymes culturales y asociaciones creativas independientes a través de créditos, becas y estímulos al mecenazgo (por ejemplo España e Inglaterra), se interpretan estas acciones en conexión con la hiperflexibilización de los empleos. Al no dar más que apoyos temporales y discontinuos no se garantiza la durabilidad de estas prácticas creativas. Los Estados y las empresas se desresponsabilizan de las garantías antes aseguradas en los mercados laborales y delegan en los individuos creativos la responsabilidad por su éxito o fracaso (Rowan 2009, citada en Canclini y Urteaga, 2011: 140).

$Y$ en este contexto de transformaciones e inestabilidad en diversos ámbitos de la vida contemporánea, se inserta el tema de la precarización laboral en cuyo marco, como hemos visto, se ha dado el surgimiento de nuevas formas de organización caracterizadas como flexibles, que estimulan la polivalencia de sus integrantes, la pro actividad, la independencia, pero que a su vez, promueven nuevas formas de empleos precarios, sin prestaciones, sin ingresos o con bajos salarios. 
De la Garza (2010) y Neffa (2010) coinciden -y yo con ellos y sus argumentos- en que la tan celebrada flexibilidad de las nuevas formas de gestión organizacional en muchos sentidos contribuye a que socialmente asumamos como "normal" este fenómeno de precarización del trabajo, en donde "emerge así una división social y técnica entre empresas: por una parte están las principales y que dan órdenes, y por otra parte están las empresas tercerizadas, las cooperativas de trabajo, los trabajadores por su propia cuenta organizados en microempresas que están ocupados en sus domicilios" (Neffa, 2010: 53).

Esto en todos los sectores de actividad y, el cultural y creativo, no han sido la excepción y cuyas aportaciones se enmarcan actualmente en torno a la idea de que "la riqueza social ahora depende más de la creación de conocimientos que de bienes, con el incremento de las ocupaciones con alto contenido de conocimiento e información" (De la Garza, 2010: 31), lo que se ha traducido en cierto grado de precarización del trabajo en el ámbito cultural, en donde si bien existe un alto grado de especialización y profesionalización de sus miembros, no existen las políticas públicas de protección y seguridad social del trabajo de los agentes culturales desde la esfera independiente, ya que muchos trabajan desde su casa (utilizando y pagando los servicios necesarios: luz, internet, teléfono), en muchas organizaciones, como en los Bazares de Arte y Diseño Independiente, no existe una oficina o lugar de trabajo específico, etc. 
De acuerdo con un estudio realizado por Néstor García Canclini y Ernesto Piedras en 2012, "el $80 \%$ de artistas visuales, editores independientes, músicos y autores multimedia, que conforman la llamada economía creativa, busca el sustento básico en otro tipo de actividades, ya que la creativa sólo les proporciona $23 \%$ de sus ingresos. Apenas el 33\% de jóvenes dedicados al desarrollo cultural cuenta con un contrato y el resto trabaja por proyecto, sin prestaciones" (Malvido, 2013 agosto 8).

Se informa en la nota que en la investigación se realizaron 175 entrevistas, en donde el $70 \%$ de los encuestados son varones, $53 \%$ tiene entre 20 y 30 años, $70 \%$ tiene licenciatura y $14 \%$ posgrado, con lo que se verifica el alto nivel de profesionalización del sector en general y, contrario a lo que sugiere Neffa (2010) en el sector cultural pareciese que la educación y la formación especializada como elementos para combatir la precariedad laboral hasta el momento no se ha visto reflejado, debido a que además socialmente no se cuenta con el debido reconocimiento de las profesiones involucradas en la actividad cultural y creativa y, por ende, de un salario y características de empleo acorde con esto.

Ahora bien, es importante señalar que no sólo en el espacio independiente se presenta este fenómeno, tampoco al interior de las instituciones públicas de cultura existen condiciones "óptimas" de trabajo, pues cada vez es más recurrente la presencia de prestadores de servicio social o becarios en la ejecución de los programas, o la subcontratación de organizaciones civiles o empresas, al tiempo que cada vez son menos los individuos contratados a tiempo completo, con prestaciones, etc.

Neffa (2010: 54) sintetiza el fenómeno de la precarización de la siguiente manera: “... lo que es viejo, estable, homogéneo y rígido se considera improductivo, costoso, propio de otra época, un <<paraíso perdido>> que nunca volverá. Frente a eso la flexibilidad se presenta como un elemento positivo, única alternativa contra el desempleo, para proporcionar un trabajo creativo, autónomo, responsable, capaz de involucrar a los 
trabajadores, al mismo tiempo que se exaltan las ventajas del emprendedurismo y de las seudocooperativas de trabajo, porque ahí no tendría lugar la relación salarial y se obtendrían mejores salarios, pagados según el rendimiento y los resultados".

Boris Marañón Pimentel y Dania López Córdova, coinciden de alguna manera con este argumento y afirman que "el discurso y modelo del emprendedor cultural es eminentemente neoliberal y tiende a una mercantilización de todas las relaciones sociales. Ahora hay muchos emprendedores culturales porque buena parte de ellos han sido motivados por ese discurso, aunque estén sujetos a la explotación, la incertidumbre económica con relación a sus ingresos, a tener o no trabajo y a una jornada laboral fuera de la ley" (García, 2013 octubre 2).

Si bien estas posturas pueden ser sumamente debatibles (y tienen tanto pros como contras), considero aportan elementos sumamente interesantes en torno a los cuales es indispensable reflexionar con base en las características actuales de nuestro país (desempleo, crisis económica, política, social), en donde queda más que claro que el panorama no es para nada simple y, aunado a esto, además se percibe que la tendencia del impulso emprendedor los próximos años seguirá esta misma línea.

De inicio, el hecho de que desde la Secretaría de Economía se haya creado el Instituto Nacional del Emprendedor parte de una iniciativa por legitimar desde el ámbito federal la noción emprendedora a través del establecimiento de los lineamientos que deben cumplir los individuos y las organizaciones para acceder a los recursos que concentra a través del Fondo Nacional Emprendedor ${ }^{90}$.

\footnotetext{
${ }^{90}$ http://www.sistemaemprendedor.gob.mx/
} 
Por otro lado, hace unos meses se anunció que desde la Secretaría de Educación Pública se ha puesto en marcha el primer modelo de formación de emprendedores para la educación media superior, que se afirma "pretende crear las condiciones de aprendizaje que potencien la capacidad de los jóvenes para generar empresas y empleos". Aunque dicho programa se sustenta bajo el argumento de "mejorar las condiciones laborales y de bienestar de los jóvenes, quienes tras cursar la educación media superior experimentan altas tasas de desempleo, elevados niveles de subempleo -dos de cada tres en promedio desempeñan ocupaciones que no requieren sino educación primaria o secundaria-, así como sueldos precarios, pues $80 \%$ sólo obtiene ingresos de hasta tres salarios mínimos" (Pérez, 2013 octubre 22), como se revisó previamente, tales argumentos no constituyen una solución real a dicho problema (y no sólo en lo que se refiere al ámbito cultural).

Desde el Conaculta, lo que se ha presentado hasta el momento del Programa Especial de Cultura y Arte 2013-2018, indica que también se seguirá esta línea que corresponde a la cuarta meta que habla del "estímulo a la capacidad creativa para incrementar el potencial económico de la cultura y de las industrias creativas" (Amador, 2014 enero 19). De esta base, se derivan los concursos y programas de estímulo que han empezado a operar dirigidos a las empresas culturales y creativas, los cuales cabe mencionar, se han diseñado en coordinación con los lineamientos de la Secretaría de Economía a través del Inadem.

En concordancia con lo anterior, a nivel local, la Política Cultural 2013-2018 de la Secretaría de Cultura de la Ciudad de México se integra por una Agenda Cultural a partir de la consolidación de 6 ejes de política pública ${ }^{91}$.

\footnotetext{
${ }^{91}$ http://www.cultura.df.gob.mx/secretaria/el-tema-es-la-cultura
} 
En el Programa Operativo Anual 2014, de dicha Secretaría se menciona, entre otras cosas, la necesidad de "establecer mecanismos para fortalecer las capacidades emprendedoras y de gestión del sector cultural y artístico".

De esta manera, resulta claro que los próximos años seguiremos teniendo noticias en el tema, lo cual abre la posibilidad de profundizar en muchos de los tópicos que se tocaron aquí desde diversas perspectivas. Particularmente, desde la plataforma de los Estudios Organizacionales, uno de ellos puede consistir en la identificación de prácticas concretas en organizaciones del sector que permita tener elementos para que más allá del isomorfismo, se dé el reconocimiento pleno de la diversidad organizacional, que con referencia en los resultados de estudios previos de traducción realizados en otros países, se puede suponer está presente aún en un contexto altamente institucionalizado como el que ha sido descrito.

Finalmente, el integrar ciertos elementos críticos a la Economía Creativa y su vínculo con la noción emprendedora, no ha sido para cuestionar el trabajo de los emprendedores culturales y creativos quienes, al contrario, dadas las circunstancias han demostrado ser sumamente innovadores y hábiles para adaptarse a este entorno cambiante e incierto a través de la construcción y fortalecimiento de una identidad colectiva, así como a partir de la implementación de estrategias novedosas para impulsar su actividad. Han sido incluidos más bien con el propósito de aportar elementos a la reflexión y el debate, para que las ideas no sean absorbidas sin una lectura lo más integral posible de todos los aspectos en juego, razón por la cual, un seguimiento puntual del tema desde sus diversas aristas resulta indispensable en un futuro próximo. 


\section{BIBLIOGRAFÍA Y FUENTES CONSULTADAS}

ALCOVER DE LA HERA, Carlos María (1998). Influencias del tiempo y de la pertinencia sobre la eficacia de los equipos de trabajo y Análisis de los factores que influyen sobre los equipos de trabajo en las organizaciones. (pp. 25-77). Madrid: Editorial Dykinson y el Centro de Estudios Superiores de Ramón Carande.

AMADOR Tello, Judith (2014, enero 19). Celebran en el Museo de Antropología los 25 años del Conaculta. Disponible en www.proceso.com

ANDRADE Díaz, Carolina Sue (2011). Organizaciones de la sociedad civil en la transformación del espacio público, el caso del corredor cultural de Regina, Tesis inédita presentada para obtener el grado de Maestra en Estudios Organizacionales, Universidad Autónoma Metropolitana, México.

BARBA Álvarez, Antonio y Pedro C. Solís P. (1997). Cultura en las organizaciones. Enfoques y metáforas de los Estudios Organizacionales, México: Vertiente Editorial.

BAUTISTA, Virginia (2013, septiembre 30). Tec de Monterrey forma a empresarios culturales. En Excélsior. Disponible en www.excelsior.com.mx

BRAMBILA, Medrano Blanca (2009). Tendencias de formación profesional de la gestión cultural en México. Tesis inédita presentada para obtener el grado de Maestra en Promoción y Desarrollo Cultural, Universidad Autónoma de Coahuila, México.

BONET, Lluís, Castañer, Xavier y Font, Josep (ed.) (2001). Gestión de proyectos culturales. Análisis de casos, España: Editorial Ariel S.A.

BRUNET, Pascal (ed.) (2012). Culture \&Innovation (s) Europe seen from the South, España: Unidad de Investigación en Economía de la Cultura y Turismo (Econcult), del Instituto Universitario de Desarrollo Local (IILD) de la Universitat de Valencia.

CASANI, Fernando, Jesús Rodríguez-Pomeda y Flor Sánchez (2012). Los nuevos modelos de negocio en la economía creativa: emociones y redes sociales. En Universia Business Review, Primer trimestre. Disponible en: http://ubr.universia.net/pdfs web/3303.pdf 
CGLU (Comisión de Cultura de la Asociación Mundial de Ciudades y Gobiernos Locales Unidos) (2004). Agenda 21 de la cultura, Disponible en http://www.agenda21culture.net/

CLARKE, Thomas y Stewart Clegg (1998).Changing Paradigms. The transformation of knowledge for the $21^{\text {st }}$ century. (pp. 9-59). London: HarperCollins Business,

CLEGG, Stewart (1990). Modern organizations. Organizations studies in the postmodern world, Sage, London, pp. 1-24 y 176-207.

COELHO, Teixeira (2009). Diccionario crítico de política cultural. Cultura e imaginario (Traducción Ángeles Godínez). Barcelona: Editorial Gedisa S.A.

CORONILLA Cruz, Raúl (2004). Propuesta metodológica para el análisis del cambio organizacional. En Montaño Hirose, Luis (Coord.) Los estudios organizacionales en México. Cambio, poder, conocimiento e identidad. (pp. 93-111), México: Universidad Autónoma Metropolitana Unidad Iztapalapa, Miguel Ángel Porrúa y Universidad de Occidente.

CROZIER, Michel y Friedberg Erhard (1990). El actor y el sistema. México: Alianza Editorial Mexicana.

CRUZ Vázquez, Eduardo (Coord.) (2010). Economía cultural para emprendedores. Perspectivas. México: Universidad Autónoma de Nuevo León-Universidad Autónoma Metropolitana. Disponible en: http://economiacultural.xoc.uam.mx/images/libro/libroeconomiacultural.pdf

CRUZ Vázquez, Eduardo y Rebeca Romo (2012, diciembre 4). DF, la región más transparente del mercado cultural. En El Economista. Disponible en http://eleconomista.com.mx/entretenimiento/2012/12/04/df-region-mas-transparentemercado-cultural

CZARNIAWSKA, Bárbara y Guje Sevón (Edit.) (2005). Global ideas. How ideas, objects and practices travel in the global economy, Sweden: Liber \& Copenhagen Business School Press.

DAFT, Richard I. (1998). Fundamentos de la estructura de la organización. En Teoría y diseño organizacional. (pp. 200-243). Thomson Editores. 
DE LA GARZA, Enrique (2010). ¿Hacia dónde va el trabajo humano? En Hacia un concepto ampliado del trabajo. Del concepto clásico al no clásico. (pp. 21-36). España: UAM Iztapalapa y Anthropos Editorial.

DE LA ROSA Alburquerque, Ayuzabet (2002). Teoría de la Organización y Nuevo Institucionalismo en el Análisis Organizacional. En Administración y organizaciones, Año 4, No. 8, pp. 15-44.

DEMERS, C. (2007). The configurational approach. En Organizational change theories. (pp. 47 - 59).California: Sage.

DIMAGGIO, Paul J. (1999). Construcción de un campo organizacional como un proyecto profesional: los museos de arte de los Estadios Unidos, 1920-1940. En Powell, W. y Paul J. DiMaggio (comp.). El Nuevo Institucionalismo en el análisis organizacional, Sección de obras de Administración Pública, Coordinado por Mauricio Merino. (pp. 333-361). México: Colegio Nacional de Ciencias Políticas y Administración Pública, A.C., Universidad Autónoma del Estado de México, Fondo de Cultura Económica.

DIMAgGIO, Paul J. y W. Powell (1999). Retorno a la jaula de hierro: el isomorfismo institucional y la racionalidad colectiva en los campos organizacionales. En Powell, W. y Paul J. DiMaggio (comp.). El Nuevo Institucionalismo en el análisis organizacional, Sección de obras de Administración Pública, Coordinado por Mauricio Merino. (pp. 104-125). México: Colegio Nacional de Ciencias Políticas y Administración Pública, A.C., Universidad Autónoma del Estado de México, Fondo de Cultura Económica.

DURÁN Salvatierra, Sylvie (2009). El tercer sector en la cultura: redes, asociaciones, organizaciones. Red Iberoamericana de Ciudades para la Cultura, 25 de febrero de 2009. Disponible en http://www.redinterlocal.org

ESPINOSA Espinosa, Aarón, Gina Ruz Rojas y Jorge Alvis Arrieta (2012). Metodología para emprendimientos culturales en clave de desarrollo. Colombia: Universidad Tecnológica de Bolívar, Ministerio de Cultura.

FONSECA Reis, Ana Carla (coord.) (2008). Economía creativa como estrategia de desarrollo: una visión de los países en desarrollo, Sao Paulo: Itatú Cultural. Disponible en http://sic.conaculta.gob.mx/centrodoc documentos/555.pdf 
GARCÍA Bermejo, Carmen (2013, Octubre 2). Manifestaciones culturales: ¿bien común o mercancía? En El Financiero. Disponible en www.elfinanciero.mx

GARCíA Canclini, Néstor (2004). Diferentes, desiguales y desconectados. Mapas de la Interculturalidad. Barcelona: Gedisa.

GARCíA Canclini, Néstor y Maritza Urteaga (Coord.) (2011) Cultura y desarrollo: una visión distinta desde los jóvenes. Madrid: Fundación Carolina-Universidad Autónoma Metropolitana. Disponible en http://www.fundacioncarolina.es

GUTIÉRREZ, Vicente (2013, marzo 7). Presentan Clúster de Industrias Creativas. En El Economista, Disponible en http://eleconomista.com.mx/entretenimiento/2013/03/07/presentan-clusterindustrias-creativas

HALL, Richard (1996a). La estructura organizacional: sus formas y resultados. En Organizaciones: estructuras, procesos y resultados. (pp. 50-91). México: Prentice-Hall.

(1996b). Estructura organizacional: explicaciones. En Organizaciones: estructuras, procesos y resultados. (pp. 92-118). México: Prentice-Hall.

HEDMO, Tina, Kerstin Sahlin-Andersson y Linda Wedlin (2005). Fields of imitation: The global expansion of Management Education. En Czarniawska, Bárbara y Guje Sevón (Edit.)(2005). Global ideas. How ideas, objects and practices travel in the global economy. (pp. 190-212). Sweden: Liber \& Copenhagen Business School Press.

HOLGuín, María Elisa (coord.) (2010). Ministerio de Cultura Manual para la implementación de procesos de emprendimiento y creación de industrias culturales. Colombia: Ministerio de Cultura de la República de Colombia y La Silueta Ediciones. Disponible en http://intranet.manizales.unal.edu.co/modules/ununesco/admin/archivos/manualempr endimientocultural.pdf

LOBATO Vico, Manuel y Mareira Quintero Rivera (2008). Mapas culturales y estadísticas: ¿para qué? que forma parte del proyecto Mapa cultural del Puerto Rico Contemporáneo, Disponible en http://gestioncultural.uprrp.edu/mapacultural 
MACCARI, Bruno y Montiel, Pablo (2012). Gestión Cultural para el desarrollo. Nociones políticas y experiencias en América Latina. Argentina: Editorial Ariel.

MALVIDO, Adriana (2013, agosto 8). Jóvenes creativos, riqueza y precariedad. En Milenio. Disponible en www.milenio.com

MARISCAL Orozco, José Luis (2006). Formación y capacitación de los gestores culturales. En Apertura, Agosto, Año/Vol. 6, Número 004, Universidad de Guadalajara, pp. 56-73. Disponible en www.udgvirtual.udg.mx/apertura/index.php/apertura4/article/ (2011). Avances y retos de la profesionalización de la gestión cultural en México. En Revista Digital de Gestión Cultural, Año 1, Número 2, Noviembre, pp. 5-27. Disponible en www.gestioncultural.org.mx

MÉxICO. Instituto Nacional de Desarrollo Social (2010). Ley Federal de Fomento a las Actividades Realizadas por Las Organizaciones de la Sociedad Civil, México, 5a.. Edición.

MEYER, A., Tsui, A. y Hinings, C.R. (1993). Configurational Approaches to organizational analysis. En Academy of Management Journal, Vol. 36, No. 6, pp. 1175-1195.

MiNTZBERG, H. (1989). Mintzberg y la dirección. (pp. 109-297) .Madrid: Días de Santos Ediciones.

MONTAÑO Hirose, Luis (2001). La razón, el efecto y la palabra. Reflexiones en torno al sujeto en la organización. En Iztapalapa, no. 50, Universidad Autónoma Metropolitana Iztapalapa.

(Coord.) (2004). Los estudios organizacionales en México. Cambio, poder, conocimiento e identidad. México: Universidad Autónoma Metropolitana Unidad Iztapalapa, Miguel Ángel Porrúa y Universidad de Occidente.

MORRIS, Timothy y Zoë Lancaster (2005).Translating Management Ideas. En Organization Studies, Núm. 27, Vol. 2, pp. 207-233. 
NAIME, Alexander (2004). Los estudios organizacionales. Prolegómenos de un campo de conocimiento en América Latina. En Montaño Hirose, Luis (Coord.) Los estudios organizacionales en México. Cambio, poder, conocimiento e identidad. (pp. 41-61). México: Universidad Autónoma Metropolitana Unidad Iztapalapa, Miguel Ángel Porrúa y Universidad de Occidente.

NAVARRETE Álvarez, Enrique (2011). Incubadora de empresas creativas: Fondeso-

Sedeco. En Actualidades, Enero-Febrero. Disponible en http://es.scribd.com/doc/116772988/127-Incubadora-de-Empresas-Creativas

NEFFA, Julio César (2010). La transición desde los verdaderos empleos al trabajo precario. En De la Garza, Enrique y Julio César Neffa (coords.) Trabajo, identidad y acción colectiva. (pp. 43-80). México: UAM Iztapalapa, Clacso, Plaza y Valdés S.A de C.V.

NOGALES Muriel, Rocío (2011). La empresa social en la lucha contra la exclusión: tres casos innovadores en el campo de la cultura. En Revista Española Tercer Sector, Núm. 17, Enero-Abril de 2011, Disponible en http://www.fundacionluisvives.org/rets/17/index.html.es

PALLARÉS Espinosa, Susana. Emprendimiento creativo y economía social. Disponible en: http://redinterlocal.net/IMG/pdf emprendimiento creativo y economia social.pdf

PÉREZ Silva, Ciro (2013, octubre 22). La SEP echa a andar modelo para formar emprendedores. En La Jornada. Disponible en www.jornada.unam.mx

PIEDRAS Feria, Ernesto (2010), Economía y Cultura en la Ciudad de México, PNUD, México.

PUGH, D.S., et al. (1973). Dimensions of organization structure. En Heydebrand, Wolf. Comparative organizations. (pp. 441-470). New Jersey: Prentice Hall e Englewood Cliffs.

PUGH, D.S. (1973). The measurement of Organization Structures: Does context determine form?. En Organizational Dynamics, Spring, pp. 19-34.

RAMíREZ Atilano, Silvia Viridiana (2011) Una propuesta para el análisis estructural de una osc: el caso del Centro de Arte y Cultura CV (CACCV), Tesis inédita presentada para obtener el grado de Maestra en Estudios Organizacionales, Universidad Autónoma Metropolitana, México. 
RAPETTI, Sandra (2002). Buscando caminos: Gestión, financiamiento y problemática de las Organizaciones Culturales del Interior del Uruguay. Investigación realizada en Salto, Colonia y Maldonado. UNESCO- Comisión Sectorial de Investigación Científica de la Universidad de la República Oriental del Uruguay. Disponible en http://unesdoc.unesco.org/images/0012/001294/129452so.pdf

RAUSELL Koster, Pau y Abeledo Sanchis, Raúl (coordinadores) (2012) La cultura como factor de innovación económica y social. España: Unidad de Investigación en Economía de la Cultura y Turismo (Econcult), del Instituto Universitario de Desarrollo Local (IILD) de la Universitat de Valencia. Disponible http://www.uv.es/econcult/pdf/Sostenuto Volume1 CAST.pdf

RODRÍGUEZ Peñuelas, Marco Antonio (2010). Métodos de investigación. Diseño de proyectos y desarrollo de tesis en ciencias administrativas, organizacionales y sociales, México: Universidad Autónoma de Sinaloa.

RUíz Navarro, José (2009). Creación de empresas en el ámbito cultural. España: Fundación Autor-Sociedad general de Autores y Editores.

$(\mathrm{s} / \mathrm{f})$. Las empresas culturales son más innovadoras y avanzadas que el resto. En Andalucía Innova, Núm. 18, pp. 16-17. Disponible en http://www.andaluciainvestiga.com/revista/pdf/n18/18p16 17.pdf

RUZ Rojas, Gina (2012, noviembre 2). Cultura, emprendimientos y desarrollo. En El Universal. Disponible en http://www.eluniversal.com.co/columna/culturaemprendimientos-y-desarrollo

SÁNCHEZ Guevara, Irene (2007) Organización del teatro independiente de México: de la red de cooperación al conflicto, Tesis inédita presentada para obtener el grado de Doctora en Estudios Organizacionales, Universidad Autónoma Metropolitana, México.

SCOTT, W. Richard (1999). Retomando los argumentos institucionales. En Powell, W. y Paul J. DiMaggio (comp.). El Nuevo Institucionalismo en el análisis organizacional, Sección de obras de Administración Pública, Coordinado por Mauricio Merino. (pp. 216-236). México: Colegio Nacional de Ciencias Políticas y Administración Pública, A.C., Universidad Autónoma del Estado de México, Fondo de Cultura Económica. 
(2003). Organizations. Rational, natural and open systems, Prentice Hall, New Jersey.

(2005). Organizaciones: características duraderas y cambiantes. Trad. Susana Moreno Parada. En Gestión y Política Pública, Vol. XIV, Núm. 3, Segundo Semestre de 2005, pp. 439-463.

SZURMUK, Mónica y Robert Mckee Irwin (coord.) (2009). Diccionario de Estudios Culturales Latinoamericanos. México: Instituto Mora y Siglo XXI Editores.

THROSBY, David (Trad. Cristina Piña y María Cóndor) (2008). Economía y Cultura, México: Conaculta.

TRÀNSIT Projectes (2012). Música para Camaleones. El Black Álbum de la sostenibilidad cultural. España: Disponible en www.musicaparacamaleones.transit.es

UNCTAD (2008).The Creative Economy Report 2008: The Challenge of Assessing the Creative Economy. Toward. Informed Policy making. Disponible en http://unctad.org/es/Docs/ditc20082cer en.pdf

UNCTAD (2010). The Creative Economy Report 2010: The Creative Economy: A Feasible Development Option, Disponible en http://unctad.org/en/pages/PublicationArchive.aspx?publicationid=946

UNESCO (2005). Formación en gestión cultural y políticas culturales. Directorio Iberoamericano de Centros de Formación. OEl, Iberformat e Interarts. Disponible en www.unesco.org/culture.

UNESCO (2009), Marco de Estadísticas Culturales de la UNESCO, Montreal: Instituto de Estadística de la UNESCO. Disponible en http://unesdoc.unesco.org/images/0019/001910/191063s.pdf

VERDUSCO, Alberto (2013, junio 24). INEGI: Desempleo en mayo sumó más de 2 millones 477 mil. En El Universal. Disponible en www.eluniversal.com 


\section{PÁGINAS WEB}

- http://www.itesm.mx/wps/wcm/connect/itesm/tecnologico+de+monterrey/carr eras+profesionales/areas+de+estudio/ciencias+sociales+y+humanidades/licencia do+en+emprendimiento+cultural+y+social/santa+fe+lcs

- http://www.itesm.mx/wps/wcm/connect/itesm/tecnologico+de+monterrey/carr eras+profesionales/areas+de+estudio/ciencias+sociales+y+humanidades/lcs

- http://www.gestioncultural.eco.unc.edu.ar/presentacion-empr/\#inicio-curso

- http://www.gestioncultural.eco.unc.edu.ar/presentacion-gcec/\#inicio-curso

- http://web.econ.uba.ar/

- http://www.mastericc.com/

- http://www.mastereconomiacreativa.es/

- http://www.berrimaster.eu/es/aspectos/modulos/

- http://www.idec.upf.edu/master-en-gestion-de-industrias-creativas-yculturales/contenidos-academicos

- http://vinculacionculturalcomunitaria.wordpress.com/2011/11/01/seminariocultura-y-desarrollo-diseno-de-indicadores/

- http://www.economiaycultura.org/

- http://www.conarte.mx/inicio/hub-conarte/encuentro-internacional-arte-ysustentabilidad/

- http://dimecreatividad.wordpress.com/2012/10/02/1er-simposiuminternacional-artecultura-y-negocios-ciudad-de-mexico-2012/

- http://www.conectakultura.org

- http://www.1a1.mx/

- http://bonusmx.com/

- http://www.abiertodediseno.mx/

- http://reinventa.mx/

- http://www.paralelo9mx.com/

- http://www.cultura.df.gob.mx

- www.m-x.com.mx.

- http://www.incubadoras.unam.mx/

- http://clustercreativo.wordpress.com/

- http://www.nafin.com/portalnf/content/home/home.html

- http://www.conaculta.gob.mx/1er-concurso-empresas-culturales/ 
- http://www.conaculta.gob.mx/detalle-nota/?id=23452\#.Uu3e1z150So

- http://www.eluniversal.com.mx/notas/878694.html

- http://fonca.conaculta.gob.mx/programa/programa-nacional-de-fomento-yestimulo-a-las-industrias-creativas-y-a-empresas-culturales/

- http://www.promexico.gob.mx/es ca/promexico/Revistas 2012

- http://www.soyentrepreneur.com/1-home.html

- http://www.soyentrepreneur.com/26208-galeria-de-emprendedores-2013.html

- http://www.inegi.org.mx/

- http://www.excelsior.com.mx/node/878015

- https://www.facebook.com/photo.php?v=10150223111051851\&set=vb.2079207 80643\&type=3\&theater

- http://www.informador.com.mx/economia/2011/281666/6/mexico-primeraeconomia-creativa-de-america-latina-onu.htm,

- http://economiacultural.xoc.uam.mx/index.php/lara/207-lider,

- http://www.soyentrepreneur.com/mexico-ocupa-el-primer-lugar-en-economiacreativa-en-america-latina.html,

- http://eleconomista.com.mx/entretenimiento/2012/02/19/mexico-debereconocer-e-impulsar-su-potencia-cultural,

- http://vivirmexico.com/2011/04/la-economia-creativa-una-zona-deoportunidades-para-mexico, http://eleconomista.com.mx/entretenimiento/2013/11/17/mexico-nuevoparaiso-creativo

- http://eleconomista.com.mx/infografias/2014/01/22/produccion-gasto-empleoculturales

- https://www.inadem.gob.mx/sectores estrategicos.html

- http://www.sistemaemprendedor.gob.mx/

- http://www.cultura.df.gob.mx/secretaria/el-tema-es-la-cultura 


\section{SITIOS WEB Y REDES SOCIALES DE LOS BAZARES DE ARTE Y DISEÑO INDEPENDIENTE EN LA CIUDAD DE MÉXICO}

- https://www.facebook.com/BazarFUSION http://www.proyectofusion.com.mx/wp/

- https://www.facebook.com/BAZAR.TRAFICO

- https://www.facebook.com/vanitasbazar http://www.vanitasbazar.com

- https://www.facebook.com/pages/Pabellon-de-Dise\%C3\%B1o-Mexicano

- https://www.facebook.com/mexicobazar

- https://www.facebook.com/EXPOVENTADIM

- https://www.facebook.com/lonjamercantil http://lonjamercantil.com/

- https://www.facebook.com/CREEYCREAMEXICO

- https://www.facebook.com/mahonia.bazar

- https://www.facebook.com/nomada.bazar.94

- https://www.facebook.com/pages/El-Perchero-Mujeres-Emprendedoras

- https://www.facebook.com/pages/Factor-Moda

- https://www.facebook.com/BazarLaCiruela

- https://twitter.com/FoodTruckBazar

- https://www.facebook.com/LibreLiebreBazar

- https://www.facebook.com/GarageArt

- https://www.facebook.com/BazarDeBarrio

- https://www.facebook.com/RetroBzar https://www.facebook.com/ArtDistrictMx

- http://artdistrict.mx/

- https://www.facebook.com/LiArteBazar

- https://www.facebook.com/TiendalncubusVisual

- https://www.facebook.com/pages/Bazar-Ambulante

- https://www.facebook.com/pages/Arte-y-Dise\%C3\%B1o-Mexicano-13

- https://www.facebook.com/purpurabazar

- https://www.facebook.com/espacio.artesanal.mexicano

- https://www.facebook.com/mexicanisimobazar

- https://www.facebook.com/Mexico1Disena

- https://www.facebook.com/bazardenadie 
LOS PROCESOS DE IMITACION

COMO TRADUCCION : EL

SURGIMIENTO DE UN CAMPO

ORGANIZACIONAL .

BAZARES DE ARTE Y DISEÑO

INDEPENDIENTE EN LA CIUDAD

DE MEXICO 2003-2013

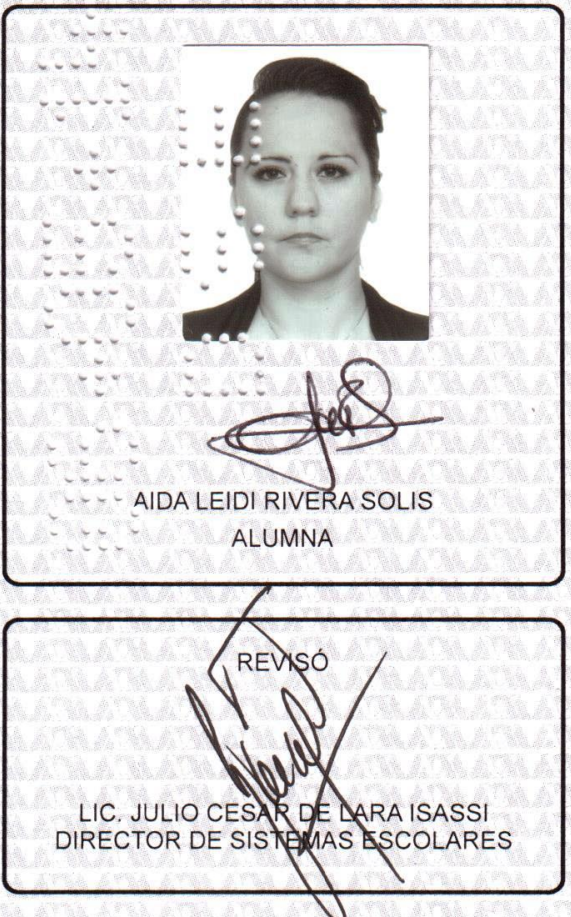

DIRECTORA DE LA DIVISIÓN DE CSH
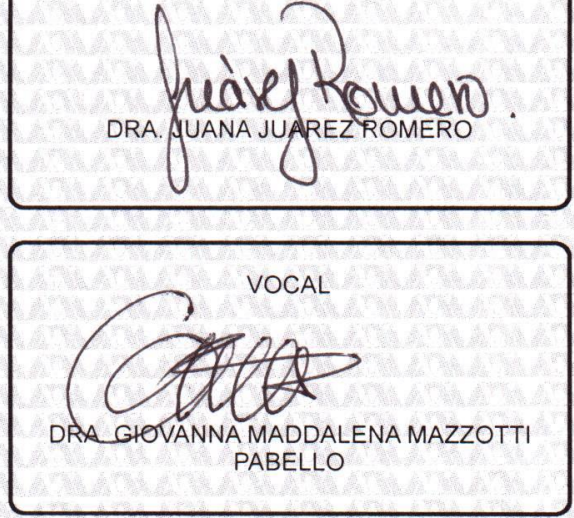

En México, D.F., se presentaron a las 11:00 horas del día 28 del mes de abril del año 2014 en la Unidad Iztapalapa de la Universidad Autónoma Metropolitana, los suscritos miembros del jurado:

DRA. IRENE SANCHEZ GUEVARA

DRA. GIOVANNA MADDALENA MAZZOTTI PABELLO

DR. PEDRO CONSTANTINO SOLIS PEREZ

Bajo la Presidencia de la primera y con carácter de Secretario el último, se reunieron para proceder al Examen de Grado cuya denominación aparece al margen, para la obtención del grado de:

MAESTRA EN ESTUDIOS ORGANIZACIONALES

DE: AIDA LEIDI RIVERA SOLIS

y de acuerdo con el artículo 78 fracción III del Reglamento de Estudios Superiores de la Universidad Autónoma Metropolitana, los miembros del jurado resolvieron:

\section{Aprobor}

Acto continuo, la presidenta del jurado comunicó a la interesada el resultado de la evaluación y, en caso aprobatorio, le fue tomada la protesta. 